Federal Reserve Bank of Dallas

Globalization and Monetary Policy Institute

Working Paper No. 272

http://www.dallasfed.org/assets/documents/institute/wpapers/2016/0272.pdf

\title{
Optimal Monetary Policy in Open Economies Revisited
}

\author{
Ippei Fujiwara \\ Keio University and ANU \\ Jiao Wang \\ Australian National University
}

May 2016

\begin{abstract}
This paper revisits optimal monetary policy in open economies, in particular, focusing on the noncooperative policy game under local currency pricing in a two-country dynamic stochastic general equilibrium model. We first derive the quadratic loss functions which noncooperative policy makers aim to minimize. Then, we show that noncooperative policy makers face extra trade-offs regarding stabilizing the real marginal costs induced by deviations from the law of one price under local currency pricing. As a result of the increased number of stabilizing objectives, welfare gains from cooperation emerge even when two countries face only technology shocks, which usually leads to equivalence between cooperation and noncooperation. Still, gains from cooperation are not large, implying that frictions other than nominal rigidities are necessary to strongly recommend cooperation as an important policy framework to increase global welfare.
\end{abstract}

JEL codes: E52, F41, F42

* Ippei Fujiwara, Keio University A2-15-45 Mita, Minato-ku, Tokyo 108-8345 Japan. ippei.fujiwara@keio.jp. Jiao Wang, Australian National University, Canberra ACT 0200 Australia. jiao.wang@anu.edu.au. We have benefited from discussions with Kosuke Aoki, Pierpaolo Benigno, Richard Dennis, Mick Devereux, Charles Engel, Jinill Kim, Warwick McKibbin and seminar participants at the Australian National University and the University of Melbourne. Fujiwara is grateful for financial support from JSPS KAKENHI Grant-in-Aid for Scientific Research (A) Grant Number 15H01939. The views in this paper are those of the authors and do not necessarily reflect the views of the Federal Reserve Bank of Dallas or the Federal Reserve System. 


\section{Introduction}

In a world of integrated trade in goods and assets, sovereign nations become more and more interdependent. The prolonged recession after the Global Financial Crisis again reminds policy makers in major economies of the depth and scope of such interrelations. Understanding the nature of cross-country spillovers of shocks and policy impacts comes back to center stage in policy discussions. Should central banks cooperate in order to internalize the possible externality from policy reactions? Is there any gain from such cooperation? And if so, how large might it be?

The desirability of policy cooperation, namely whether there exist gains from cooperation, has been one of the central issues in macroeconomics. The root of the discussion can be traced way back to Hume (1752), who first noticed possible policy spillovers among countries. Since then, there have been vast studies investigating the nature of policy games in open economies. Recently, many have studied optimal monetary policy in open economies using the microfounded, open-economy stickyprice models based on the so-called New Open Economy Macroeconomics (hereafter, NOEM) initiated by Obstfeld and Rogoff (1995) and Svensson and van Wijnbergen (1989). Contrary to the traditional studies using the Mundell-Fleming model, correct welfare can be computed with the NOEM models. Thus, comparison of different policies becomes possible without resort to ad hoc criteria.

As will be discussed in detail in the next subsection, optimal monetary policy in open economies has been investigated under many different settings in the NOEM, such as under cooperation or noncooperation, producer currency pricing (hereafter, PCP) or local currency pricing (hereafter, LCP), and with or without home bias. Consequently, our understanding of how monetary policy should be conducted in an interconnected world is deepened. There is, however, one last missing piece, which has not yet been analyzed in a theoretical dynamic stochastic general equilibrium (hereafter, DSGE) model. That is, how the optimal noncooperative monetary policy under LCP should be conducted, or whether there is any gain from cooperation under LCP. These are the questions to which we aim to give answers in this paper.

For this purpose, we first solve the equilibrium conditions under monopolistic competition and sticky prices in a two-country model. Also, the Ramsey (deterministic) steady states under both cooperative and noncooperative regimes are computed. In both schemes, the deterministic steady state turns out to be identical to that under the flexible-price equilibrium. ${ }^{1}$ Thus, the exact welfare comparison between cooperation and noncooperation becomes possible. Then, we approximate welfare around this deterministic steady state up to the second order. In a noncooperative regime,

\footnotetext{
${ }^{1}$ In addition, this steady state is at efficient levels since the optimal sales subsidy, which is identical regardless of cooperation and noncooperation, eliminates the steady state distortion stemming from suboptimally low output under monopolistic competition. Early literature with the linear-quadratic optimal monetary policy problems such as Rotemberg and Woodford (1997) or Woodford (2003) assume such a subsidy to obtain the correct second-order approximated welfare. Benigno and Woodford (2005) propose a method to compute the correct second-order welfare measure when the steady state is distorted.
} 
even if the steady state is efficient thanks to the optimal subsidy, linear terms cannot be eliminated. Following Sutherland (2002), Benigno and Woodford (2005) and Benigno and Benigno (2006), we take a second-order approximation to the structural equations to substitute out the linear terms by only second-order terms. Correct welfare metrics up to the second-order approximation are thus obtained.

Our loss functions show that noncooperative policy makers naturally aim to stabilize variables whose fluctuations are to be minimized by cooperative policy makers as analyzed in Engel (2011), including output, producer price index (hereafter, PPI) inflation rates, import price inflation rates, and deviations from the law of one price. ${ }^{2}$ In addition, they also seek to stabilize fluctuations in the real marginal costs that firms face when setting prices in both domestic and export markets. These additional objectives are unique to the noncooperative game and therefore the sources for potential gains from cooperation, which are absent in the previous studies on optimal monetary policy in open economies. ${ }^{3}$

Then, in order to clarify the nature of optimal monetary policy in open economies, we compare impulse responses under optimal monetary policies among three cases: (1) PCP; (2) cooperative regime and LCP; (3) noncooperative regime and LCP. Note that in our setting with only technology shocks, optimal cooperative as well as noncooperative policies result in identical allocations and prices under PCP. ${ }^{4}$

Fluctuations in consumer price index (hereafter, CPI) inflation rates become smaller under LCP than under PCP. This is because the violation of the law of one price induces inefficient price dispersions within producer as well as export prices, as emphasized by Engel (2011). As a result, the 'inward-looking' policy that focuses on stabilization of PPI inflation rates is no more optimal under LCP. In addition, under LCP, noncooperative policy makers stabilize CPI inflation rates more than cooperative central banks do. This larger stabilization motive arises from the unique objectives in the loss functions under noncooperation. Inability to cooperate constrains the dynamics toward more efficient outcomes. Reactions of domestic output to a domestic technology shock become smaller under noncooperation. Without any frictions, the global welfare increases when the production of the country with favorable efficiency shocks increases. This difference in the responses of output creates room for cooperative policies to improve global welfare.

We also compute the welfare gain from cooperation under LCP by solving the nonlinear Ramsey problem. Welfare gains from cooperation become largest with log utility even though both countries become insular in structural equations under PCP. Still, welfare gains computed from nonlinear Ramsey problems are not sizable with only technology shocks. Within the reasonable range of parameter calibration, the wel-

\footnotetext{
${ }^{2}$ Note that last terms are not considered under PCP, since the law of one price holds.

${ }^{3}$ Technically, these additional objectives arise from the linear terms in the second-order approximated welfare, that are eventually substituted by second-order approximated aggregate supply conditions.

${ }^{4}$ Note that our model assumes a Cobb-Douglas aggregator for domestic and foreign goods. For the cases where cooperative and noncooperative policies produce different outcomes, see Benigno and Benigno (2003).
} 
fare cost stemming from the inability to cooperate can only be, at most, 0.04 per cent in consumption units, in response to one standard deviation of technology shocks. Corsetti (2008) remarks that in early leading studies, the quantitative assessment of the welfare gains from cooperation is found far from sufficient to be in favor of cooperation, and whether it still holds in richer models is a critical research question. Our paper finds that given only price rigidities,sizable welfare gains may not arise from cooperation.

\subsection{Literature Review}

Let us first classify the previous studies on optimal monetary policy in open economies by three dimensions. ${ }^{5}$ The first dimension regards the assumption on nominal rigidities, that is, either the one-period ahead price setting or the staggered price setting à la Calvo (1983). ${ }^{6}$ In early studies using the NOEM framework, nominal rigidities are introduced as the one-period ahead price setting. With money supply as the control variable of monetary policy, analytical solutions can be obtained. Thus, no approximation is necessary for optimal policy analysis. With more relevance to the price setting behavior and monetary policy in practice, the staggered price contract together with nominal interest rates controlled by the central bank becomes the major assumption about nominal frictions, in particular after Clarida, Galí, and Gertler (2002) in the open-economy context. ${ }^{7}$ In contrast to the one-period ahead price setting, optimal monetary policy is analyzed in a linear-quadratic framework following Rotemberg and Woodford (1997), Woodford (2003) and Benigno and Woodford (2005). Central banks maximize the correctly approximated social welfare up to the second order subject to the linearly approximated structural equations. The second dimension is about export price setting, namely PCP or LCP. ${ }^{8}$ In the former, export prices fully reflect exchange rate fluctuations, while not at all in the latter. The third dimension is whether monetary policy in open economies is conducted in a cooperative or noncooperative manner.

Table 1 offers a taxonomy of previous studies on optimal monetary policy in open economies. Regarded as the beginning of the NOEM framework for monetary policy analysis in open economies, Obstfeld and Rogoff (1995) develop a micro-founded two-country model with PCP and a one-period in advance price setting rule to ana-

\footnotetext{
${ }^{5}$ Corsetti, Dedola, and Leduc (2010) offer a comprehensive survey of optimal monetary policy in open economies including other aspects such as financial market imperfections.

${ }^{6}$ Rotemberg (1982) proposes a different type of price stickiness due to a staggered cost adjustment process.

${ }^{7}$ According to the Calvo rule, firms reset prices in a forward-looking rational expectation manner. This raises the question of how to affect and/or manage the private sector's rational expectation for monetary policy practice. Related theoretical discussions include conducting monetary policy under commitment versus under discretion, delegation problem, credibility of cooperation, targeting rules versus instrument rules, etc.. Investigation of these issues are beyond the scope of this paper. As an incomplete list, see, for example, Persson and Tabellini (1995), Benigno (2002), Bilbiie (2002), Jensen (2002), Woodford (2003) and Svensson (2002, 2003, 2004).

${ }^{8}$ Corsetti and Pesenti (2005b) briefly analyze a third and less used pricing behavior: Dollar-pricing.
} 
lyze the dynamics of exchange rates and other variables in response to money supply shocks. Their investigation of the (log-linearized) global welfare appraises the firstorder welfare effect of monetary expansion on raising global demand and world output. It also suggests that the conventional Mundell-Fleming paradigm may overstate the importance of the beggar-thy-neighbor effects that a currency-depreciating country inflicts on trading partners since the induced terms-of-trade and current-account effects are only of second-order welfare importance. Corsetti and Pesenti (2001) extend the model of Obstfeld and Rogoff (1995) to highlight the international dimension of distortions stemming from a country's monopoly power on its terms of trade by assuming different elasticities of substitution within and across goods categories. ${ }^{9}$ They keep the assumptions of $\mathrm{PCP}$, one-period ahead price resetting rule and money supply shocks but focus on national welfares. A domestic monetary expansion can be either beggar-thy-neighbor or beggar-thyself depending on the elasticity of substitution, giving rise to national policy makers' incentives to manipulate the terms of trade in favor of their own welfare. Obstfeld and Rogoff (2002) assume the one-period ahead rule for nominal wage setting (prices for goods are flexible) and the existence of the nontradable sector for their examination of international cooperation under PCP. Utility of each country is expressed in terms of covariances of logs of endogenous variables, and monetary rules are assumed as explicit (log-linear) functions of exogenous productivity shocks in a stochastic environment. ${ }^{10}$ When nominal stickiness has little interaction with real distortions, welfare gains from cooperation (in percentage output) are relatively small. ${ }^{11}$

Devereux and Engel (2003) assume LCP and both strategic games in a two-country model while keeping the price setting in the period-by-period basis. ${ }^{12}$ They derive and compare optimal monetary rules (as log-linear functions of productivity and velocity shocks) to examine the desirability of flexible exchange rates as advocated in Friedman (1953). The flexible exchange rate regime is no longer optimal under LCP. Distortions stemming from the violation of the law of one price should be corrected by restricting the fluctuations of nominal exchange rates. Thus, optimal policy under LCP fully stabilizes fluctuations in exchange rates in both games. Corsetti and Pesenti (2005a) propose a unifying approach to model the exchange rate pass-through in which PCP and LCP are two extreme cases of the parameterization. ${ }^{33}$ No welfare gains from cooperation are found under either complete or no exchange rate passthrough. In general cases with partial exchange rate pass-through they argue that a country can do better than 'keeping one's house in order' but whether the gains are

\footnotetext{
${ }^{9}$ For a detailed discussion on this issue, see Tille (2001).

${ }^{10}$ Productivity shocks, along with cost-push shocks, become the main sources of exogenous disturbances that optimal monetary policy responds to in later studies.

${ }^{11}$ Note that Obstfeld and Rogoff (2002) define the cooperation gain as the gain from deviating from flex-wage equilibrium to cooperative equilibrium. Noncooperative equilibrium lies between the flexwage and cooperative policy responses and thus the estimation is an upper bound on the gains from moving from noncooperation to cooperation.

${ }^{12}$ Much empirical evidence points to the possibility of LCP, see, for example, Engel (1999), Engel and Rogers (2001), Parsley and Wei (2001), and Atkeson and Burstein (2008).

${ }^{13}$ Corsetti and Pesenti (2005a) also offer insights from the staggered price setting.
} 
sizable is left for future studies with more realistic model settings.

Clarida, Galí, and Gertler (2002), Benigno and Benigno (2003, 2006) all assume the staggered price adjustment rule à la Calvo (1983) and obtain quadratic loss functions under cooperation as well as noncooperation for their respective optimal policy analysis under PCP. ${ }^{14}$ By contrast, Clarida, Galí, and Gertler (2002) choose output as policy variables under noncooperative regime and set the first derivative of national utility function to zero by assuming an appropriate subsidy to eliminate the linear terms in the second-order approximation of the utility function. As a result, Ramsey steady states become different between cooperation and noncooperation. Benigno and Benigno (2003) set up a ratio of the notional price over the average actual price as noncooperative policy instruments, and obtain a zero first derivative of the national utility function from households' price setting condition as monopolists selling goods to achieve the elimination of the linear terms. The quadratic loss function under noncooperation can be derived since price stability turns out to be optimal monetary policy. Benigno and Benigno (2006) choose PPI inflation rates for their noncooperative games and make use of second-order approximations of some of the structural equations to substitute out those linear terms following Sutherland (2002) and Benigno and Woodford (2005). Besides the methodological differences, these three studies also take on different focuses on the implications of optimal policy analysis. Specifically, Clarida, Galí, and Gertler (2002) appraise the potential gains from cooperation arising from internalizing the terms-of-trade externalities, in the context of (inefficient) costpush shocks and discretionary optimal policy. Benigno and Benigno (2003) explore the theoretical conditions under which flexible-price allocations are optimal, and cooperative and noncooperative allocations coincide under PCP. Finally, Benigno and Benigno (2006) show how to design simple rules for noncooperative policy makers to achieve cooperative allocations in the linear-quadratic framework with technology shocks, markup shocks and government spending shocks.

Engel (2011) incorporates the staggered price setting rule for optimal monetary analysis under LCP and the cooperative regime. Home bias in consumption preferences is also assumed. ${ }^{15}$ With home bias, central banks face the trade-off between the costs of currency misalignment and stabilization of asymmetric output fluctuations. The derived quadratic global loss function highlights international relative price misalignments stemming from the violation of the law of one price under LCP. Thus, optimal cooperative policy under LCP should trade off these misalignments with inflation and output goals, and should target CPI inflation rates rather than just PPI inflation rates. Our paper is an extension from Engel (2011) to the noncooperative game, providing the final block of the class of the NOEM literature as summarized in

\footnotetext{
${ }^{14}$ Benigno and Benigno (2003) also assume a one-period ahead price setting rule for policies under commitment and the Calvo rule for policies under discretion.

${ }^{15}$ Faia and Monacelli (2008) and Duarte and Obstfeld (2008) also consider different consumption preferences for a similar purpose.
} 
Table $1 .{ }^{16}$

Table 1: Taxonomy of optimal monetary policy in open economies

\begin{tabular}{|c|c|c|c|c|}
\hline Games $\quad$ Pricing & \multicolumn{2}{|c|}{ PCP } & \multicolumn{2}{|c|}{ LCP } \\
\hline \multirow[t]{2}{*}{ Cooperation } & $\begin{array}{l}\text { one-period } \\
\text { ahead }\end{array}$ & OR (1995), OR (2002) & $\begin{array}{l}\text { one-period } \\
\text { ahead }\end{array}$ & DE (2003), CP (2005a) \\
\hline & staggered & $\begin{array}{l}\text { CGG (2002), BB } \\
\text { (2003), BB (2006) }\end{array}$ & staggered & Engel (2011) \\
\hline \multirow[t]{2}{*}{ Noncooperation } & $\begin{array}{c}\text { one-period } \\
\text { ahead }\end{array}$ & CP (2001), OR (2002) & $\begin{array}{c}\text { one-period } \\
\text { ahead }\end{array}$ & DE (2003), CP (2005a) \\
\hline & staggered & $\begin{array}{l}\text { CGG (2002), BB } \\
\text { (2003), BB (2006) }\end{array}$ & staggered & This Paper (2016) \\
\hline
\end{tabular}

Note: OR denotes Obstfeld and Rogoff, CP denotes Corsetti and Pesenti, CGG denotes Clarida, Galí and Gertler, BB denotes Benigno and Benigno, and DE denotes Devereux and Engel.

The rest of the paper is organized as follows. Section 2 specifies the model and derives equilibrium conditions. Section 3 sets up optimal policy problems in both nonlinear and linear-quadratic frameworks. Quadratic loss functions under LCP and noncooperation are derived. Section 4 compares impulse responses under both games and computes welfare cost stemming from noncooperation. Section 5 concludes.

\section{The Model}

The model is close to the one considered in Engel (2011). There are two countries of equal size, Home and Foreign, each populated with a continuum of households with population size normalized to unity. Agents in the two countries consume both home goods and foreign goods but have a symmetric home bias. Households supply labor services to firms within their own country via a competitive labor market. Households are also the owner of domestic firms. Firms maximize profits in a monopolistically competitive market using labor as the only input according to aggregate technology. Governments levy a lump-sum tax on households and subsidize firms so that the deterministic steady-state output level becomes efficient. Central banks are benevolent and aim to maximize social welfare through either cooperation or noncooperation.

\footnotetext{
${ }^{16}$ For the sake of completeness of this literature review, we note that there are other studies that also incorporate the key features of the models in the class of the NOEM. Obstfeld and Rogoff (1998, 2000) and de Paoli (2009) assume PCP in their monetary policy analysis. Bacchetta and van Wincoop (2000), Betts and Devereux (2000) and Engel (2003) consider LCP and one-period ahead price setting. Sutherland (2006) assumes LCP for monetary policy analysis in a small open economy.
} 


\subsection{Households}

A representative household in the home country maximizes welfare:

$$
W_{H, t_{0}} \equiv \mathbb{E}_{t_{0}} \sum_{t=t_{0}}^{\infty} \beta^{t-t_{0}}\left[u\left(C_{t}\right)-v\left(h_{t}\right)\right]
$$

subject to the budget constraint:

$$
\mathbb{E}_{t}\left[m_{t, t+1} A_{t+1}\right]+B_{t+1}+P_{t} C_{t} \leq A_{t}+\left(1+i_{t-1}\right) B_{t}+W_{t} h_{t}+\Pi_{t}+T_{t},
$$

for $t \geq t_{0}$, where the consumption aggregator $C_{t}$, the aggregate consumption of locally produced goods $C_{H, t}$, and the aggregate consumption of imported goods $C_{F, t}$ is given by

$$
\begin{aligned}
C_{t} & =C_{H, t}^{\frac{v}{2}} C_{F, t}^{1-\frac{v}{2}}, \\
C_{H, t} & =\left[\int_{0}^{1} C_{H, t}(j)^{1-\frac{1}{\varepsilon}} \mathrm{d} j\right]^{\frac{\varepsilon}{\varepsilon-1}}, \\
C_{F, t} & =\left[\int_{0}^{1} C_{F, t}\left(j^{*}\right)^{1-\frac{1}{\varepsilon}} \mathrm{d} j^{*}\right]^{\frac{\varepsilon}{\varepsilon-1}},
\end{aligned}
$$

respectively. $u($.$) is the period utility function, increasing and concave in consump-$ tion. $v($.$) is the period disutility function, increasing and convex in labor h_{t}$ (measured by working hours). $W_{t}$ denotes the nominal wage. $A_{t+1}$ denotes the holdings of the state contingent (Arrow) securities at the end of period $t$ denominated in the domestic currency, which equates the marginal rates of substitutions of two countries even ex post. $m_{t, t+1}$ denotes the price of the Arrow securities in period $t$ which gives an unitary return in period $t+1 . B_{t}$ is the amount of one-period risk-free nominal bonds held at the beginning of period $t$ with net rate of return $i_{t-1} . \Pi_{t}$ represents the dividend from the ownership of firms. $T_{t}$ represents the lump-sum tax levied by the government. $\beta$ is the discount factor. $\epsilon$ denotes the elasticity of substitution among differentiated varieties within each country. $v \in[0,2]$ determines the (symmetric) home bias. When $v$ is larger (smaller) than unity, consumer preference exhibits home (foreign) bias. There is no home bias when $v$ equals unity. $C_{H, t}(j)$ and $C_{F, t}\left(j^{*}\right)$ denote the home representative household's consumption of the goods produced by the home firm $j$ and the foreign firm $j^{*}$, respectively. Note that Lagrange multipliers on the constraints in equations (2.2) to (2.4) represent CPI $P_{t}$, PPI $P_{H, t}$, and the import price index $P_{F, t}$. A representative household in the foreign country solves a similar optimization problem on the welfare:

$$
W_{F, t_{0}} \equiv \mathbb{E}_{t_{0}} \sum_{t=t_{0}}^{\infty} \beta^{t-t_{0}}\left[u\left(C_{t}^{*}\right)-v\left(h_{t}^{*}\right)\right]
$$




\subsection{Firms}

Firm $j$ in the home country sets prices in a monopolistically competitive market to maximize the present discounted value of profits:

$$
\mathbb{E}_{t_{0}} \sum_{t=t_{0}}^{\infty} \theta^{t-t_{0}} m_{t_{0}, t} \Pi_{t}(j)
$$

where

$$
\Pi_{t}(j)=(1+\tau) P_{H, t}(j) C_{H, t}(j)+(1+\tau) S_{t} P_{H, t}^{*}(j) C_{H, t}^{*}(j)-W_{t} h_{t}(j)
$$

subject to the production function:

$$
Y_{t}(j)=\exp \left(z_{t}\right) h_{t}(j),
$$

and the resource constraint:

$$
Y_{t}(j)=C_{H, t}(j)+C_{H, t}^{*}(j) .
$$

$S_{t}$ denotes the nominal exchange rate of the foreign currency in units of the home currency. $\tau$ represents the government subsidy rate. Firm $j$ produces $Y_{t}(j)$ of the product by hiring $h_{t}(j)$ of labor service from the domestic households according to aggregate production technology exp $\left(z_{t}\right)$, where $z_{t}$ follows an AR(1) exogenous process. Firms set their optimal prices in a staggered manner à la Calvo (1983) rule. Each time, only with probability $1-\theta$, can they re-optimize their prices. Note that the Lagrange multiplier on a constraint where the production function in equation (2.6) and the resource constraint in equation (2.7) are combined represents nominal marginal costs:

$$
N M C_{t}=\frac{W_{t}}{\exp \left(z_{t}\right)}
$$

There is no firm specificity in marginal costs.

Regarding the export price, there are two types of price setting. Under PCP, firms fully reflect changes in exchange rates in export prices. Thus, the law of one price holds:

$$
P_{H, t}(j)=S_{t} P_{H, t}^{*}(j) .
$$

On the other hand, under LCP, firms faces the same Calvo (1983) friction even when setting export prices. As a result, firm $j$ reoptimizes both $P_{H, t}(j)$ and $P_{H, t}^{*}(j)$ in order to maximize profits. ${ }^{17}$

Firm $j^{*}$ in the foreign country solves a similar profit maximization problem.

\footnotetext{
${ }^{17}$ We do not consider interim cases as in Monacelli (2005).
} 


\subsection{Governments and Central Banks}

The government in each country collects a lump sum tax from households and subsidizes firms to eliminate steady state distortions stemming from monopolistic competition. ${ }^{18}$ Thus, the subsidy rate is given by

$$
\tau=\frac{1}{\epsilon-1}
$$

Governments' budget constraints are

$$
\begin{aligned}
T_{t} & =\tau \int_{0}^{1}\left[P_{H, t}(j) C_{H, t}(j)+S_{t} P_{H, t}^{*}(j) C_{H, t}^{*}(j)\right] \mathrm{d} j, \\
T_{t}^{*} & =\tau \int_{0}^{1}\left[\frac{P_{F, t}\left(j^{*}\right)}{S_{t}} C_{F, t}\left(j^{*}\right)+P_{F, t}^{*}\left(j^{*}\right) C_{F, t}^{*}\left(j^{*}\right)\right] \mathrm{d} j^{*} .
\end{aligned}
$$

Balanced budgets are always achieved for the two governments.

Benevolent central banks aim to maximize social welfare as Ramsey planners. We consider two cases: both central banks cooperate to maximize global welfare; each maximizes social welfare of its own country in a noncooperative game. Details of such optimal policies will be discussed later.

\subsection{Aggregate Conditions}

Taking the integral of equation (2.6) over $j$ gives the aggregate production function of the home country:

$$
Y_{t}=\exp \left(z_{t}\right) h_{t}
$$

Taking the integral of the resource constraint equation (2.7) over $j$ and making use of the Hicksian demand functions for good $j$ by consumers in both countries gives the aggregate resource constraint of the home country:

$$
Y_{t}=C_{H, t} \Delta_{H, t}+C_{H, t}^{*} \Delta_{H, t}^{*}
$$

where $\Delta_{H, t} \equiv \int_{0}^{1}\left[\frac{P_{H, t}(j)}{P_{H, t}}\right]^{-\epsilon} \mathrm{d} j$ and $\Delta_{H, t}^{*} \equiv \int_{0}^{1}\left[\frac{P_{H, t}^{*}(j)}{P_{H, t}^{*}}\right]^{-\epsilon} \mathrm{d} j$ are the price dispersion terms. (Derivation of the Hicksian demand functions is in Appendix A.) The foreign country has an analogous production function and resource constraint.

We assume a complete assets market, and thus trades in the Arrow securities equate the marginal rates of substitution between two countries even ex post:

$$
\frac{u^{\prime}\left(C_{t+1}\right)}{u^{\prime}\left(C_{t}\right)} \frac{P_{t}}{P_{t+1}}=\frac{u^{\prime}\left(C_{t+1}^{*}\right)}{u^{\prime}\left(C_{t}^{*}\right)} \frac{S_{t} P_{t}^{*}}{S_{t+1} P_{t+1}^{*}} .
$$

\footnotetext{
${ }^{18}$ There is no strategic interaction between the government and the central bank.
} 
With the assumption of the symmetric initial conditions of wealth, the standard risk sharing condition is obtained as follows:

$$
u^{\prime}\left(C_{t}^{*}\right)=e_{t} u^{\prime}\left(C_{t}\right),
$$

where we define the real exchange rate:

$$
e_{t} \equiv \frac{S_{t} P_{t}^{*}}{P_{t}} .
$$

Note that $e_{t}$ is unity only when purchasing power parity (PPP) holds (i.e. identical consumption preferences and under $\mathrm{PCP}$ ). Otherwise it is time-varying either because of the non-identical consumption preferences under PCP, or due to the imperfect passthrough under LCP.

\subsubsection{Gains from Price Stability}

Under PCP,

$$
\Delta_{H, t}^{*} \equiv \int_{0}^{1}\left[\frac{S_{t} P_{H, t}^{*}(j)}{S_{t} P_{H, t}^{*}}\right]^{-\epsilon} d j=\Delta_{H, t} .
$$

Resource constraint and production function becomes

$$
C_{H, t}+C_{H, t}^{*}=\Delta_{H, t}^{-1} Y_{t}=\Delta_{H, t}^{-1} \exp \left(z_{t}\right) h_{t} .
$$

Price dispersion stemming from the staggered price contracts becomes distortionary and works as if it were a negative technology shock. Thus, welfare can be enhanced by achieving price stability, namely $P_{H, t}(j)=P_{H, t}, P_{H, t}^{*}(j)=P_{H, t}^{*}$ or $\Delta_{H, t}=\Delta_{H, t}^{*}=1$.

\subsection{Equilibrium Conditions}

The home representative household's period utility is specified as

$$
\begin{aligned}
& u\left(C_{t}\right) \equiv \frac{C_{t}^{1-\sigma}-1}{1-\sigma}, \\
& v\left(h_{t}\right) \equiv \chi \frac{h_{t}^{1+\omega}}{1+\omega} .
\end{aligned}
$$

The system of equations consists of the first-order necessary conditions from solving households' as well as firms' optimization problem together with market clearing conditions. All nominal variables are detrended as follows: $p_{H, t}=P_{H, t} / P_{t}$, $p_{H, t}^{*}=P_{H, t}^{*} / P_{t}^{*}, p_{F, t}=P_{F, t} / P_{t}, p_{F, t}^{*}=P_{F, t}^{*} / P_{t}^{*}, \pi_{t}=P_{t} / P_{t-1}, \pi_{t}^{*}=P_{t}^{*} / P_{t-1}^{*}, \pi_{H, t}=$ $P_{H, t} / P_{H, t-1}, \pi_{H, t}^{*}=P_{H, t}^{*} / P_{H, t-1}^{*}, \pi_{F, t}=P_{F, t} / P_{F, t-1}, \pi_{F, t}^{*}=P_{F, t}^{*} / P_{F, t-1}^{*}, M C_{t}=N M C_{t} / P_{t}$, $M C_{t}^{*}=N M C_{t}^{*} / P_{t}^{*}, w_{t}=W_{t} / P_{t}$ and $w_{t}^{*}=W_{t}^{*} / P_{t}^{*}$. Thus the system of equilibrium 
conditions is summarized as follows:

Table 2: Equilibrium conditions

Home (i) $C_{t}^{-\sigma}=\beta \mathbb{E}_{t} \frac{1+i_{t}}{\pi_{t+1}} C_{t+1}^{-\sigma}$,

(ii) $\frac{\chi h_{t}^{\omega}}{C_{t}^{-\sigma}}=w_{t}$,

(iii) $C_{H, t}=\frac{v}{2} p_{H, t}^{-1} C_{t}$,

(iv) $C_{F, t}=\left(1-\frac{v}{2}\right) p_{F, t}^{-1} C_{t}$,

(v) $p_{H, t}^{\frac{v}{2}} p_{F, t}^{1-\frac{v}{2}}=\left(\frac{v}{2}\right)^{\frac{v}{2}}\left(1-\frac{v}{2}\right)^{1-\frac{v}{2}}$,

(vi) $M C_{t}=\frac{w_{t}}{\exp \left(z_{t}\right)}$,

(vii) $\exp \left(z_{t}\right) h_{t}=C_{H, t} \Delta_{H, t}+C_{H, t}^{*} \Delta_{H, t}^{*}$

(viii) $Y_{t}=\exp \left(z_{t}\right) h_{t}$

(ix) $\Delta_{H, t}=(1-\theta)\left(\frac{1-\theta \pi_{H, t}^{\epsilon-1}}{1-\theta}\right)^{\frac{\epsilon}{\epsilon-1}}$

$$
+\theta \pi_{H, t}^{\epsilon} \Delta_{H, t-1},
$$

(x) $\Delta_{H, t}^{*}=(1-\theta)\left(\frac{1-\theta \pi_{H, t}^{* \epsilon-1}}{1-\theta}\right)^{\frac{\epsilon}{\epsilon-1}}$

$$
+\theta\left(\pi_{H, t}^{*}\right)^{\epsilon} \Delta_{H, t-1}^{*},
$$

(xi) $K_{H, t}=F_{H, t}\left[\frac{1-\theta\left(\pi_{H, t}\right)^{\epsilon-1}}{1-\theta}\right]^{\frac{1}{1-\epsilon}}$,

(xii) $K_{H, t}=\frac{C_{H, t} M C_{t}}{e_{t}}$

$$
+\beta \theta \mathbb{E}_{t} \frac{C_{t+1}^{-\sigma} e_{t+1}}{C_{t}^{-\sigma} e_{t}} \pi_{H, t+1}^{\epsilon} K_{H, t+1},
$$

(xiii) $F_{H, t}=\frac{C_{H, t} p_{H, t}}{e_{t}}$

$$
+\beta \theta \mathbb{E}_{t} \frac{C_{t+1}^{-\sigma} e_{t+1}}{C_{t}^{-\sigma} e_{t}} \pi_{H, t+1}^{\epsilon-1} F_{H, t+1},
$$

(xiv) $K_{H, t}^{*}=F_{H, t}^{*}\left[\frac{1-\theta\left(\pi_{H, t}^{*}\right)^{\epsilon-1}}{1-\theta}\right]^{\frac{1}{1-\epsilon}}$,

$(\mathrm{xv}) K_{H, t}^{*}=\frac{C_{H, t}^{*} M C_{t}}{e_{t}}$

$$
+\beta \theta \mathbb{E}_{t} \frac{C_{t+1}^{-\sigma} e_{t+1}}{C_{t}^{-\sigma} e_{t}}\left(\pi_{H, t+1}^{*}\right)^{\epsilon} K_{H, t+1}^{*},
$$

(xvi) $F_{H, t}^{*}=C_{H, t}^{*} p_{H, t}^{*}$

$$
+\beta \theta \mathbb{E}_{t} \frac{C_{t+1}^{-\sigma} e_{t+1}}{C_{t}^{-\sigma} e_{t}}\left(\pi_{H, t+1}^{*}\right)^{\epsilon-1} F_{H, t+1}^{*},
$$

Foreign

$(\operatorname{xix})\left(C_{t}^{*}\right)^{-\sigma}=\beta \mathbb{E}_{t} \frac{1+i_{t}^{*}}{\pi_{t+1}^{*}}\left(C_{t+1}^{*}\right)^{-\sigma}$,

$(\mathrm{xx}) \frac{\chi\left(h_{t}^{*}\right)^{\omega}}{\left(C_{t}^{*}\right)^{-\sigma}}=w_{t}^{*}$,

(xxi) $C_{H, t}^{*}=\left(1-\frac{v}{2}\right) p_{H, t}^{*-1} C_{t}^{*}$,

(xxii) $C_{F, t}^{*}=\frac{v}{2} p_{F, t}^{*-1} C_{t}^{*}$,

(xxiii) $\left(p_{H, t}^{*}\right)^{1-\frac{v}{2}}\left(p_{F, t}^{*}\right)^{\frac{v}{2}}=\left(\frac{v}{2}\right)^{\frac{v}{2}}\left(1-\frac{v}{2}\right)^{1-\frac{v}{2}}$,

(xxiv) $M C_{t}^{*}=\frac{w_{t}^{*}}{\exp \left(z_{t}^{*}\right)}$,

$(\mathrm{xxv}) \exp \left(z_{t}^{*}\right) h_{t}^{*}=C_{F, t} \Delta_{F, t}+C_{F, t}^{*} \Delta_{F, t^{\prime}}^{*}$

$\left(\operatorname{xxvi)} Y_{t}^{*}=\exp \left(z_{t}^{*}\right) h_{t}^{*}\right.$,

(xxvii) $\Delta_{F, t}=(1-\theta)\left(\frac{1-\theta \pi_{, t,}^{\epsilon-1}}{1-\theta}\right)^{\frac{\epsilon}{\epsilon-1}}$

$+\theta \pi_{F, t}^{\epsilon} \Delta_{F, t-1}$,

(xxviii) $\Delta_{F, t}^{*}=(1-\theta)\left[\frac{1-\theta\left(\pi_{F, t}^{*}\right)^{\epsilon-1}}{1-\theta}\right]^{\frac{\epsilon}{\epsilon-1}}$

$$
+\theta\left(\pi_{F, t}^{*}\right)^{\epsilon} \Delta_{F, t-1}^{*},
$$

(xxix) $K_{F, t}=F_{F, t}\left[\frac{1-\theta\left(\pi_{F, t}\right)^{\epsilon-1}}{1-\theta}\right]^{\frac{1}{1-\epsilon}}$,

$(\mathrm{xxx}) K_{F, t}=e_{t} C_{F, t} M C_{t}^{*}$

$$
+\beta \theta \mathbb{E}_{t} \frac{C_{t+1}^{*-\sigma} e_{t}}{C_{t}^{*-\sigma} e_{t+1}} \pi_{F, t+1}^{\epsilon} K_{F, t+1},
$$

(xxxi) $F_{F, t}=C_{F, t} p_{F, t}$

$$
+\beta \theta E_{t} \frac{C_{t+1}^{*-\sigma} e_{t}}{C_{t}^{*-\sigma} e_{t+1}} \pi_{F, t+1}^{\epsilon-1} F_{F, t+1},
$$

(xxxii) $K_{F, t}^{*}=F_{F, t}^{*}\left[\frac{1-\theta\left(\pi_{F, t}^{*}\right)^{\epsilon-1}}{1-\theta}\right]^{\frac{1}{1-\epsilon}}$,

(xxxiii) $K_{F, t}^{*}=e_{t} C_{F, t}^{*} M C_{t}^{*}$

$$
+\beta \theta E_{t} \frac{C_{t+1}^{*-\sigma} e_{t}}{C_{t}^{*-\sigma} e_{t+1}}\left(\pi_{F, t+1}^{*}\right)^{\epsilon} K_{F, t+1}^{*},
$$

(xxxiv) $F_{F, t}^{*}=e_{t} C_{F, t}^{*} p_{F, t}^{*}$

$$
+\beta \theta E_{t} \frac{C_{t+1}^{*-\sigma} e_{t}}{C_{t}^{*-\sigma} e_{t+1}}\left(\pi_{F, t+1}^{*}\right)^{\epsilon-1} F_{F, t+1}^{*},
$$




$$
\begin{aligned}
& \text { (xvii) } \pi_{H, t}=\pi_{t} \frac{p_{H, t}}{p_{H, t-1}}, \quad(\operatorname{xxxv}) \pi_{F, t}=\pi_{t} \frac{p_{F, t}}{p_{F, t-1}}, \\
& \text { (xviii) } \pi_{H, t}^{*}=\pi_{t}^{*} \frac{p_{H, t}^{*}}{p_{H, t-1}^{*}}, \quad \quad(x x x v i) \pi_{F, t}^{*}=\pi_{t}^{*} \frac{p_{F, t}^{*}}{p_{F, t-1}^{*}}, \\
& \text { (xxxvii) }\left(C_{t}^{*}\right)^{-\sigma}=e_{t} C_{t}^{-\sigma} \text {. }
\end{aligned}
$$

These equations together with monetary policy rules solve the rational expectations equilibrium. Equations (xi) to (xiii), (xiv) to (xvi), (xxix) to (xxxi) and (xxxii) to (xxxiv), which are derived from firms' profit maximization problems, represent the new Keynesian Phillips curves for $p_{H}, p_{H}^{*}, p_{F}$ and $p_{F}^{*}$, respectively. $K \mathrm{~s}$ and $F \mathrm{~s}$ are auxiliary variables, the details of which are shown in Appendix A.

Under PCP, equations (xiv) to (xvi) and (xxix) to (xxxi) collapse to

$$
\begin{aligned}
\left(\operatorname{xxxviii)} p_{H, t}^{*}\right. & =\frac{p_{H, t}}{e_{t}}, \\
(\operatorname{xxxix}) p_{F, t} & =e_{t} p_{F, t}^{*}
\end{aligned}
$$

and equations (x) and (xxvii) are replaced by

$$
\begin{aligned}
(\operatorname{xxxx}) \Delta_{H, t}^{*} & =\Delta_{H, t}, \\
(\mathrm{xxxxi}) \Delta_{F, t} & =\Delta_{F, t}^{*} .
\end{aligned}
$$

\subsection{Log-Linearized Equations}

We approximate the above structural equations around the deterministic steady state up to the first order. Note that the deterministic steady state is efficient as monopolistic distortion in production is effectively eliminated by an appropriate subsidy. Thus, this deterministic steady state coincides with the Ramsey steady state, which will be discussed in the following section. ${ }^{19}$ Details of the derivation of the steady state are also shown in Appendix A. Below, the circumflex ${ }^{\wedge}$ indicates the log-deviation of a variable from its respective steady state.

Linear approximation to equations (xi) to (xiii), (xxxii) to (xxxiv), (xxix) to (xxxi)

\footnotetext{
${ }^{19}$ As Woodford (2003), Chapter 6 argues, this type of steady state is the one that is appropriate for ranking alternative policies. See also Benigno and Woodford (2005) and Khan, King, and Wolman (2003).
} 
and (xiv) to (xvi) leads to the New Keynesian Phillips curves:

$$
\begin{aligned}
\pi_{H, t} & =\beta \mathbb{E}_{t} \pi_{H, t+1}+\frac{(1-\beta \theta)(1-\theta)}{\theta}\left(\widehat{m c}_{t}-\hat{p}_{H, t}\right), \\
\pi_{F, t}^{*} & =\beta \mathbb{E}_{t} \pi_{F, t+1}^{*}+\frac{(1-\beta \theta)(1-\theta)}{\theta}\left(\widehat{m c}_{t}^{*}-\hat{p}_{F, t}^{*}\right), \\
\pi_{F, t} & =\beta \mathbb{E}_{t} \pi_{F, t+1}+\frac{(1-\beta \theta)(1-\theta)}{\theta}\left(\widehat{m c}_{t}^{*}-\hat{p}_{F, t}+\hat{e}_{t}\right), \\
\pi_{H, t}^{*} & =\beta \mathbb{E}_{t} \pi_{H, t+1}^{*}+\frac{(1-\beta \theta)(1-\theta)}{\theta}\left(\widehat{m c}_{t}-\hat{p}_{H, t}^{*}-\hat{e}_{t}\right) .
\end{aligned}
$$

As in the closed-economy model of Galí and Gertler (1999) or the open-economy model under PCP of Benigno and Benigno (2006), in equations (2.8) and (2.9), PPI inflation rates depend on the real marginal costs that producers face when setting prices for the domestic market. Equations (2.10) and (2.11), appearing specifically in the open-economy model under LCP, show that import price inflation rates depend on the real marginal costs that producers face when setting prices for the importing country's market. $^{20}$

First-order approximation to equations (ix) to (x) and (xvii) to (xviii) results in

$$
\hat{\Delta}_{H, t}=\hat{\Delta}_{H, t}^{*}=\hat{\Delta}_{F, t}^{*}=\hat{\Delta}_{F, t}=0 .
$$

Together with linearly approximated equations (ii) to (viii), (xx) to (xxvi), and (xxxvii), we have

$$
\begin{aligned}
\widehat{m c}_{t}-\hat{p}_{H, t} & =(\sigma+\omega) \hat{y}_{t}-(1+\omega) z_{t}+\frac{(2-v)(1-\sigma)}{2}\left(\hat{q}_{t}+\hat{e}_{t}\right)+\frac{2-v}{2} \hat{d}_{t}, \\
\widehat{m c}_{t}^{*}-\hat{p}_{F, t}^{*} & =(\sigma+\omega) \hat{y}_{t}^{*}-(1+\omega) z_{t}^{*}+\frac{(2-v)(1-\sigma)}{2}\left(\hat{q}_{t}^{*}-\hat{e}_{t}\right)+\frac{2-v}{2} \hat{d}_{t}^{*}, \\
\widehat{m c}_{t}^{*}-\hat{p}_{F, t}+\hat{e}_{t} & =(\sigma+\omega) \hat{y}_{t}^{*}-(1+\omega) z_{t}^{*}+\frac{(2-v)(1-\sigma)}{2}\left(\hat{q}_{t}^{*}-\hat{e}_{t}\right)-\frac{v}{2} \hat{d}_{t}^{*}, \\
\widehat{m c}_{t}-\hat{p}_{H, t}^{*}-\hat{e}_{t} & =(\sigma+\omega) \hat{y}_{t}-(1+\omega) z_{t}+\frac{(2-v)(1-\sigma)}{2}\left(\hat{q}_{t}+\hat{e}_{t}\right)-\frac{v}{2} \hat{d}_{t}
\end{aligned}
$$

where $\hat{q}_{t}$ and $\hat{q}_{t}^{*}$ denote log deviations of the domestic and foreign terms of trade from their steady states:

$$
\begin{aligned}
Q_{t} & \equiv \frac{P_{F, t}}{S_{t} P_{H, t}^{*}}=\frac{p_{F, t}}{e_{t} p_{H, t}^{*}}, \\
Q_{t}^{*} & \equiv \frac{S_{t} P_{H, t}^{*}}{P_{F, t}}=\frac{e_{t} p_{H, t}^{*}}{p_{F, t}},
\end{aligned}
$$

${ }^{20}$ Note that $\frac{M C_{t}}{p_{H, t}}=\frac{N M C_{t}}{P_{H, t}}$ is the marginal cost evaluated at output price level while $M C_{t}=\frac{N M C_{t}}{P_{t}}$ is the marginal cost evaluated at consumer price level. The former is relevant to firms' pricing decisions. 
and $\hat{d}_{t}$ and $\hat{d}_{t}^{*}$ denote those of the deviations from the law of one price:

$$
\begin{aligned}
D_{t} & \equiv \frac{S_{t} P_{H, t}^{*}}{P_{H, t}}=\frac{e_{t} p_{H, t}^{*}}{p_{H, t}}, \\
D_{t}^{*} & \equiv \frac{P_{F}}{S_{t} P_{F, t}^{*}}=\frac{p_{F, t}}{e_{t} p_{F, t}^{*}} .
\end{aligned}
$$

Equations (2.12) to (2.15) show that, in open economies, deviations from steady state of the real marginal costs are not only proportional to deviations from steady state of output, but also depend on relative prices. The first and the second terms are those also included in the New Keynesian models in the closed economy. The third and the fourth terms appear only in open economies. Specifically, the third terms capture the interdependence: economic activities abroad affect the domestic economy via international relative prices. The qualitative impacts depend on $\sigma$. When $\sigma>1$ $(\sigma<1)$, positive changes in the international relative prices exert negative (positive) impacts on the real marginal costs. When $\sigma=1$, the spillovers are zero. Note that the transmission mechanism of such spillovers differs under PCP and LCP. Under PCP, the real exchange rate moves in proportion to the terms of trade of the home country. A deterioration of the terms of trade, associated with a real exchange rate depreciation, has two opposing effects: it increases the consumption through the global assets market and therefore increases the marginal costs; it decreases the consumption due to higher import prices and therefore decreases the marginal costs. According to the terminologies by Clarida, Galí, and Gertler (2002) for PCP, the former is called the risk-sharing effect while the latter is called the terms-of-trade effect. When $\sigma>1(\sigma<1)$, the latter (former) dominates or, in other words, the home and foreign goods are Edgeworth substitutes (complements). When $\sigma=1$, the two effects are cancelled out and thus two countries become insular. Under LCP, on the other hand, consumer prices of the imported goods are inelastic to movements in exchange rates and thus changes in the terms of trade do not entail the expenditure-switching effect as under PCP. Consumption and the real marginal costs are less responsive to the international relative prices represented by the third terms. ${ }^{21}$ A depreciation of the real exchange rate leads to an improvement of the home terms of trade under LCP due to the increases in the homecurrency denominated revenues from export sales. It is deviations from the law of one price that affect the real marginal costs under LCP, which are the fourth terms. Equations (2.12) and (2.15) illustrate that deviations from the law of one price for the home goods increase (decrease) the real marginal costs that firms face when selling the home goods domestically (abroad), ceteris paribus. The changes in the marginal costs in turn lead to PPI inflation at home (import price deflation abroad), via the New Keynesian Phillips curves in equations (2.8) and (2.11). As will be shown later, these terms are also objectives to be minimized by noncooperative policy makers under LCP. Note that the spillovers on the marginal costs represented by the fourth terms exist inde-

\footnotetext{
${ }^{21}$ See also Corsetti and Pesenti (2005b) for a discussion in a one-period ahead price adjustment model under LCP and Corsetti, Dedola, and Leduc (2010) for a discussion focusing on effects of international relative prices on consumption.
} 
pendently of goods' substitutability or complementarity, that is whether $\sigma$ is greater, smaller or equal to 1 .

Log-linearization to the aggregate resource constraints in equations (vii) and (xxv), and the risk sharing condition in equation (xxxvii) gives

$$
\hat{y}_{t}-\hat{y}_{t}^{*}+\frac{v}{2} \hat{p}_{H, t}+\frac{2-v}{2} \hat{p}_{H, t}^{*}-\frac{(v-1)}{\sigma} \hat{e}_{t}-\frac{v}{2} \hat{p}_{F, t}^{*}-\frac{2-v}{2} \hat{p}_{F, t}=0 .
$$

Also, we have log exact deviations for the definitions of inflation rates in equations (xvii), (xviii), (xxxv) and (xxxvi):

$$
\begin{aligned}
\pi_{H, t} & =\pi_{t}+\hat{p}_{H, t}-\hat{p}_{H, t-1}, \\
\pi_{H, t}^{*} & =\pi_{t}^{*}+p_{H, t}^{*}-\hat{p}_{H, t-1}^{*}, \\
\pi_{F, t} & =\pi_{t}+\hat{p}_{F, t}-\hat{p}_{F, t-1}, \\
\pi_{F, t}^{*} & =\pi_{t}^{*}+\hat{p}_{F, t}^{*}-\hat{p}_{F, t-1}^{*},
\end{aligned}
$$

Note that under PCP, the law of one price holds, thus

$$
\hat{d}_{t}=\hat{d}_{t}^{*}=0 .
$$

Consequently,

$$
\begin{aligned}
\hat{p}_{H, t} & =\hat{e}_{t}+\hat{p}_{H, t}^{*}, \\
\hat{p}_{F, t} & =\hat{e}_{t}+\hat{p}_{F, t}^{*} .
\end{aligned}
$$

\section{Optimal Monetary Policy in Open Economies}

In this section, we first set up the Ramsey problem. Optimal monetary policy under noncooperation is derived in an open-loop Nash equilibrium. Then, we derive the quadratic loss functions which central banks aim to minimize by the second-order approximation to social welfare around the Ramsey steady state.

\subsection{Ramsey Policy Problems}

Central banks under cooperation maximize global welfare:

$$
W_{W, t_{0}}=W_{H, t_{0}}+W_{F, t_{0}}
$$

subject to the nonlinear equilibrium conditions in equations (i) to (xxxvii).

On the other hand, under noncooperation, the domestic central bank maximizes equation (2.1) subject to equations (i) to (xxxvii) given $\left\{\pi_{F, t}^{*}\right\}_{t=t_{0}}^{\infty}$, while the foreign central bank maximizes equation (2.5) subject to equations (i) to (xxxvii) given $\left\{\pi_{H, t}\right\}_{t=t_{0}}^{\infty}$. The equilibrium conditions of the Ramsey policy under both cooperation and noncooperation are shown in Appendix B. The choice of the policy variables taken as given 
in a noncooperative game is crucial in determining the equilibrium. ${ }^{22}$ We follow Benigno and Benigno (2006) and choose PPI inflation rates as the policy variables for the noncooperative game.

The aims of computing the Ramsey policy in this paper are twofold. First, we need to obtain the Ramsey steady state around which the equilibrium conditions are approximated. It turns out that irrespective of cooperation or noncooperation, the Ramsey steady state is that under the flexible price equilibrium, or the equilibrium under the constant aggregate price levels. Second, we compute the welfare cost stemming from the inability to cooperate. The welfare cost is computed in the next section in a conventional manner following Lucas (1992) in a consumption unit.

\subsection{Linear-Quadratic Framework}

As Appendix B shows, the characteristics of the optimal noncooperative monetary policy under LCP is not easy to be understood from the optimality conditions from the Ramsey policy. In this subsection, we derive the quadratic objective functions which the central banks aim to minimize under LCP in a noncooperative game.

The domestic welfare can be approximated up to the second order as

$$
\begin{aligned}
W_{H, t_{0}} & \equiv \mathbb{E}_{t_{0}} \sum_{t=t_{0}}^{\infty} \beta^{t-t_{0}}\left(\frac{C_{t}^{1-\sigma}-1}{1-\sigma}-\chi \frac{h_{t}^{1+\omega}}{1+\omega}\right) \\
& \approx \mathbb{E}_{t_{0}} \sum_{t=t_{0}}^{\infty} \beta^{t-t_{0}} C^{1-\sigma}\left(\hat{c}_{t}-\hat{h}_{t}+\frac{1-\sigma}{2} \hat{c}_{t}^{2}-\frac{1+\omega}{2} \hat{h}_{t}^{2}\right)+\text { t.i.p }+ \text { h.o.t, }
\end{aligned}
$$

where $C$ is steady-state value of $C_{t}$, t.i.p and h.o.t denote the terms independent of policy and higher order term than the second order, respectively. As shown by Kim and Kim (2003) with a simple example, existence of the linear terms in the loss functions leads to spurious welfare evaluation. Thus, these must be substituted out by the second-order terms.

In a closed economy, the log exact form of the resource constraint is given by

$$
z_{t}+\hat{h}_{t}=\hat{c}_{t}+\hat{\Delta}_{H, t} .
$$

Thus, as shown by Woodford (2003), the linear terms $\hat{c}_{t}-\hat{h}_{t}$ are replaced by the price dispersion terms $-\hat{\Delta}_{H, t}$, which is of the second order and eventually replaced by the quadratic term of inflation rates (see Appendix C). ${ }^{23}$

In open economies, linear terms cannot be easily substituted out as in the closed economy. For example, under PCP with a logarithmic utility function, as shown in Fu-

\footnotetext{
${ }^{22}$ Wang (2015) examines a set of choices as policy variables including PPI inflation rates, import price inflation rates, CPI inflation rates, outputs and nominal interest rates in a two-country model with LCP. When nominal interest rates are chosen to be the policy variables, equilibrium indeterminacy occurs. This repeats the findings in Blake (2012), de Fiore and Liu (2002) and Coenen et al. (2010) although they use different models with nominal rigidities from Wang (2015).

${ }^{23}$ Note that $z_{t}$ is independent of policy.
} 
jiwara, Kam, and Sunakawa (2015), the log exact form of the home resource constraint is given by

$$
\begin{aligned}
z_{t}+\hat{h}_{t} & =-\hat{p}_{H, t}+\hat{c}_{t}+\hat{\Delta}_{H, t} \\
& =2 \hat{q}_{t}+\hat{c}_{t}+\hat{\Delta}_{H, t} .
\end{aligned}
$$

The linear terms $\hat{c}_{t}-\hat{h}_{t}$ are now replaced by not only the price dispersion terms $-\hat{\Delta}_{H, t}$ but also the terms of trade $-\hat{q}_{t}$ which is absent in the closed economy. Thus, each central bank in an open economy is incentivized to strategically manipulate the terms of trade in its favor. This indeed represents the terms-of-trade externality as analyzed in Corsetti and Pesenti (2001), Benigno (2002) and Benigno and Benigno (2006). Sutherland (2002), Benigno and Woodford (2005) and Benigno and Benigno (2006) substitute out the linear terms by the quadratic terms by using the second-order approximation to the structural equations for correct welfare evaluation. Note that under cooperative regime, the sum of the linear terms of the global welfare $\hat{c}_{t}-\hat{h}_{t}+\hat{c}_{t}^{*}-\hat{h}_{t}^{*}$ leads to the cancellation of the terms-of-trade term by using the log exact form of the foreign resource constraint:

$$
z_{t}^{*}+\hat{h}_{t}^{*}=-2 \hat{q}_{t}+\hat{c}_{t}^{*}+\hat{\Delta}_{F, t}^{*} .
$$

The terms of trade externality is internalized, by definition, under cooperation. Thus, even with LCP, as shown by Engel (2011), social welfare under cooperation can be approximated up to the second order without resort to the second-order approximation to the equilibrium conditions. Log-linear approximation to the resource constraints in equations (vii) and (xxv) results in

$$
\begin{aligned}
z_{t}+\hat{h}_{t} & =c_{t}+\frac{v}{2}\left(-p_{H, t}+\hat{\Delta}_{H, t}\right)+\frac{2-v}{2}\left(-p_{H, t}^{*}-\frac{1}{\sigma} \hat{e}_{t}+\hat{\Delta}_{H, t}^{*}\right), \\
z_{t}^{*}+\hat{h}_{t}^{*} & =c_{t}^{*}+\frac{v}{2}\left(-p_{F, t}^{*}+\hat{\Delta}_{F, t}^{*}\right)+\frac{2-v}{2}\left(-p_{F, t}+\frac{1}{\sigma} \hat{e}_{t}+\hat{\Delta}_{F, t}\right),
\end{aligned}
$$

where the log exact forms of the demands in equations (iii), (xxi), (iv), (xxii) and the risk sharing condition in equation (xxxvii) are substituted. Together with the log exact forms of equations (v) and (xxiii), we can derive

$$
\hat{c}_{t}-\hat{h}_{t}+\hat{c}_{t}^{*}-\hat{h}_{t}^{*}=-\frac{v}{2} \hat{\Delta}_{H, t}-\frac{2-v}{2} \hat{\Delta}_{H, t}^{*}-\frac{v}{2} \hat{\Delta}_{F, t}^{*}-\frac{2-v}{2} \hat{\Delta}_{F, t} .
$$

Thus, central banks under cooperation aim to stabilize fluctuations in four inflation rates: $\pi_{H, t} \pi_{H, t}^{*}, \pi_{F, t}^{*}$ and $\pi_{F, t}$. Appendix $C$ shows how to transform price dispersions into inflation rates.

Under the noncooperative regime and LCP, linear terms for the terms of trade cannot be eliminated. Thus, they need to be substituted out by the second-order approximation to AS equations under the assumption of commitment, resource constraints 
and price dispersions. Details are shown in Appendix C. In particular, equations (6.118) and (6.119) in Appendix $C$ show how linear terms can be replaced by quadratic terms.

Upon obtaining the quadratic expressions for the linear terms, the loss function that the home central bank aims to minimize is then given by

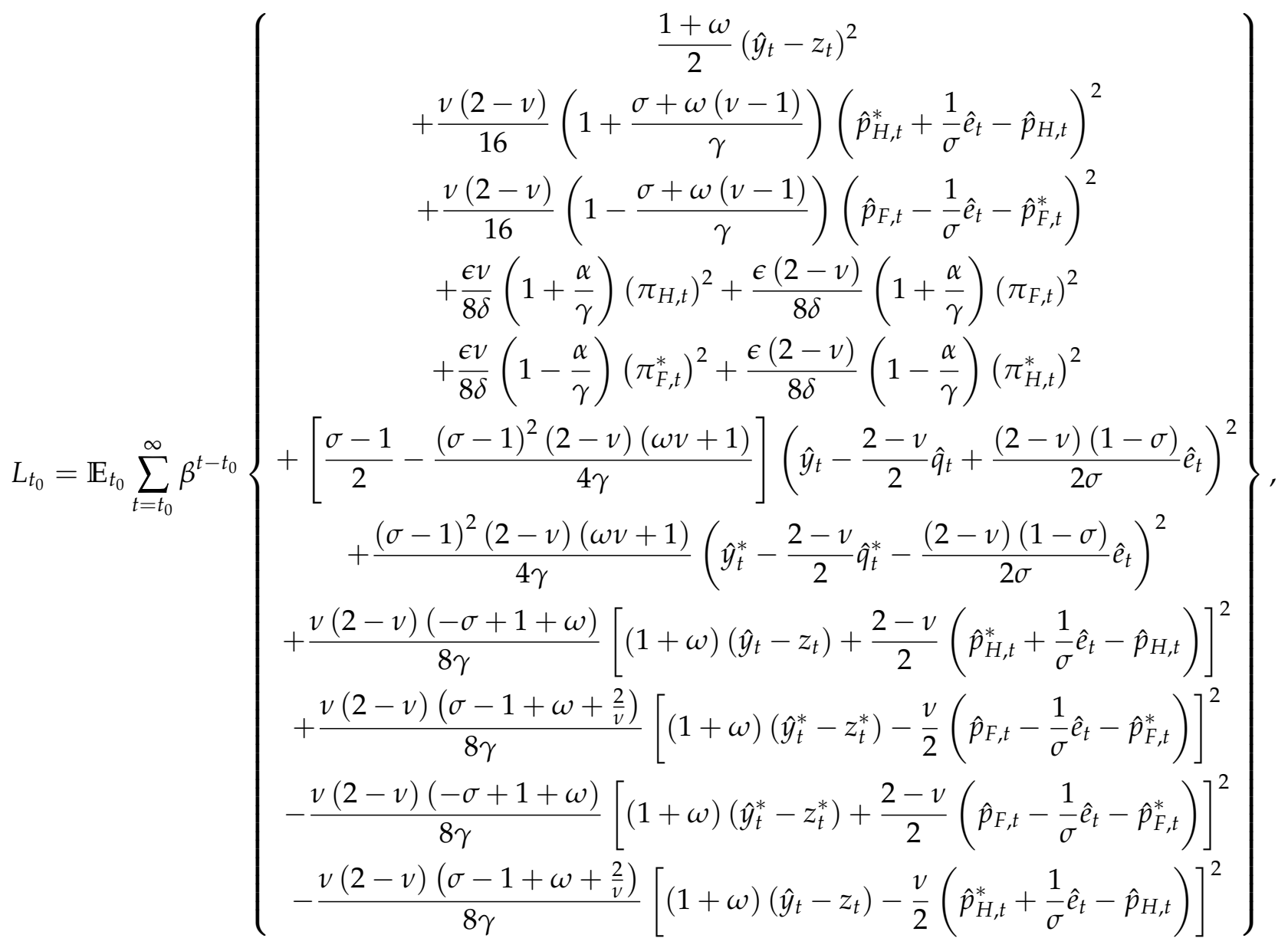


and the loss function that the foreign central bank aims to minimize is given by

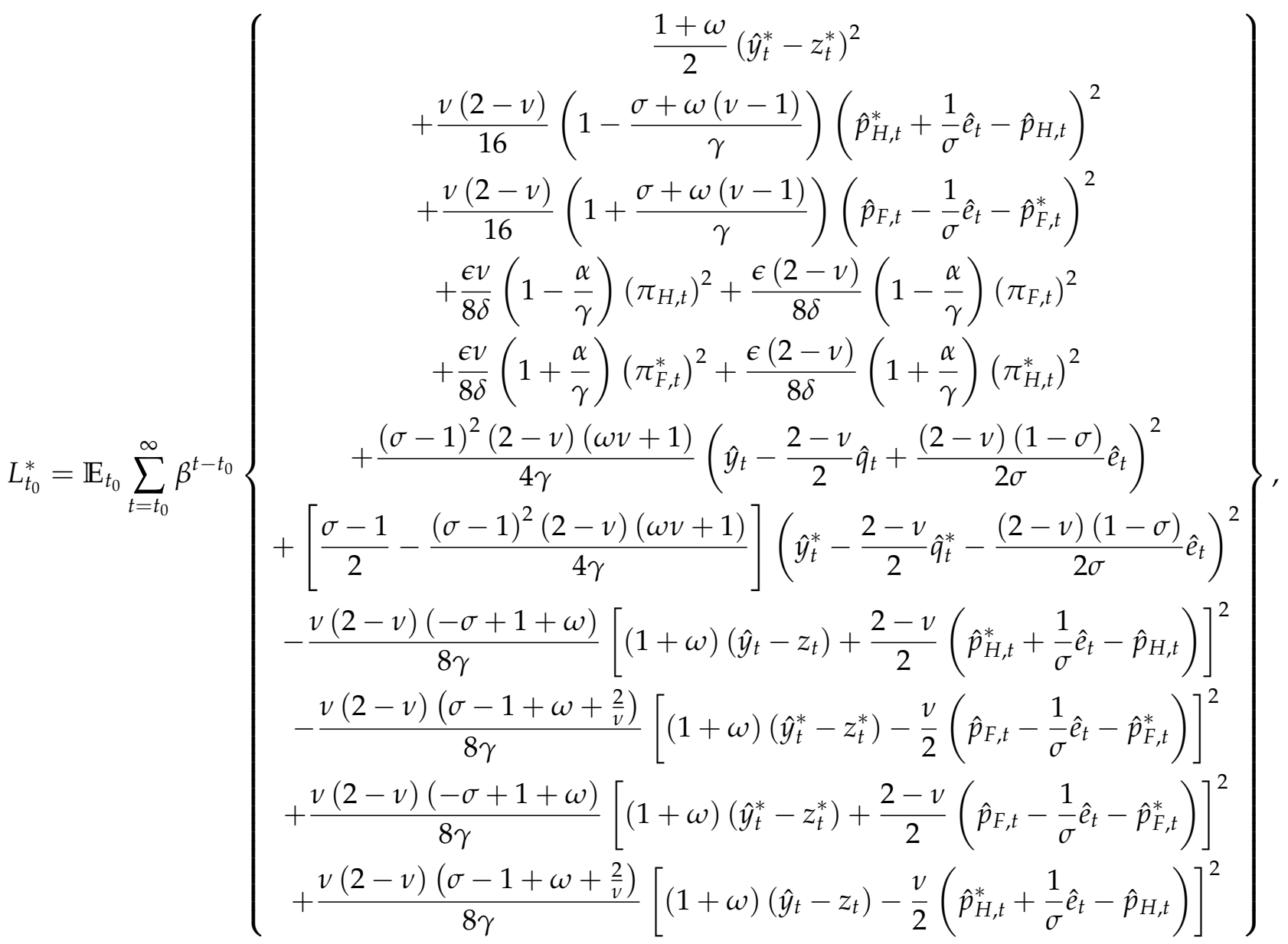

where $\alpha=\omega+1+(1-\sigma)(1-v), \gamma=\sigma v \omega(2-v)+\sigma+\omega(1-v)^{2}$, and $\delta=$ $\frac{(1-\theta)(1-\beta \theta)}{\theta}$. The expressions of the loss functions are simplified and more intuitive when we set $\sigma=1$. Note that as discussed in Section 2.6, the international spillovers exist under LCP even when $\sigma=1$ so imposing this restriction does not mean the absence of gains from cooperation.

When $\sigma=1$, the quadratic loss function which the domestic central bank aims to 
minimize is given by

$$
L_{t_{0}}=\mathbb{E}_{t_{0}} \sum_{t=t_{0}}^{\infty} \beta^{t-t_{0}}\left\{\begin{array}{c}
\frac{1+\omega}{2}\left(\hat{y}_{t}-z_{t}\right)^{2} \\
+\frac{\epsilon v}{4 \delta}\left(\pi_{H, t}\right)^{2}+\frac{\epsilon(2-v)}{4 \delta}\left(\pi_{F, t}\right)^{2} \\
+\frac{v(2-v) \Omega}{8}\left(\hat{d}_{t}\right)^{2}+\frac{v(2-v)(1-\Omega)}{8}\left(\hat{d}_{t}^{*}\right)^{2} \\
+\frac{v(1-\Omega)}{4}\left((1+\omega)\left(\hat{y}_{t}-z_{t}\right)+\frac{2-v}{2} \hat{d}_{t}\right)^{2} \\
+\frac{(2-v) \Omega}{4}\left((1+\omega)\left(\hat{y}_{t}^{*}-z_{t}^{*}\right)-\frac{v}{2} \hat{d}_{t}^{*}\right)^{2} \\
-\frac{v(1-\Omega)}{4}\left((1+\omega)\left(\hat{y}_{t}^{*}-z_{t}^{*}\right)+\frac{2-v}{2} \hat{d}_{t}^{*}\right)^{2} \\
-\frac{(2-v) \Omega}{4}\left((1+\omega)\left(\hat{y}_{t}-z_{t}\right)-\frac{v}{2} \hat{d}_{t}\right)^{2}
\end{array}\right\},
$$

while that for the foreign central bank is

$$
L_{t_{0}}^{*}=\mathbb{E}_{t_{0}} \sum_{t=t_{0}}^{\infty} \beta^{t-t_{0}}\left\{\begin{array}{c}
\frac{1+\omega}{2}\left(\hat{y}_{t}^{*}-z_{t}^{*}\right)^{2} \\
+\frac{\epsilon v}{4 \delta}\left(\pi_{F, t}^{*}\right)^{2}+\frac{\epsilon(2-v)}{4 \delta}\left(\pi_{H, t}^{*}\right)^{2} \\
+\frac{v(2-v) \Omega}{8}\left(\hat{d}_{t}^{*}\right)^{2}+\frac{v(2-v)(1-\Omega)}{8}\left(\hat{d}_{t}\right)^{2} \\
+\Omega)\left((1+\omega)\left(\hat{y}_{t}^{*}-z_{t}^{*}\right)+\frac{2-v}{2} \hat{d}_{t}^{*}\right)^{2} \\
+\frac{(2-v) \Omega}{4}\left((1+\omega)\left(\hat{y}_{t}-z_{t}\right)-\frac{v}{2} \hat{d}_{t}\right)^{2} \\
-\frac{v(1-\Omega)}{4}\left((1+\omega)\left(\hat{y}_{t}-z_{t}\right)+\frac{2-v}{2} \hat{d}_{t}\right)^{2} \\
-\frac{(2-v) \Omega}{4}\left((1+\omega)\left(\hat{y}_{t}^{*}-z_{t}^{*}\right)-\frac{v}{2} \hat{d}_{t}^{*}\right)^{2}
\end{array}\right\},
$$

where $\Omega \equiv \frac{1+\omega \frac{v}{2}}{1+\omega}$ and $0<\Omega \leqslant 1$.

Equations (3.2) and (3.3) show that the noncooperative loss function of each policy maker under LCP consists of nine quadratic terms. The first terms, quadratic deviations from steady state of output (employment), represent the inefficient fluctuations in output and therefore consumption stemming from markup fluctuations in the realization of productivity shocks, which hinder consumption smoothing; the second and third terms, squared inflation rates of local as well as imported products, arise from the staggered price contracts, which create price dispersions; the fourth and 
fifth terms are the direct consequences from the breakdown of the law of one price; the final four terms, as explained in Section 2.6, represent inefficient fluctuations in the real marginal costs, which leads to fluctuations in both PPI and import price inflation rates. The signs associated with those terms represent the national central bank's incentives to simultaneously stabilize the inflation rates relevant to its own country and destabilize those relevant to the counterpart country.

Table 3 offers comparison of the loss functions under LCP and noncooperation to those under (1) PCP and cooperation, (2) PCP and noncooperation, and (3) LCP and cooperation. We start the comparison given LCP (Table 3, column 2). The first five terms in the noncooperative loss functions, in equations (3.2) and (3.3), are also those in the cooperative loss functions. The last four terms regarding fluctuations in the real marginal costs, representing the terms-of-trade externality, are unique to the noncooperative policy makers. The existence of the additional terms indicates national policy makers' additional concern for stabilization of inflation rates in both goods categories. Under LCP, that means gains from stabilization of CPI inflation rates.

Then, we compare column 2 to column 1. The number of objectives (trade-offs) that policy makers aim to minimize is substantially reduced from LCP to PCP, regardless of the nature of strategic games. The key to understand this difference is the law of one price, which holds only under PCP, renders (a) price dispersions within export goods identical to those within locally produced and consumed goods; (b) $\hat{d}_{t}=\hat{d}_{t}^{*}=0$ by definitions; and (c) stabilization of the real marginal costs is in line with stabilization of output fluctuations. Therefore, the additional trade-offs regarding fluctuations in the real marginal costs that separate the noncooperative loss functions away from the cooperative ones under LCP no longer exist under PCP. Allocations and prices under both games coincide under PCP. 
Table 3: Quadratic loss functions under PCP / LCP and under cooperation / noncooperation

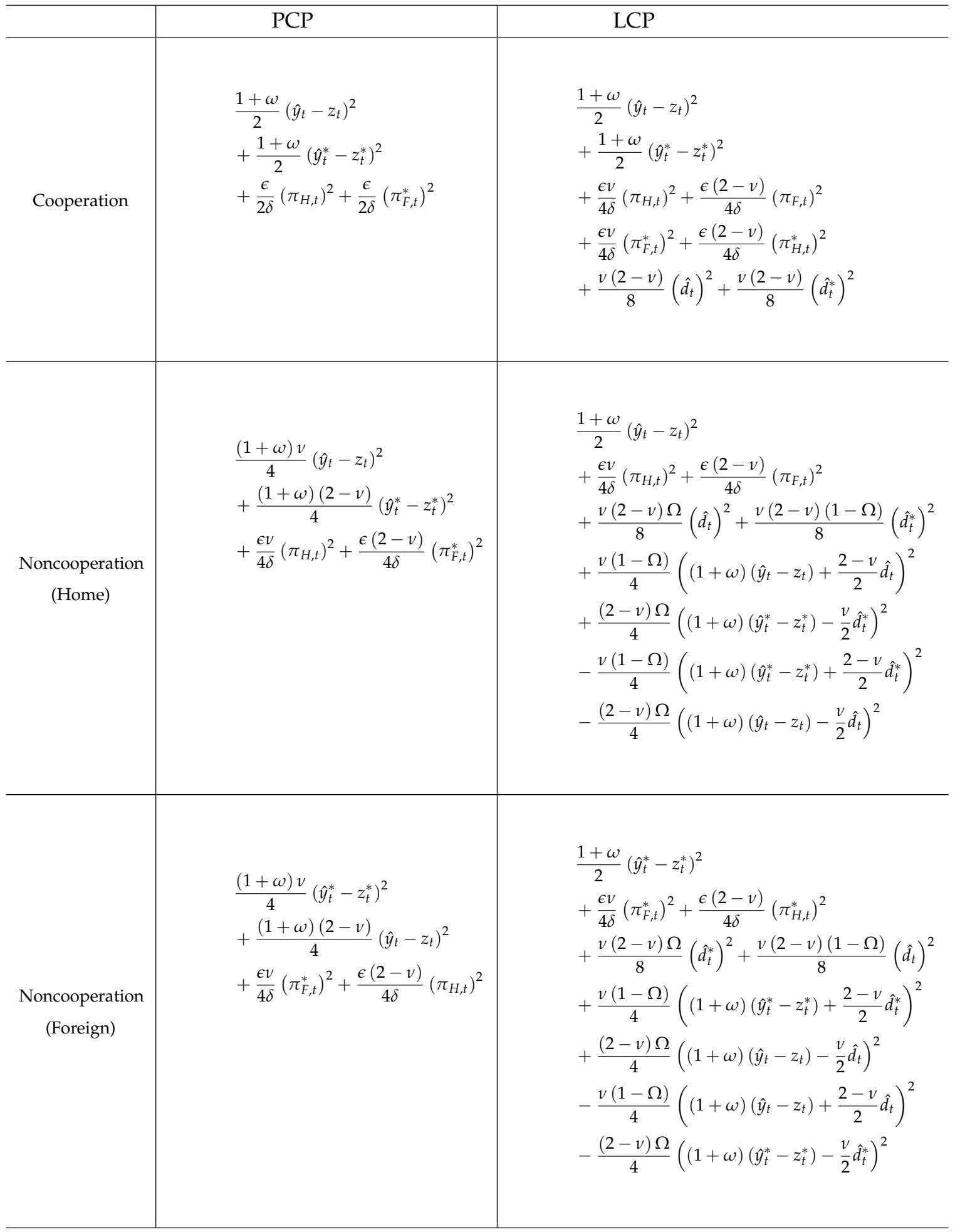

Note: we present the period loss functions in the Table. The loss function of each policy maker is the present discounted value of the sum of current and expected future period loss functions. 
Quadratic loss functions are minimized by the central banks subject to the constraint relating to cross country output difference, equation (2.20), the familiar New Keynesian Phillips curves with equations (2.12)-(2.15) substituted into equations (2.8)(2.11):

$$
\begin{aligned}
\pi_{H, t} & =\beta \mathbb{E}_{t} \pi_{H, t+1}+\delta\left[(\sigma+\omega) \hat{y}_{t}-(1+\omega) z_{t}+\frac{(2-v)(1-\sigma)}{2}\left(\hat{q}_{t}+\hat{e}_{t}\right)+\frac{2-v}{2} \hat{d}_{t}\right], \\
\pi_{F, t} & =\beta \mathbb{E}_{t} \pi_{F, t+1}+\delta\left[(\sigma+\omega) \hat{y}_{t}^{*}-(1+\omega) z_{t}^{*}+\frac{(2-v)(1-\sigma)}{2}\left(\hat{q}_{t}^{*}-\hat{e}_{t}\right)-\frac{v}{2} \hat{d}_{t}^{*}\right], \\
\pi_{F, t}^{*} & =\beta \mathbb{E}_{t} \pi_{F, t+1}^{*}+\delta\left[(\sigma+\omega) \hat{y}_{t}^{*}-(1+\omega) z_{t}^{*}+\frac{(2-v)(1-\sigma)}{2}\left(\hat{q}_{t}^{*}-\hat{e}_{t}\right)+\frac{2-v}{2} \hat{d}_{t}^{*}\right], \\
\pi_{H, t}^{*} & =\beta \mathbb{E}_{t} \pi_{H, t+1}^{*}+\delta\left[(\sigma+\omega) \hat{y}_{t}-(1+\omega) z_{t}+\frac{(2-v)(1-\sigma)}{2}\left(\hat{q}_{t}+\hat{e}_{t}\right)-\frac{v}{2} \hat{d}_{t}\right],
\end{aligned}
$$

where $\hat{q}_{t}=\hat{p}_{F, t}-\hat{e}_{t}-\hat{p}_{H, t}^{*}, \hat{q}_{t}^{*}=\hat{e}_{t}+\hat{p}_{H, t}^{*}-\hat{p}_{F, t}, \hat{d}_{t}=\hat{p}_{H, t}^{*}+\hat{e}_{t}-\hat{p}_{H, t}$, and $\hat{d}_{t}^{*}=$ $\hat{p}_{F, t}-\hat{e}_{t}-\hat{p}_{F, t}^{*}$, as well as the relations between inflation rates and relative prices from detrending the system, equations (2.21)-(2.24), and definitions of aggregate price indexes:

$$
\begin{aligned}
& \frac{v}{2} \hat{p}_{H, t}+\frac{2-v}{2} \hat{p}_{F, t}=0, \\
& \frac{2-v}{2} \hat{p}_{H, t}^{*}+\frac{v}{2} \hat{p}_{F, t}^{*}=0 .
\end{aligned}
$$

Under noncooperation, the domestic central bank minimizes (3.2) subject to equations (2.20), (2.21)-(2.24), (3.4)-(3.7), and (3.8)-(3.9), given foreign PPI inflation rates $\left\{\pi_{F, t}^{*}\right\}$ for all $t \geq t_{0}$. Similarly, the foreign central bank minimizes (3.3) subject to equations (2.20), (2.21)-(2.24), (3.4)-(3.7), and (3.8)-(3.9), given domestic PPI inflation rates $\left\{\pi_{H, t}\right\}$ for all $t \geq t_{0}$. Each central bank conducts optimal commitment policy from the timeless perspective as in Woodford (2003).

\section{Results}

In this section, we first draw impulse responses of the two countries to a positive technology shock to the home country. The dynamics are obtained under the optimal monetary policy in Section 3.2. We consider cooperative and noncooperative games under both PCP and LCP. As discussed in previous section, cooperative and noncooperative allocations and prices coincide under PCP. We then compute welfare gains from cooperation using the Ramsey policy problem presented in Section 3.1.

\subsection{Impulse Responses}

The baseline parameters are calibrated as in Table $4 . \beta, \chi$ and the probability of not being able to reset prices $\theta$ are set at the conventional values. $v$ is set at 1.5 as in Engel (2011) which means that households put 3/4 of the weight on consumption 
of domestic goods in utility. $\sigma$ usually takes the range from 1 to 5 . We set it to 1 , consistent with our derivation of simplified loss functions in previous section. The elasticity of substitution among different varieties within goods category is set at 7.66. Empirical data show that the range of the inverse of the Frisch elasticity $1 / \omega$ is 0.05 0.3 so we set $\omega$ at 4.71 in the range. Note that Engel (2011) assumes a linear disutility of labor, $\omega=0$, which later we will show to be a special case in which welfare gains from cooperation are zero. In addition, the log-technology follows an AR(1) stochastic process with serial correlation $\rho$ set at 0.856 and standard deviation at $0.0064 .{ }^{24}$

Table 4: Parameter values (Baseline)

\begin{tabular}{|c|c|c|}
\hline Parameter & Value & Description \\
\hline$\beta$ & 0.99 & Subjective discount factor \\
\hline$\theta$ & 0.75 & $\begin{array}{l}\text { Probability of a firm not being chosen to reset its prices at each } \\
\text { period }\end{array}$ \\
\hline$\epsilon$ & 7.66 & $\begin{array}{l}\text { Elasticity of substitution among different products within goods } \\
\text { category }\end{array}$ \\
\hline$v$ & 1.5 & $\begin{array}{l}\text { Weight that households put on consumption of domestic goods } \\
\text { in utility }(v / 2)\end{array}$ \\
\hline$\sigma$ & 1 & $\begin{array}{l}\text { Inverse of the intertemporal elasticity of substitution of } \\
\text { consumption }\end{array}$ \\
\hline$\chi$ & 1 & Coefficient associated with disutility of labor \\
\hline$\omega$ & 4.71 & Inverse of the Frisch elasticity \\
\hline
\end{tabular}

Figure 1 depicts the impulse responses under PCP and under LCP to one standard deviation of a positive technology shock to the home country (we scale up the impulse responses by 100 so the dynamics in Figure 1 are measured in per cent). In response to technology improvement shocks, optimal policy is always expansionary in the country experiencing such shocks and contractionary in the country without shocks. Specific to results in Figure 1, it means a (nominal and) real exchange rate depreciation for the home country.

Under PCP, optimal policy brings in efficient responses of output and fully stabilizes PPI inflation rates, in response to efficient shocks. A one standard deviation of the home technology shocks leads to an increase of home output by 0.64 per cent. With the efficient responses of output, optimal policy is able to fully stabilize PPI inflation rates of the two countries. Imported goods prices then fluctuate with exchange rates and changes in CPI inflation rates reflect changes in import price inflation rates proportionately (the proportion is equal to the weight of imported goods in the consumption basket, i.e. $25 \%$ ). The home terms of trade weakens with the real depreciation. Foreign output stays unchanged when $\sigma=1$ because there are no spillovers.

Under LCP and cooperation, optimal policy trades off output responses with stabilization of CPI inflation rates. Specifically, a one standard deviation of the home

\footnotetext{
${ }^{24}$ For the range of $\sigma$, see Benigno and Benigno (2006), for the range of $\omega$, see Erceg, Gust, and LopezSalido (2007), and for technology calibration, see Schmitt-Grohé and Uribe (2007).
} 
productivity improvement shock now leads to an increase of home output by less than 0.64 per cent, which translates into a fall in PPI inflation rates of the home country. The real exchange rate depreciation under LCP leads to an improvement of the home terms of trade, raising the real purchasing power of the home country at any given price level. Thus demand for both goods rises and foreign output increases to meet the higher demand. CPI inflation rates of both countries are stabilized to a much larger extent by optimal policy under LCP than under PCP.

Under LCP and noncooperation, optimal policy seeks to stabilize CPI inflation rates more so than it does under cooperation, as demonstrated by the additional terms in the noncooperative loss functions in Section 3.2. As a trade-off, home output increases less than it does under cooperation and home PPI inflation rates fall further. Optimal policy is less expansionary in the home country and thus the real exchange rate depreciates less under noncooperation than under cooperation. The home terms of trade deteriorates and the foreign terms of trade improves, compared to their respective cooperative positions. Given any price level, foreign consumers' demand for the foreign goods increases and foreign output rises further accordingly. 
Figure 1: Impulse responses under PCP and LCP to a positive technology shock to the home country by one S.D.
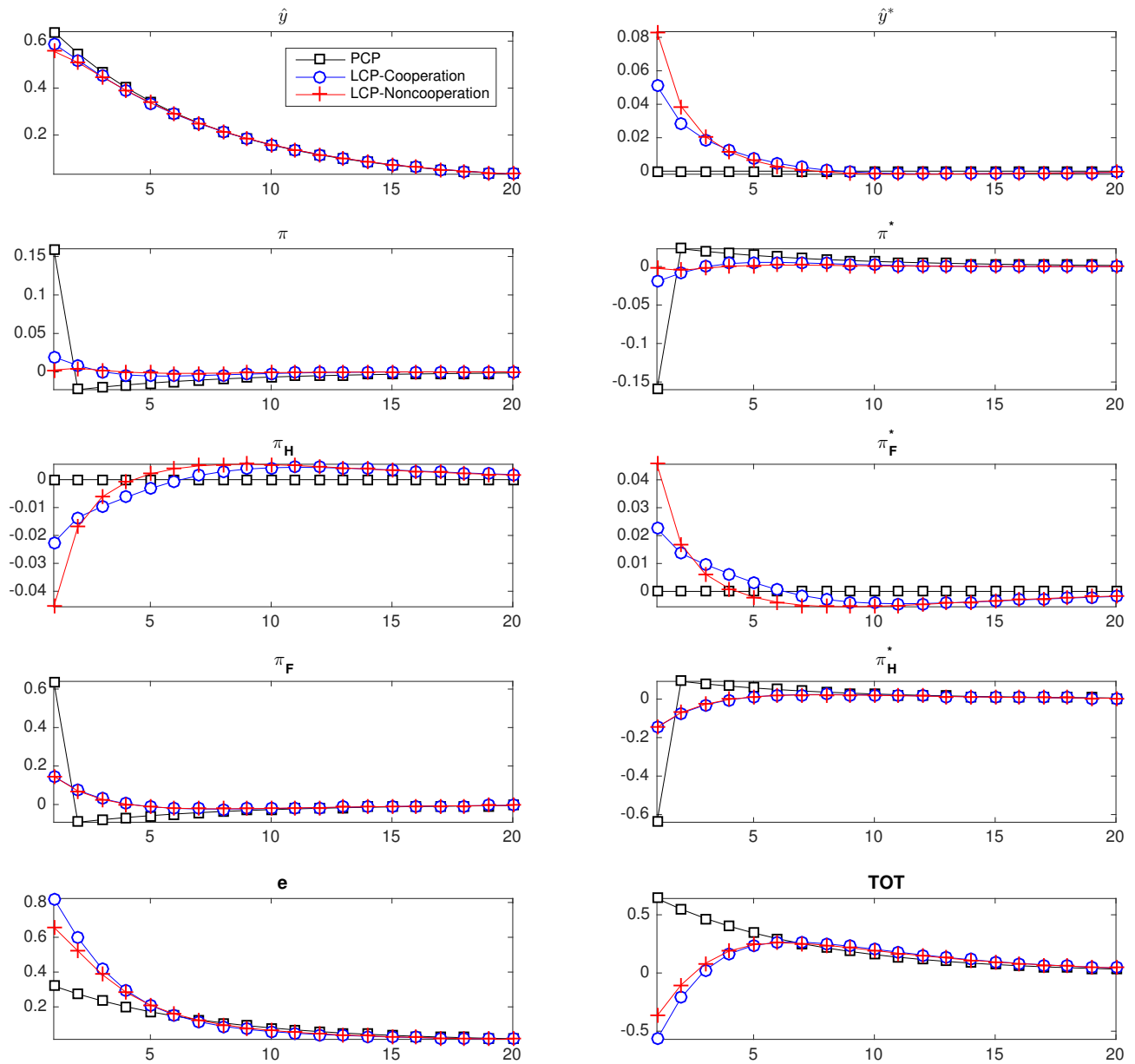

\subsection{Welfare Cost}

The welfare cost from noncooperation is measured in consumption units by Lucas (1992). Specifically, the welfare cost measures the proportion of aggregate consumption that a representative household has to give up so that it is as well-off under the cooperative regime as under the noncooperative regime. Denote ' $c$ ' and ' $n$ ' as superscript for the cooperative game and noncooperative game, respectively. Following Schmitt-Grohé and Uribe (2007), denote $\lambda^{c}$ as the welfare cost from noncooperation 
for the home representative household and we have

$$
W_{H, t_{0}}^{n}=\mathbb{E}_{t_{0}} \sum_{t=t_{0}}^{\infty} \beta^{t-t_{0}}\left[u\left(\left(1-\lambda^{c}\right) C_{t}^{c}\right)-v\left(h_{t}^{c}\right)\right] .
$$

When $\sigma=1$,

$$
W_{H, t_{0}}^{n}=\mathbb{E}_{t_{0}} \sum_{t=t_{0}}^{\infty} \beta^{t-t_{0}}\left(\log \left[\left(1-\lambda^{c}\right) C_{t}^{c}\right]-\chi \frac{\left(h_{t}^{c}\right)^{1+\omega}}{1+\omega}\right)
$$

thus $\lambda^{c}$ is given by

$$
\lambda^{c}=1-\exp (1-\beta)\left(W_{H, t_{0}}^{n}-W_{H, t_{0}}^{c}\right),
$$

where $W_{H, t_{0}}^{c}$ and $W_{H, t_{0}}^{n}$ are the present discounted value of the lifetime utility of the home representative household under cooperation and noncooperation, respectively, as defined in equation (2.1). When $\sigma \neq 1$,

$$
W_{H, t_{0}}^{n}=\mathbb{E}_{t_{0}} \sum_{t=t_{0}}^{\infty} \beta^{t-t_{0}}\left(\frac{\left[\left(1-\lambda^{c}\right) C_{t}^{c}\right]^{1-\sigma}}{1-\sigma}-\chi \frac{\left(h_{t}^{c}\right)^{1+\omega}}{1+\omega}\right)
$$

thus $\lambda^{c}$ is given by

$$
\lambda^{c}=1-\left(\frac{W_{H, t_{0}}^{n}+\mathbb{H}_{t_{0}}^{c}}{\mathbb{C}_{t_{0}}^{c}}\right)^{\frac{1}{1-\sigma}},
$$

where $\mathbb{C}_{t_{0}}^{c}=\mathbb{E}_{t_{0}} \sum_{t=t_{0}}^{\infty} \beta^{t-t_{0}} \frac{\left(C_{t}^{c}\right)^{1-\sigma}}{1-\sigma}$ and $\mathbb{H}_{t_{0}}^{c}=\mathbb{E}_{t_{0}} \sum_{t=t_{0}}^{\infty} \beta^{t-t_{0}} \chi \frac{\left(h_{t}^{c}\right)^{1+\omega}}{1+\omega}$ are the present discounted value of the home representative household' lifetime stream of consumption and working hours under cooperative policy, respectively, and $W_{H, t_{0}}^{n}$ is the present discounted value of the lifetime utility of the home representative household under noncooperative policy.

We apply the perturbation method to the nonlinear model in Section 3.1 to compute $W_{H, t_{0}}^{c}$ and $W_{H, t_{0}}^{n}{ }^{25}$ Figure 2 depicts the welfare cost from noncooperation of the home country, the foreign country and the world economy as functions of $v$ and $\sigma$ for $0 \leq v \leq 2$ and $\sigma=1,3,5$ when $\omega=4.71$. Figure 3 depicts the three-dimension figures of the welfare cost from noncooperation as functions of $v$ and $\sigma$ for $0 \leq v \leq 2$ and $1 \leq \sigma \leq 5$ when $\omega=4.71$. The remaining parameters are calibrated as in Table 4 .

In the baseline parameterization as shown by the line of $\sigma=1$ in Figure 2, the estimated mean welfare cost from noncooperation is $\lambda^{c}=0.037 \%$ in response to a positive home technology shock of one standard deviation. It means that the home households under the cooperative optimal policy have to give up 0.037 per cent of

\footnotetext{
${ }^{25}$ We develop our code in Dynare and execute it in MATLAB. Code is available upon request.
} 
their consumption to be as well-off as under the noncooperative regime. Figures 3 shows that in general there exist nonzero gains from cooperation under LCP. The welfare gains from cooperation are largest under $\sigma=1$ even though two countries are insular in structural equations under PCP. Overall, the size of the gain is relatively small, though not negligible. These results imply that in order to have a large welfare gain from cooperation, frictions other than nominal rigidities or other shocks must be considered.

There are two special cases in which gains from cooperation under LCP become zero: 1) consumption preferences exhibit no home bias, $v=1$ and closed economy, $v=0$ or 2; and 2) disutility of labor becomes linear, i.e. $\omega=0$. The former makes the two countries identical in every aspect or reduce to closed economies. In particular, when there is no home bias, as mentioned in Engel (2011), there exists no trade-off between eliminating distortions from the breakdown of the law of one price and the inefficient output fluctuations. The latter eliminates the costs stemming from fluctuating labor and therefore output, which are the sources of the deviations from the law of one price as a determinant of the real marginal costs. 
Figure 2: Welfare costs from noncooperation as functions of $v$ under $\sigma=1,3,5$, in percentage
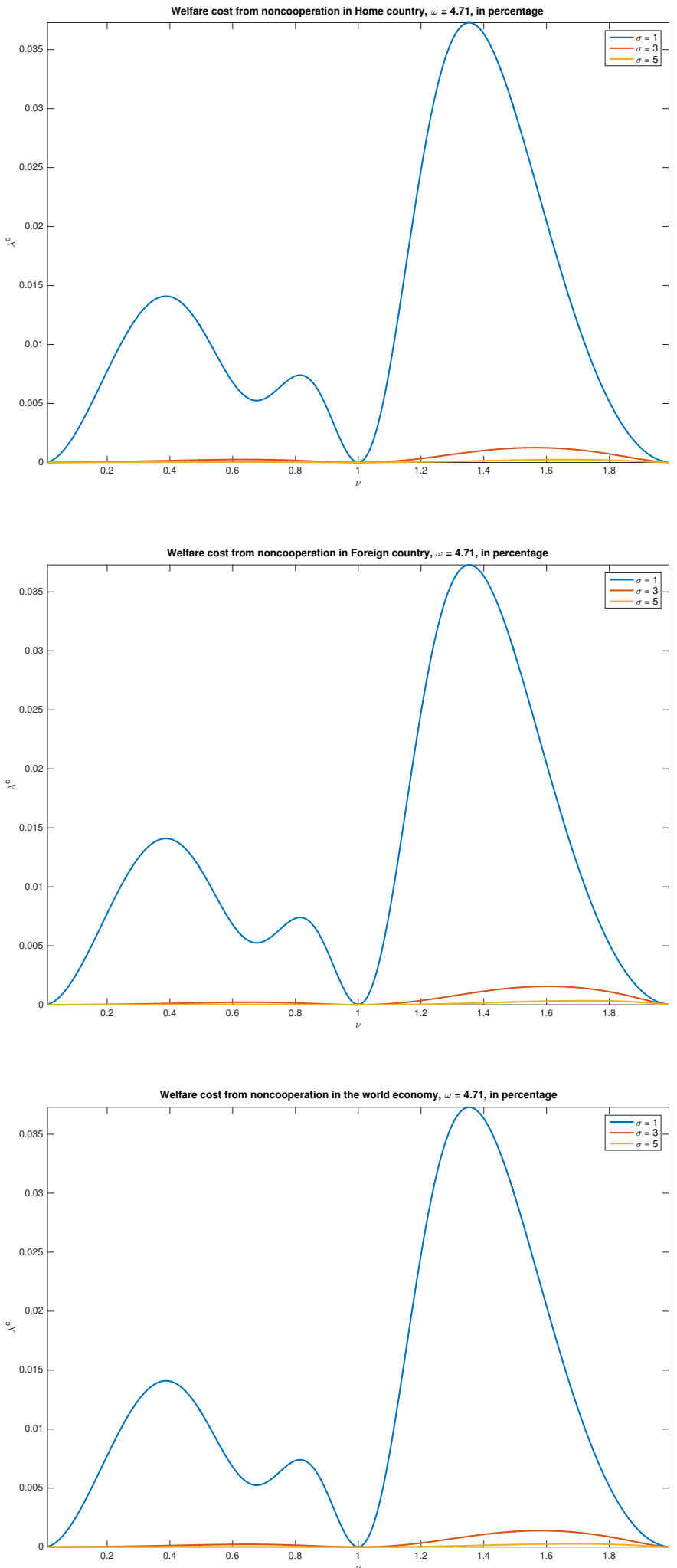
Figure 3: Welfare costs from noncooperation as functions of $v$ and $\sigma$ in threedimension, in percentage
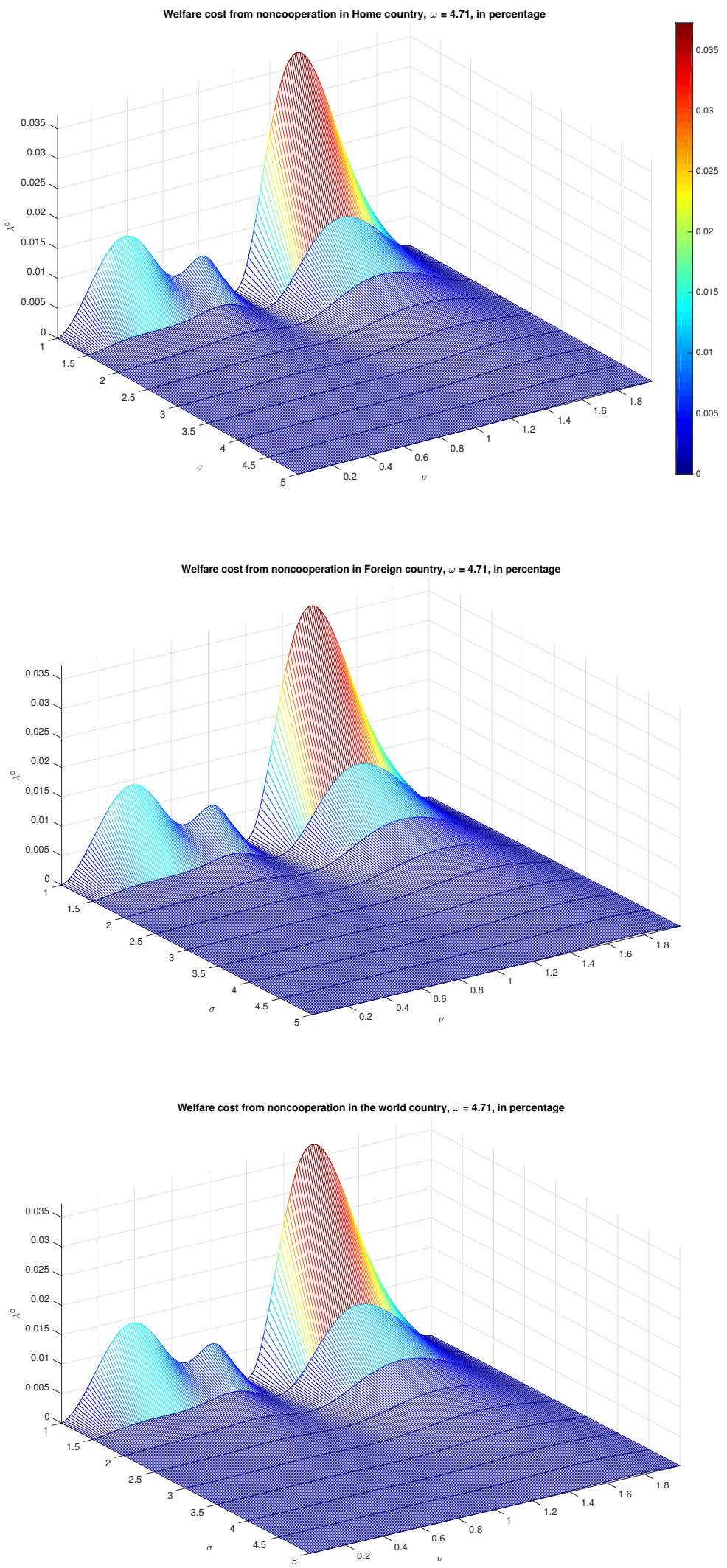


\section{Conclusion}

This paper finds that there exist gains from cooperation with optimal monetary policy under LCP in response to technology shocks. A two-country DSGE model is developed in the paper and a linear-quadratic approach is adopted to obtain the quadratic loss functions of noncooperative policy makers. The paper shows that noncooperative policy makers under LCP face extra trade-offs regarding stabilizing the real marginal costs induced by deviations from the law of one price. Optimal monetary policy seeks to stabilize CPI inflation rates more so than it does under cooperation. Also, our study suggests that as long as nominal rigidities are the sole distortions in the economy, gains from cooperation are not sizable.

This paper follows Engel (2011) in the optimal monetary policy analysis. One of the strong assumptions of the model is a complete assets market. Corsetti, Dedola, and Leduc (2010) review the development in the NOEM literature and point out that a complete assets market is a highly restrictive assumption which prohibits investigations of inefficiencies other than nominal rigidities. Given the findings in this paper, it would be interesting to investigate the welfare implication of optimal monetary policy under LCP and the incomplete assets market. 


\section{References}

Atkeson, A., Burstein, A., 2008. Pricing-to-market, trade costs, and international relative prices. The American Economic Review 98 (5), 1998-2031.

Bacchetta, P., van Wincoop, E., 2000. Does exchange-rate stability increase trade and welfare? The American Economic Review 90 (5), 1093-1109.

Benigno, G., Benigno, P., 2003. Price stability in open economies. The Review of Economic Studies 70 (4), 743-764.

Benigno, G., Benigno, P., 2006. Designing targeting rules for international monetary policy cooperation. Journal of Monetary Economics 53 (3), 473-506.

Benigno, P., 2002. A simple approach to international monetary policy coordination. Journal of International Economics 57 (1), 177-196.

Benigno, P., Woodford, M., 2005. Inflation stabilization and welfare: The case of a distorted steady state. Journal of the European Economic Association 3 (6), 11851236.

Betts, C., Devereux, M. B., 2000. Exchange rate dynamics in a model of pricing-tomarket. Journal of International Economics 50 (1), 215-244.

Bilbiie, F. O., 2002. Perfect versus optimal contracts: An implementability-efficiency tradeoff. European University Institute, unpublished.

Blake, A., 2012. Fixed interest rate over finite horizons. Bank of England Working Paper No. 454.

Calvo, G. A., 1983. Staggered prices in a utility-maximizing framework. Journal of Monetary Economics 12 (3), 383-398.

Clarida, R., Galí, J., Gertler, M., 2002. A simple framework for international monetary policy analysis. Journal of Monetary Economics 49 (5), 879-904.

Coenen, G., Lombardo, G., Smets, F., Straub, R., 2010. International transmission and monetary policy cooperation. In: Galí, J., Gertler, M. J. (Eds.), International Dimensions of Monetary Policy. University of Chicago Press, pp. 157-192.

Corsetti, G., 2008. New open economy macroeconomics. In: Durlauf, S. N., Blume, L. E. (Eds.), The New Palgrave Dictionary of Economics, 2nd Edition. Palgrave Macmillan, Basingstoke.

Corsetti, G., Dedola, L., Leduc, S., 2010. Optimal monetary policy in open economies. In: Friedman, B. M., Woodford, M. (Eds.), Handbook of Monetary Economics. Vol. 3. North-Holland, Amsterdam, pp. 861-933. 
Corsetti, G., Pesenti, P., 2001. Welfare and macroeconomic interdependence. The Quarterly Journal of Economics 116 (2), 421-445.

Corsetti, G., Pesenti, P., 2005a. International dimensions of optimal monetary policy. Journal of Monetary Economics 52 (2), 281-305.

Corsetti, G., Pesenti, P., 2005b. The simple geometry of transmission and stabilization in closed and open economies. NBER Working Paper No. 11341.

de Fiore, F., Liu, Z., 2002. Open and equilibrium determinacy under interest rate rules. European Central Bank Working Paper No. 173.

de Paoli, B., 2009. Monetary policy and welfare in a small open economy. Journal of International Economics 77 (1), 11-22.

Devereux, M. B., Engel, C., 2003. Monetary policy in the open economy revisited: Price setting and exchange-rate flexibility. The Review of Economic Studies 70 (4), 765-783.

Duarte, M., Obstfeld, M., 2008. Monetary policy in the open economy revisited: The case for exchange-rate flexibility restored. Journal of International Money and Finance 27 (6), 949-957.

Engel, C., 1999. Accounting for U.S. real exchange rate changes. Journal of Political Economy 107 (3), 507-538.

Engel, C., 2003. Expenditure switching and exchange-rate policy. In: Gertler, M., Rogoff, K. (Eds.), NBER Macroeconomics Annual 2002. Vol. 17. MIT Press, Cambridge, MA, pp. 231-300.

Engel, C., 2011. Currency misalignments and optimal monetary policy: A reexamination. The American Economic Review 101 (6), 2796-2822.

Engel, C., Rogers, J. H., 2001. Violating the law of one price: Should we make a federal case out of it? Journal of Money, Credit and Banking 33 (1), 1-15.

Erceg, C. J., Gust, C., Lopez-Salido, D., 2007. The transmission of domestic shocks in the open economy. NBER Working Paper No. 13613.

Faia, E., Monacelli, T., 2008. Optimal monetary policy in a small open economy with home bias. Journal of Money, Credit and Banking 40 (4), 721-750.

Friedman, M., 1953. The case for flexible exchange rates. In: Essays in Positive Economics. University of Chicago Press, Chicago, IL, pp. 157-203.

Fujiwara, I., Kam, T., Sunakawa, T., 2015. Sustainable international monetary policy cooperation. Federal Reserve Bank of Dallas Working Paper No. 234. 
Galí, J., Gertler, M., 1999. Inflation dynamics: A structural econometric analysis. Journal of Monetary Economics 44 (2), 195-222.

Hume, D., 1752. Essays: Moral, Political and Literary. Liberty Fund, Indianapolis, IN.

Jensen, H., 2002. Targeting nominal income growth or inflation? The American Economic Review 92 (4), 928-956.

Khan, A., King, R. G., Wolman, A. L., 2003. Optimal monetary policy. The Review of Economic Studies 70 (4), 825-860.

Kim, J., Kim, S. H., 2003. Spurious welfare reversals in international business cycle models. Journal of International Economics 60 (2), 471-500.

Lucas, R. E., 1992. On efficiency and distribution. The Economic Journal 102 (411), 233-247.

Monacelli, T., 2005. Monetary policy in a low pass-through environment. Journal of Money, Credit and Banking 37 (6), 1047-1066.

Obstfeld, M., Rogoff, K., 1995. Exchange rate dynamics redux. Journal of Political Economy 103 (3), 624-60.

Obstfeld, M., Rogoff, K., 1998. Risk and exchange rates. NBER Working Paper No. 6694.

Obstfeld, M., Rogoff, K., 2000. New directions for stochastic open economy models. Journal of International Economics 50 (1), 117-153.

Obstfeld, M., Rogoff, K., 2002. Global implications of self-oriented national monetary rules. The Quarterly Journal of Economics 117 (2), 503-535.

Parsley, D. C., Wei, S.-J., 2001. Explaining the border effect: The role of exchange rate variability, shipping costs, and geography. Journal of International Economics 55 (1), 87-105.

Persson, T., Tabellini, G., 1995. Double-edged incentives: Institutions and policy coordination. In: Grossman, G. M., Rogoff, K. (Eds.), Handbook of International Economics. Vol. 3. North-Holland, Amsterdam, pp. 1973-2030.

Rotemberg, J., Woodford, M., 1997. An optimization-based econometric framework for the evaluation of monetary policy. In: NBER Macroeconomics Annual 1997. Vol. 12. MIT Press, Cambridge, MA, pp. 297-361.

Rotemberg, J. J., 1982. Monopolistic price adjustment and aggregate output. The Review of Economic Studies 49 (4), 517-531.

Schmitt-Grohé, S., Uribe, M., 2007. Optimal simple and implementable monetary and fiscal rules. Journal of Monetary Economics 54 (6), 1702-1725. 
Sutherland, A., 2002. A simple second-order solution method for dynamic general equilibrium models. University of St. Andrews, Discussion Paper Series No. 0211.

Sutherland, A., 2006. The expenditure switching effect, welfare and monetary policy in a small open economy. Journal of Economic Dynamics and Control 30 (7), 11591182.

Svensson, L. E., 2002. Inflation targeting: Should it be modeled as an instrument rule or a targeting rule? European Economic Review 46 (4), 771-780.

Svensson, L. E., 2003. What is wrong with Taylor rules? Using judgment in monetary policy through targeting rules. Journal of Economic Literature 41 (2), 426-477.

Svensson, L. E., 2004. Targeting rules vs. instrument rules for monetary policy: What is wrong with McCallum and Nelson? NBER Working Paper No. 10747.

Svensson, L. E. O., van Wijnbergen, S., 1989. Excess capacity, monopolistic competition, and international transmission of monetary disturbances. The Economic Journal 99 (397), 785-805.

Tille, C., 2001. The role of consumption substitutability in the international transmission of monetary shocks. Journal of International Economics 53 (2), 421-444.

Wang, J., 2015. Choices of policy variables for noncooperative monetary policy. Australian National University, unpublished.

Woodford, M., 2003. Interest and Price: Foundations of A Theory of Monetary Policy. Princeton University Press, Princeton, NJ. 


\section{Appendix}

\section{Appendix A. Structural equations}

\section{A.1 Structural Equations of Private Agents}

In this section we show the derivation of the first-order conditions listed in Table 2 in the text. First, equations (i)-(ii), (xix)-(xx) are derived from the representative household's optimization problem with respect to consumption, labor and nominal bond holdings in the home and foreign country, respectively. Next, equations (iii)-(iv), (xxi)-(xxii) are from cost minimization problem of the two representative households. The home representative household, for example, chooses $C_{H, t}$ and $C_{F, t}$ to minimize

$$
P_{H, t} C_{H, t}+P_{F, t} C_{F, t}
$$

subject to the aggregate consumption

$$
C_{t}=C_{H, t}^{\frac{v}{2}} C_{F, t}^{1-\frac{v}{2}}
$$

taking as given the price indexes $P_{H, t}$ and $P_{F, t}$. The first-order conditions give (iii)(iv). Similarly the foreign consumers' cost minimization problem gives (xxi)-(xxii). Substituting the Hicksian demand functions (iii)-(iv) into equation (6.1) gives price index equation (v). Analogously, substitution of the foreign Hicksian demand functions into foreign consumption aggregator $C_{t}^{*}$ gives (xxiii). Equations (vi)-(viii) for the home country and (xxiv)-(xxvi) for the foreign country are derived in the text.

Next, we derive firms' price optimizing conditions under LCP. Specifically, home firm $j$ takes into account the probability that it will not get to reset prices consecutively for certain periods of time and chooses $P_{H, t_{0}}(j)$ and $P_{H, t_{0}}^{*}(j)$ to maximize its present discounted value of profits

$$
\mathbb{E}_{t_{0}} \sum_{t=t_{0}}^{\infty} \theta^{t-t_{0}} m_{t_{0}, t}\left\{(1+\tau) P_{H, t_{0}}(j) C_{H, t}(j)+(1+\tau) S_{t} P_{H, t_{0}}^{*}(j) C_{H, t}^{*}(j)-W_{t} h_{t}(j)\right\}
$$

subject to the demand functions

$$
\begin{aligned}
& C_{H, t}(j)=\left(\frac{P_{H, t_{0}}(j)}{P_{H, t}}\right)^{-\epsilon} C_{H, t} \\
& C_{H, t}^{*}(j)=\left(\frac{P_{H, t_{0}}^{*}(j)}{P_{H, t}^{*}}\right)^{-\epsilon} C_{H, t}^{*}
\end{aligned}
$$

and the resource constraint

$$
Y_{t}(j)=\exp \left(z_{t}\right) h_{t}=C_{H, t}(j)+C_{H, t}^{*}(j),
$$


taking as given the aggregate price indexes $P_{H, t}, P_{H, t}^{*}$ and consumption levels $C_{H, t}$, $C_{H, t}^{*}$. Since all the domestic firms face the same optimizing problem, they eventually set the same price for the same market. Denote the optimal price as $\tilde{P}_{H, t_{0}}$ and $\tilde{P}_{H, t_{0}}^{*}$. The first-order conditions with respect to $\tilde{P}_{H, t_{0}}=\tilde{P}_{H, t_{0}}(j)$ are given by

$$
\left(\frac{\tilde{P}_{H, t_{0}}}{P_{H, t_{0}}}\right)=\frac{\epsilon}{(\epsilon-1)(1+\tau)} \frac{\mathbb{E}_{t_{0}} \sum_{t=t_{0}}^{\infty}(\beta \theta)^{t-t_{0}} C_{t}^{-\sigma} C_{H, t} M C_{t}\left(\frac{P_{H, t_{0}}}{P_{H, t}}\right)^{-\epsilon}}{\mathbb{E}_{t_{0}} \sum_{t=t_{0}}^{\infty}(\beta \theta)^{t-t_{0}} C_{t}^{-\sigma} C_{H, t} p_{H, t}\left(\frac{P_{H, t_{0}}}{P_{H, t}}\right)^{1-\epsilon}} .
$$

In addition, the price index $P_{H, t_{0}}$ evolves according to

$$
P_{H, t_{0}}^{1-\epsilon}=\theta P_{H, t_{0}-1}^{1-\epsilon}+(1-\theta) \tilde{P}_{H, t_{0}}^{1-\epsilon}
$$

that is

$$
\frac{\tilde{P}_{H, t_{0}}}{P_{H, t_{0}}}=\left[\frac{1-\theta\left(\pi_{H, t_{0}}\right)^{\epsilon-1}}{1-\theta}\right]^{\frac{1}{1-\epsilon}},
$$

where we define $\pi_{H, t_{0}}=\frac{P_{H, t_{0}}}{P_{H, t_{0}-1}}$.

Combining the above two equations regarding $\frac{\tilde{P}_{H, t_{0}}}{P_{H, t_{0}}}$ and define

$$
\begin{aligned}
K_{H, t_{0}} & \equiv \mathbb{E}_{t_{0}} \sum_{t=t_{0}}^{\infty}(\beta \theta)^{t-t_{0}} C_{t}^{-\sigma} C_{H, t} M C_{t}\left(\frac{P_{H, t_{0}}}{P_{H, t}}\right)^{-\epsilon} \\
F_{H, t_{0}} & \equiv \mathbb{E}_{t_{0}} \sum_{t=t_{0}}^{\infty}(\beta \theta)^{t-t_{0}} C_{t}^{-\sigma} C_{H, t} p_{H, t}\left(\frac{P_{H, t_{0}}}{P_{H, t}}\right)^{1-\epsilon}
\end{aligned}
$$

and we obtain equation (xi) in Table 2. Write $K_{H, t_{0}}$ and $F_{H, t_{0}}$ for any $t \geq t_{0}$ in a recursive way and we have equations (xii)-(xiii). Note that we have imposed the subsidy condition $\frac{\epsilon}{(\epsilon-1)(1+\tau)}=1$ in the text.

The first-order conditions with respect to $\tilde{P}_{H, t_{0}}^{*}=\tilde{P}_{H, t_{0}}^{*}(j)$ are given by

$$
\left(\frac{\tilde{P}_{H, t_{0}}^{*}}{P_{H, t_{0}}^{*}}\right)=\frac{\epsilon}{(\epsilon-1)(1+\tau)} \frac{\mathbb{E}_{t_{0}} \sum_{t=t_{0}}^{\infty}(\beta \theta)^{t-t_{0}} C_{t}^{-\sigma} C_{H, t}^{*} M C_{t}\left(\frac{P_{H, t_{0}}^{*}}{P_{H, t}^{*}}\right)^{-\epsilon}}{\mathbb{E}_{t_{0}} \sum_{t=t_{0}}^{\infty}(\beta \theta)^{t-t_{0}} C_{t}^{-\sigma} C_{H, t}^{*} e_{t} p_{H, t}^{*}\left(\frac{P_{H, t_{0}}^{*}}{P_{H, t}^{*}}\right)^{1-\epsilon}}
$$


and the evolution of $P_{H, t_{0}}^{*}$ is given by

$$
\frac{\tilde{P}_{H, t_{0}}^{*}}{P_{H, t_{0}}^{*}}=\left[\frac{1-\theta\left(\pi_{H, t_{0}}^{*}\right)^{\epsilon-1}}{1-\theta}\right]^{\frac{1}{1-\epsilon}}
$$

Define $K_{H, t_{0}}^{*}$ and $F_{H, t_{0}}^{*}$ in an analogous way and combine the two above equations, and we obtain equation (xiv). Equations (xv) and (xvi) are the recursive expressions of $K_{H, t_{0}}^{*}$ and $F_{H, t_{0}}^{*}$ for any $t \geq t_{0}$. Repeat the proceeding process for foreign firm $j^{* \prime} \mathrm{s}$ optimization problem and we have equations (xxix)-(xxxiv).

Next, equations regarding price dispersions, (ix)-(x) and (xxvii)-(xxviii) are derived as follows: Take, for example, the definition of price dispersion within home goods sold in the domestic market,

$$
\Delta_{H, t}=\int_{0}^{1}\left[\frac{P_{H, t}(j)}{P_{H, t}}\right]^{-\epsilon} d j .
$$

By the law of large number, it can be written as

$$
\begin{aligned}
\Delta_{H, t} & =\int_{0}^{\theta}\left[\frac{P_{H, t-1}(j)}{P_{H, t}}\right]^{-\epsilon} d j+\int_{\theta}^{1}\left[\frac{\tilde{P}_{H, t}}{P_{H, t}}\right]^{-\epsilon} d j \\
& =\theta \int_{0}^{1}\left(\frac{P_{H, t-1}}{P_{H, t}}\right)^{-\epsilon}\left[\frac{P_{H, t-1}(j)}{P_{H, t-1}}\right]^{-\epsilon} d j+(1-\theta) \int_{0}^{1}\left[\frac{\tilde{P}_{H, t}}{P_{H, t}}\right]^{-\epsilon} d j \\
& =\theta\left(\frac{P_{H, t-1}}{P_{H, t}}\right)^{-\epsilon} \int_{0}^{1}\left[\frac{P_{H, t-1}(j)}{P_{H, t-1}}\right]^{-\epsilon} d j+(1-\theta)\left[\frac{\tilde{P}_{H, t}}{P_{H, t}}\right]^{-\epsilon} \\
& =\theta\left(\frac{P_{H, t-1}}{P_{H, t}}\right)^{-\epsilon} \Delta_{H, t-1}+(1-\theta)\left[\frac{1-\theta\left(\frac{P_{H, t-1}}{P_{H, t}}\right)^{1-\epsilon}}{1-\theta}\right]^{\frac{\epsilon}{\epsilon-1}} .
\end{aligned}
$$

In the last step we make use of the definition for period $t-1$ and the price evolution process of $P_{H, t}$ as shown above. The remaining three price dispersion equations can be derived similarly.

Finally, equations (xvii)-(xviii) and (xxxv)-(xxxvi) are from the detrending definitions. Equation (xxxvii) is the risk sharing condition from the assumption of complete assets market in the text.

\section{A.2 Deterministic Steady State}

In this section we derive the deterministic steady-state values of endogenous variables in Table 2. At this steady state, log-technology is at its zero mean, that is $z=0$. Prices are stable, that is $\Delta_{H}=\Delta_{H}^{*}=\Delta_{F}=\Delta_{F}^{*}=1 ; \pi=\pi^{*}=\pi_{H}=\pi_{H}^{*}=\pi_{F}=\pi_{F}^{*}=1$; $K_{H}=F_{H} ; K_{F}^{*}=F_{F}^{*} ; K_{H}^{*}=F_{H}^{*} ; K_{F}=F_{F}$. Given these relations, the steady-state system 
in Table 2 can be solved as follows:

$$
\begin{aligned}
& p_{H}=p_{F}=p_{H}^{*}=p_{F}^{*}=M C=M C^{*}=w=w^{*}=k \\
& e=1 \\
& i=i^{*}=\frac{1}{\beta}-1 \\
& C^{*}=C \\
& K_{H}=F_{H}=K_{F}^{*}=F_{F}^{*}=\frac{v}{2(1-\beta \theta)} C \\
& K_{H}^{*}=F_{H}^{*}=K_{F}=F_{F}=\frac{2-v}{2(1-\beta \theta)} C \\
& C_{H}=C_{F}^{*}=\frac{v}{2} k^{-1} C \\
& C_{H}^{*}=C_{F}=\left(1-\frac{v}{2}\right) k^{-1} C \\
& Y=h=Y^{*}=h^{*}=k^{-1} C,
\end{aligned}
$$

where steady-state aggregate consumption $C$ is given by

$$
C=\left(\frac{k^{1+\omega}}{\chi}\right)^{1 /(\omega+\sigma)}
$$

and $k \equiv\left(\frac{v}{2}\right)^{\frac{v}{2}}\left(1-\frac{v}{2}\right)^{1-\frac{v}{2}}$. Note that the steady-state equations equating the real wage to marginal rate of substitution between consumption and leisure, and the steadystate equation regarding the resource constraint are given as

$$
\begin{aligned}
& \chi h^{\omega} C^{\sigma}=k \\
& h=k^{-1} C .
\end{aligned}
$$

They are useful for the second-order approximation to the utility functions that we will show later. 


\section{Appendix B. Ramsey Policy}

In this section, we first set up the Ramsey problem for the cooperative global policy maker and derive the necessary optimality conditions. We then solve for the deterministic steady state of this system. We repeat the proceeding process for the noncooperative policy makers.

The structural equations describing decentralized decisions of private agents and aggregate equilibrium conditions are given as follows (they are listed in Table 2 in the text and $k=\left(\frac{v}{2}\right)^{\frac{v}{2}}\left(1-\frac{v}{2}\right)^{1-\frac{v}{2}}$ in the following equations):

$C_{t}^{-\sigma} w_{t}-\chi h_{t}^{\omega}=0$

$\beta \mathbb{E}_{t}\left(\frac{1+i_{t}}{\pi_{t+1}} C_{t+1}^{-\sigma}\right)-C_{t}^{-\sigma}=0$

$\frac{v}{2} p_{H, t}^{-1} C_{t}-C_{H, t}=0$

$$
\begin{aligned}
& \left(1-\frac{v}{2}\right) p_{F, t}^{-1} C_{t}-C_{F, t}=0 \\
& 1-k^{-1}\left(p_{H, t}\right)^{v / 2}\left(p_{F, t}\right)^{1-v / 2}=0 \\
& \left(C_{t}^{*}\right)^{-\sigma} w_{t}^{*}-\chi\left(h_{t}^{*}\right)^{\omega}=0
\end{aligned}
$$

$\beta \mathbb{E}_{t}\left(\frac{1+i_{t}^{*}}{\pi_{t+1}^{*}}\left(C_{t+1}^{*}\right)^{-\sigma}\right)-\left(C_{t}^{*}\right)^{-\sigma}=0$

$$
\left(1-\frac{v}{2}\right) p_{H, t}^{*-1} C_{t}^{*}-C_{H, t}^{*}=0
$$

$\frac{v}{2} p_{F, t}^{*-1} C_{t}^{*}-C_{F, t}^{*}=0$ 


$$
\begin{aligned}
& 1-k^{-1}\left(p_{H, t}^{*}\right)^{1-v / 2}\left(p_{F, t}^{*}\right)^{v / 2}=0 \\
& C_{t}^{-\sigma} e_{t}-\left(C_{t}^{*}\right)^{-\sigma}=0 \\
& \frac{w_{t}}{\exp \left(z_{t}\right)}-M C_{t}=0 \\
& C_{H, t} \Delta_{H, t}+C_{H, t}^{*} \Delta_{H, t}^{*}-\exp \left(z_{t}\right) h_{t}=0 \\
& \exp \left(z_{t}\right) h_{t}-Y_{t}=0
\end{aligned}
$$

$$
\begin{aligned}
& (1-\theta)\left[\frac{1-\theta\left(\pi_{H, t}\right)^{\epsilon-1}}{1-\theta}\right]^{\frac{\epsilon}{\epsilon-1}}+\theta\left(\pi_{H, t}\right)^{\epsilon} \Delta_{H, t-1}-\Delta_{H, t}=0 \\
& (1-\theta)\left[\frac{1-\theta\left(\pi_{H, t}^{*}\right)^{\epsilon-1}}{1-\theta}\right]^{\frac{\epsilon}{\epsilon-1}}+\theta\left(\pi_{H, t}^{*}\right)^{\epsilon} \Delta_{H, t-1}^{*}-\Delta_{H, t}^{*}=0
\end{aligned}
$$$$
F_{H, t}\left[\frac{1-\theta\left(\pi_{H, t}\right)^{\epsilon-1}}{1-\theta}\right]^{\frac{1}{1-\epsilon}}-K_{H, t}=0
$$$$
-F_{H, t}+\frac{C_{H, t} p_{H, t}}{e_{t}}+\beta \theta \mathbb{E}_{t} \frac{C_{t+1}^{-\sigma}}{C_{t}^{-\sigma}} \frac{e_{t+1}}{e_{t}} \pi_{H, t+1}^{\epsilon-1} F_{H, t+1}=0
$$

$$
-K_{H, t}+\frac{C_{H, t} M C_{t}}{e_{t}}+\beta \theta \mathbb{E}_{t} \frac{C_{t+1}^{-\sigma}}{C_{t}^{-\sigma}} \frac{e_{t+1}}{e_{t}} \pi_{H, t+1}^{\epsilon} K_{H, t+1}=0
$$




$$
\begin{aligned}
& F_{H, t}^{*}\left[\frac{1-\theta\left(\pi_{H, t}^{*}\right)^{\epsilon-1}}{1-\theta}\right]^{\frac{1}{1-\epsilon}}-K_{H, t}^{*}=0 \\
& -F_{H, t}^{*}+C_{H, t}^{*} p_{H, t}^{*}+\beta \theta \mathbb{E}_{t} \frac{C_{t+1}^{-\sigma} e_{t+1}}{C_{t}^{-\sigma} e_{t}}\left(\pi_{H, t+1}^{*}\right)^{\epsilon-1} F_{H, t+1}^{*}=0 \\
& -K_{H, t}^{*}+\frac{C_{H, t}^{*} M C_{t}}{e_{t}}+\beta \theta \mathbb{E}_{t} \frac{C_{t+1}^{-\sigma} e_{t+1}}{C_{t}^{-\sigma} e_{t}}\left(\pi_{H, t+1}^{*}\right)^{\epsilon} K_{H, t+1}^{*}=0 \\
& \frac{w_{t}^{*}}{\exp \left(z_{t}^{*}\right)}-M C_{t}^{*}=0 \\
& C_{F, t} \Delta_{F, t}+C_{F, t}^{*} \Delta_{F, t}^{*}-\exp \left(z_{t}^{*}\right) h_{t}^{*}=0 \\
& F_{F, t}^{*}\left[\frac{1-\theta\left(\pi_{F, t}^{*}\right)^{\epsilon-1}}{1-\theta}\right]^{\frac{1}{1-\epsilon}}-K_{F, t}^{*}=0 \\
& \exp \left(z_{t}^{*}\right) h_{t}^{*}-Y_{t}^{*}=0 \\
& (1-\theta)\left[\frac{1-\theta\left(\pi_{F, t}^{*}\right)^{\epsilon-1}}{1-\theta}\right]^{\frac{\epsilon}{\epsilon-1}}+\theta\left(\pi_{F, t}^{*}\right)^{\epsilon} \Delta_{F, t-1}^{*}-\Delta_{F, t}^{*}=0 \\
& (1-\theta)\left[\frac{1-\theta\left(\pi_{F, t}\right)^{\epsilon-1}}{1-\theta}+\theta\left(\pi_{F, t}\right)^{\epsilon} \Delta_{F, t-1}-\Delta_{F, t}=0\right. \\
& \frac{\epsilon}{\epsilon-1} \\
& +
\end{aligned}
$$




$$
\begin{aligned}
& -F_{F, t}^{*}+e_{t} C_{F, t}^{*} p_{F, t}^{*}+\beta \theta \mathbb{E}_{t} \frac{\left(C_{t+1}^{*}\right)^{-\sigma} e_{t}}{\left(C_{t}^{*}\right)^{-\sigma} e_{t+1}}\left(\pi_{F, t+1}^{*}\right)^{\epsilon-1} F_{F, t+1}^{*}=0 \\
& -K_{F, t}^{*}+e_{t} C_{F, t}^{*} M C_{t}^{*}+\beta \theta \mathbb{E}_{t} \frac{\left(C_{t+1}^{*}\right)^{-\sigma} e_{t}}{\left(C_{t}^{*}\right)^{-\sigma} e_{t+1}}\left(\pi_{F, t+1}^{*}\right)^{\epsilon} K_{F, t+1}^{*}=0 \\
& F_{F, t}\left[\frac{1-\theta\left(\pi_{F, t}\right)^{\epsilon-1}}{1-\theta}\right]^{\frac{1}{1-\epsilon}}-K_{F, t}=0 \\
& -F_{F, t}+C_{F, t} p_{F, t}+\beta \theta \mathbb{E}_{t} \frac{\left(C_{t+1}^{*}\right)^{-\sigma} e_{t}}{\left(C_{t}^{*}\right)^{-\sigma} e_{t+1}} \pi_{F, t+1}^{\epsilon-1} F_{F, t+1}=0 \\
& -K_{F, t}+e_{t} C_{F, t} M C_{t}^{*}+\beta \theta \mathbb{E}_{t} \frac{\left(C_{t+1}^{*}\right)^{-\sigma} e_{t}}{\left(C_{t}^{*}\right)^{-\sigma} e_{t+1}} \pi_{F, t+1}^{\epsilon} K_{F, t+1}=0 \\
& \pi_{t} \frac{p_{H, t}}{p_{H, t-1}}-\pi_{H, t}=0 \\
& \pi_{t}^{*} \frac{p_{H, t}^{*}}{p_{H, t-1}^{*}}-\pi_{H, t}^{*}=0 \\
& \pi_{t}^{*} \frac{p_{F, t}^{*}}{p_{F, t-1}^{*}}-\pi_{F, t}^{*}=0 \\
& \pi_{t} \frac{p_{F, t}}{p_{F, t-1}}-\pi_{F, t}=0
\end{aligned}
$$

\section{B.1 Cooperation}

A global policy maker maximizes welfare of both countries

$$
W_{W, t_{0}}=\mathbb{E}_{t_{0}} \sum_{t=t_{0}}^{\infty} \beta^{t-t_{0}}\left(\frac{C_{t}^{1-\sigma}-1}{1-\sigma}+\frac{C_{t}^{* 1-\sigma}-1}{1-\sigma}-\chi \frac{h_{t}^{1+\omega}}{1+\omega}-\chi \frac{h_{t}^{* 1+\omega}}{1+\omega}\right)
$$


with respect to 39 endogenous variables $\left\{i_{t}, i_{t}^{*}, C_{t}, C_{t}^{*}, C_{H, t}, C_{F, t}, C_{H, t}^{*}, C_{F, t}^{*}, h_{t}, h_{t}^{*}, \pi_{t}\right.$, $\pi_{t}^{*}, \pi_{H, t}, \pi_{H, t}^{*}, \pi_{F, t}, \pi_{F, t}^{*}, p_{H, t}, p_{F, t}, p_{H, t}^{*}, p_{F, t}^{*}, w_{t}, w_{t}^{*}, e_{t}, M C_{t}, M C_{t}^{*}, Y_{t}, Y_{t}^{*}, \Delta_{H, t}, \Delta_{H, t}^{*}$ $\left.\Delta_{F, t}, \Delta_{F, t}^{*}, K_{H, t}, F_{H, t}, K_{H, t}^{*}, F_{H, t}^{*}, K_{F, t}, F_{F, t}, K_{F, t}^{*}, F_{F, t}^{*}\right\}$ for all $t \geq t_{0}$, subject to the above 37 structural constraints equations (6.2) (6.38) associated with Lagrangian multipliers $\lambda_{1, t} \sim \lambda_{37, t}$ in sequence.

The 39 first-order conditions for all $t \geq t_{0}$ are as follows (we use an itemized list to keep track of the endogenous variable with respect to which the particular first-order condition is derived).

- $i_{t}$ :

$$
\lambda_{2, t} \beta \mathbb{E}_{t} \frac{C_{t+1}^{-\sigma}}{\pi_{t+1}}=0
$$

that is

$$
\lambda_{2, t}=0
$$

- $i_{t}^{*}$ :

$$
\lambda_{7, t} \beta \mathbb{E}_{t} \frac{C_{t+1}^{*-\sigma}}{\pi_{t+1}^{*}}=0
$$

that is

$$
\lambda_{7, t}=0
$$

- $C_{t}$ :

$$
\begin{aligned}
& C_{t}^{-\sigma}+\lambda_{1, t}(-\sigma) C_{t}^{-\sigma-1} w_{t}+\lambda_{3, t} \frac{v}{2} p_{H, t}^{-1}+\lambda_{4, t}\left(1-\frac{v}{2}\right) p_{F, t}^{-1}+\lambda_{11, t}(-\sigma) C_{t}^{-\sigma-1} e_{t} \\
& +\lambda_{18, t} \beta \theta \sigma \mathbb{E}_{t} \frac{C_{t+1}^{-\sigma}}{C_{t}^{-\sigma+1}} \frac{e_{t+1}}{e_{t}} \pi_{H, t+1}^{\epsilon-1} F_{H, t+1}+\lambda_{18, t-1} \theta(-\sigma) \frac{C_{t}^{-\sigma-1}}{C_{t-1}^{-\sigma}} \frac{e_{t}}{e_{t-1}} \pi_{H, t}^{\epsilon-1} F_{H, t} \\
& +\lambda_{19, t} \beta \theta \sigma \mathbb{E}_{t} \frac{C_{t+1}^{-\sigma}}{C_{t}^{-\sigma+1}} \frac{e_{t+1}}{e_{t}} \pi_{H, t+1}^{\epsilon} K_{H, t+1}+\lambda_{19, t-1} \theta(-\sigma) \frac{C_{t}^{-\sigma-1}}{C_{t-1}^{-\sigma}} \frac{e_{t}}{e_{t-1}} \pi_{H, t}^{\epsilon} K_{H, t} \\
& +\lambda_{21, t} \beta \theta \sigma \mathbb{E}_{t} \frac{C_{t+1}^{-\sigma}}{C_{t}^{-\sigma+1}} \frac{e_{t+1}}{e_{t}} \pi_{H, t+1}^{* \epsilon-1} F_{H, t+1}^{*}+\lambda_{21, t-1} \theta(-\sigma) \frac{C_{t}^{-\sigma-1}}{C_{t-1}^{-\sigma}} \frac{e_{t}}{e_{t-1}} \pi_{H, t}^{* \epsilon-1} F_{H, t}^{*} \\
& +\lambda_{22, t} \beta \theta \sigma \mathbb{E}_{t} \frac{C_{t+1}^{-\sigma}}{C_{t}^{-\sigma+1}} \frac{e_{t+1}}{e_{t}} \pi_{H, t+1}^{* \epsilon} K_{H, t+1}^{*}+\lambda_{22, t-1} \theta(-\sigma) \frac{C_{t}^{-\sigma-1}}{C_{t-1}^{-\sigma}} \frac{e_{t}}{e_{t-1}} \pi_{H, t}^{* \epsilon} K_{H, t}^{*}=0
\end{aligned}
$$


- $C_{t}^{*}$ :

$$
\begin{gathered}
C_{t}^{*-\sigma}+\lambda_{6, t}(-\sigma) C_{t}^{*-\sigma-1} w_{t}^{*}+\lambda_{8, t}\left(1-\frac{v}{2}\right) p_{H, t}^{*-1}+\lambda_{9, t} \frac{v}{2} p_{F, t}^{*-1}-\lambda_{11, t}(-\sigma) C_{t}^{*-\sigma-1} \\
+\lambda_{29, t} \beta \theta \sigma \mathbb{E}_{t} \frac{C_{t+1}^{*-\sigma} e_{t}}{C_{t}^{*-\sigma+1} e_{t+1}}\left(\pi_{F, t+1}^{*}\right)^{\epsilon-1} F_{F, t+1}^{*}-\lambda_{29, t-1} \theta \sigma \frac{C_{t}^{*-\sigma-1}}{C_{t-1}^{*-\sigma}} \frac{e_{t-1}}{e_{t}}\left(\pi_{F, t}^{*}\right)^{\epsilon-1} F_{F, t}^{*} \\
+\lambda_{30, t} \beta \theta \sigma \mathbb{E}_{t} \frac{C_{t+1}^{*-\sigma} e_{t}}{C_{t}^{*-\sigma+1} e_{t+1}}\left(\pi_{F, t+1}^{*}\right)^{\epsilon} K_{F, t+1}^{*}-\lambda_{30, t-1} \theta \sigma \frac{C_{t}^{*-\sigma-1}}{C_{t-1}^{*-\sigma}} \frac{e_{t-1}}{e_{t}}\left(\pi_{F, t}^{*}\right)^{\epsilon} K_{F, t}^{*} \\
+\lambda_{32, t} \beta \theta \sigma \mathbb{E}_{t} \frac{C_{t+1}^{*-\sigma} e_{t}}{C_{t}^{*-\sigma+1} e_{t+1}}\left(\pi_{F, t+1}\right)^{\epsilon-1} F_{F, t+1}-\lambda_{32, t-1} \theta \sigma \frac{C_{t}^{*-\sigma-1}}{C_{t-1}^{*-\sigma}} \frac{e_{t-1}}{e_{t}}\left(\pi_{F, t}\right)^{\epsilon-1} F_{F, t} \\
+\lambda_{33, t} \beta \theta \sigma \mathbb{E}_{t} \frac{C_{t+1}^{*-\sigma} e_{t}}{C_{t}^{*-\sigma+1} e_{t+1}}\left(\pi_{F, t+1}\right)^{\epsilon} K_{F, t+1}-\lambda_{33, t-1} \theta \sigma \frac{C_{t}^{*-\sigma-1}}{C_{t-1}^{*-\sigma}} \frac{e_{t-1}}{e_{t}}\left(\pi_{F, t}\right)^{\epsilon} K_{F, t}=0
\end{gathered}
$$

- $C_{H, t}$ :

$$
-\lambda_{3, t}+\lambda_{13, t} \Delta_{H, t}+\lambda_{18, t} p_{H, t} e_{t}^{-1}+\lambda_{19, t} M C_{t} e_{t}^{-1}=0
$$

- $C_{H, t}^{*}$ :

$$
-\lambda_{8, t}+\lambda_{13, t} \Delta_{H, t}^{*}+\lambda_{21, t} p_{H, t}^{*}+\lambda_{22, t} M C_{t} e_{t}^{-1}=0
$$

- $C_{F, t}$ :

$$
-\lambda_{4, t}+\lambda_{24, t} \Delta_{F, t}+\lambda_{32, t} p_{F, t}+\lambda_{33, t} M C_{t}^{*} e_{t}=0
$$

- $C_{F, t}^{*}$ :

$$
-\lambda_{9, t}+\lambda_{24, t} \Delta_{F, t}^{*}+\lambda_{29, t} p_{F, t}^{*} e_{t}+\lambda_{30, t} M C_{t}^{*} e_{t}=0
$$

- $h_{t}$ :

$$
-\chi h_{t}^{\omega}-\lambda_{1, t} \omega \chi h_{t}^{\omega-1}-\lambda_{13, t} \exp \left(z_{t}\right)+\lambda_{14, t} \exp \left(z_{t}\right)=0
$$

- $h_{t}^{*}$ :

$$
-\chi h_{t}^{* \omega}-\lambda_{6, t} \omega \chi h_{t}^{* \omega-1}-\lambda_{24, t} \exp \left(z_{t}^{*}\right)+\lambda_{25, t} \exp \left(z_{t}^{*}\right)=0
$$


- $\pi_{t}$ :

$$
+\lambda_{34, t} \frac{p_{H, t}}{p_{H, t-1}}+\lambda_{37, t} \frac{p_{F, t}}{p_{F, t-1}}=0
$$

- $\pi_{t}^{*}$ :

$$
+\lambda_{35, t} \frac{p_{H, t}^{*}}{p_{H, t-1}^{*}}+\lambda_{36, t} \frac{p_{F, t}^{*}}{p_{F, t-1}^{*}}=0
$$

- $\pi_{H, t}$ :

$$
\begin{array}{r}
-\lambda_{15, t}\left[\frac{1-\theta\left(\pi_{H, t}\right)^{\epsilon-1}}{1-\theta}\right]^{\frac{1}{\epsilon-1}} \theta \epsilon \pi_{H, t}{ }^{\epsilon-2} \\
+\lambda_{15, t} \theta \epsilon \pi_{H, t}{ }^{\epsilon-1} \Delta_{H, t-1} \\
+\lambda_{17, t} F_{H, t}\left[\frac{1-\theta\left(\pi_{H, t}\right)^{\epsilon-1}}{1-\theta}\right]^{\frac{\epsilon}{1-\epsilon}}\left(\frac{\theta}{1-\theta}\right)\left(\pi_{H, t}\right)^{\epsilon-2} \\
+\lambda_{18, t-1} \theta(\epsilon-1) \frac{C_{t}^{-\sigma}}{C_{t-1}^{-\sigma}} \frac{e_{t}}{e_{t-1}} \pi_{H, t}^{\epsilon-2} F_{H, t} \\
+\lambda_{19, t-1} \theta(\epsilon) \frac{C_{t}^{-\sigma}}{C_{t-1}^{-\sigma}} \frac{e_{t}}{e_{t-1}} \pi_{H, t}^{\epsilon-1} K_{H, t}
\end{array}
$$


- $\pi_{H, t}^{*}$ :

$$
\begin{array}{r}
-\lambda_{16, t}\left[\frac{1-\theta\left(\pi_{H, t}^{*}\right)^{\epsilon-1}}{1-\theta}\right]^{\frac{1}{\epsilon-1}} \theta \epsilon\left(\pi_{H, t}^{*}\right)^{\epsilon-2} \\
+\lambda_{16, t} \theta \epsilon\left(\pi_{H, t}^{*}\right)^{\epsilon-1} \Delta_{H, t-1}^{*} \\
+\lambda_{20, t} F_{H, t}^{*}\left[\frac{1-\theta\left(\pi_{H, t}^{*}\right)^{\epsilon-1}}{1-\theta}\right]^{\frac{\epsilon}{1-\epsilon}}\left(\frac{\theta}{1-\theta}\right)\left(\pi_{H, t}^{*}\right)^{\epsilon-2} \\
+\lambda_{21, t-1} \theta(\epsilon-1) \frac{C_{t}^{-\sigma}}{C_{t-1}^{-\sigma}} \frac{e_{t}}{e_{t-1}} \pi_{H, t}^{* \epsilon-2} F_{H, t}^{*} \\
+\lambda_{22, t-1} \theta(\epsilon) \frac{C_{t}^{-\sigma}}{C_{t-1}^{-\sigma}} \frac{e_{t}}{e_{t-1}} \pi_{H, t}^{* \epsilon-1} K_{H, t}^{*} \\
-\lambda_{35, t}=0
\end{array}
$$

- $\pi_{F, t}$ :

$$
\begin{array}{r}
-\lambda_{26, t}\left[\frac{1-\theta\left(\pi_{F, t}\right)^{\epsilon-1}}{1-\theta}\right]^{\frac{1}{\epsilon-1}} \theta \epsilon\left(\pi_{F, t}\right)^{\epsilon-2} \\
+\lambda_{26, t} \theta \epsilon\left(\pi_{F, t}\right)^{\epsilon-1} \Delta_{F, t-1} \\
+\lambda_{31, t} F_{F, t}\left[\frac{1-\theta\left(\pi_{F, t}\right)^{\epsilon-1}}{1-\theta}\right]^{\frac{\epsilon}{1-\epsilon}}\left(\frac{\theta}{1-\theta}\right)\left(\pi_{F, t}\right)^{\epsilon-2} \\
+\lambda_{32, t-1} \theta(\epsilon-1) \frac{C_{t}^{*-\sigma}}{C_{t-1}^{*-\sigma}} \frac{e_{t-1}}{e_{t}} \pi_{F, t}^{\epsilon-2} F_{F, t} \\
+\lambda_{33, t-1} \theta(\epsilon) \frac{C_{t}^{*-\sigma}}{C_{t-1}^{*-\sigma}} \frac{e_{t-1}}{e_{t}} \pi_{F, t}^{\epsilon-1} K_{F, t} \\
-\lambda_{37, t}=0
\end{array}
$$


- $\pi_{F, t}^{*}$ :

$$
\begin{array}{r}
-\lambda_{27, t}\left[\frac{1-\theta\left(\pi_{F, t}^{*}\right)^{\epsilon-1}}{1-\theta}\right]^{\frac{1}{\epsilon-1}} \theta \epsilon\left(\pi_{F, t}^{*}\right)^{\epsilon-2} \\
+\lambda_{27, t} \theta \epsilon\left(\pi_{F, t}^{*}\right)^{\epsilon-1} \Delta_{F, t-1}^{*} \\
+\lambda_{28, t} F_{F, t}^{*}\left[\frac{1-\theta\left(\pi_{F, t}^{*}\right)^{\epsilon-1}}{1-\theta}\right]^{\frac{\epsilon}{1-\epsilon}}\left(\frac{\theta}{1-\theta}\right)\left(\pi_{F, t}^{*}\right)^{\epsilon-2} \\
+\lambda_{29, t-1} \theta(\epsilon-1) \frac{C_{t}^{*-\sigma}}{C_{t-1}^{*-\sigma}} \frac{e_{t-1}}{e_{t}} \pi_{F, t}^{* \epsilon-2} F_{F, t}^{*} \\
+\lambda_{30, t-1} \theta(\epsilon) \frac{C_{t}^{*-\sigma}}{C_{t-1}^{*-\sigma}} \frac{e_{t-1}}{e_{t}} \pi_{F, t}^{* \epsilon-1} K_{F, t}^{*} \\
-\lambda_{36, t}=0
\end{array}
$$

- $p_{H, t}$ :

$$
\begin{array}{r}
-\lambda_{3, t} \frac{v}{2} \frac{C_{t}}{p_{H, t}^{2}}-\lambda_{5, t} \frac{v}{2} k^{-1}\left(p_{H, t}\right)^{-1+v / 2}\left(p_{F, t}\right)^{1-v / 2} \\
+\lambda_{18, t} \frac{C_{H, t}}{e_{t}}+\lambda_{34, t} \pi_{t} \frac{1}{p_{H, t-1}}-\lambda_{34, t+1} \beta \mathbb{E}_{t}\left(\pi_{t+1}\right) \frac{p_{H, t+1}}{p_{H, t}^{2}} \\
=0
\end{array}
$$

- $p_{H, t}^{*}$ :

$$
\begin{array}{r}
-\lambda_{8, t}\left(1-\frac{v}{2}\right) \frac{C_{t}^{*}}{p_{H, t}^{* 2}}-\lambda_{10, t}\left(1-\frac{v}{2}\right) k^{-1}\left(p_{H, t}^{*}\right)^{-v / 2}\left(p_{F, t}^{*}\right)^{v / 2} \\
+\lambda_{21, t} C_{H, t}^{*}+\lambda_{35, t} \pi_{t}^{*} \frac{1}{p_{H, t-1}^{*}}-\lambda_{35, t+1} \beta \mathbb{E}_{t}\left(\pi_{t+1}^{*}\right) \frac{p_{H, t+1}^{*}}{p_{H, t}^{* 2}} \\
=0
\end{array}
$$


- $p_{F, t}$ :

$$
\begin{array}{r}
-\lambda_{4, t}\left(1-\frac{v}{2}\right) \frac{C_{t}}{p_{F, t}^{2}}-\lambda_{5, t}\left(1-\frac{v}{2}\right) k^{-1}\left(p_{H, t}\right)^{v / 2}\left(p_{F, t}\right)^{-v / 2} \\
+\lambda_{32, t} C_{F, t}+\lambda_{37, t} \pi_{t} \frac{1}{p_{F, t-1}}-\lambda_{37, t+1} \beta \mathbb{E}_{t}\left(\pi_{t+1}\right) \frac{p_{F, t+1}}{p_{F, t}^{2}} \\
=0
\end{array}
$$

- $p_{F, t}^{*}$ :

$$
\begin{array}{r}
-\lambda_{9, t} \frac{v}{2} \frac{C_{t}^{*}}{p_{F, t}^{* 2}}-\lambda_{10, t} \frac{v}{2} k^{-1}\left(p_{H, t}^{*}\right)^{1-v / 2}\left(p_{F, t}^{*}\right)^{-1+v / 2} \\
+\lambda_{29, t} e_{t} C_{F, t}^{*}+\lambda_{36, t} \pi_{t}^{*} \frac{1}{p_{F, t-1}^{*}}-\lambda_{36, t+1} \beta \mathbb{E}_{t}\left(\pi_{t+1}^{*}\right) \frac{p_{F, t+1}^{*}}{p_{F, t}^{* 2}} \\
=0
\end{array}
$$

- $w_{t}$ :

$$
\lambda_{1, t} C_{t}^{-\sigma}+\lambda_{12, t} \frac{1}{\exp \left(z_{t}\right)}=0
$$

- $w_{t}^{*}$ :

$$
\lambda_{6, t} C_{t}^{*-\sigma}+\lambda_{23, t} \frac{1}{\exp \left(z_{t}^{*}\right)}=0
$$


- $e_{t}$ :

$$
\begin{array}{r}
\lambda_{11, t} C_{t}^{-\sigma}-\lambda_{18, t} \frac{C_{H, t} p_{H, t}}{e_{t}^{2}}-\lambda_{19, t} \frac{C_{H, t} M C_{t}}{e_{t}^{2}}-\lambda_{22, t} \frac{C_{H, t}^{*} M C_{t}}{e_{t}^{2}} \\
+\lambda_{29, t} C_{F, t}^{*} p_{F, t}^{*}+\lambda_{30, t} C_{F, t}^{*} M C_{t}^{*}+\lambda_{33, t} C_{F, t} M C_{t}^{*} \\
-\lambda_{18, t} \beta \theta \mathbb{E}_{t} \frac{C_{t+1}^{-\sigma}}{C_{t}^{-\sigma}} \frac{e_{t+1}}{e_{t}^{2}} \pi_{H, t+1}^{\epsilon-1} F_{H, t+1}+\lambda_{18, t-1} \theta \frac{C_{t}^{-\sigma}}{C_{t-1}^{-\sigma}} \frac{1}{e_{t-1}} \pi_{H, t}^{\epsilon-1} F_{H, t} \\
-\lambda_{19, t} \beta \theta \mathbb{E}_{t} \frac{C_{t+1}^{-\sigma}}{C_{t}^{-\sigma}} \frac{e_{t+1}}{e_{t}^{2}} \pi_{H, t+1}^{\epsilon} K_{H, t+1}+\lambda_{19, t-1} \theta \frac{C_{t}^{-\sigma}}{C_{t-1}^{-\sigma}} \frac{1}{e_{t-1}} \pi_{H, t}^{\epsilon} K_{H, t} \\
-\lambda_{21, t} \beta \theta \mathbb{E}_{t} \frac{C_{t+1}^{-\sigma}}{C_{t}^{-\sigma}} \frac{e_{t+1}}{e_{t}^{2}} \pi_{H, t+1}^{* \epsilon-1} F_{H, t+1}^{*}+\lambda_{21, t-1} \theta \frac{C_{t}^{-\sigma}}{C_{t-1}^{-\sigma}} \frac{1}{e_{t-1}} \pi_{H, t}^{* \epsilon-1} F_{H, t}^{*} \\
-\lambda_{22, t} \beta \theta \mathbb{E}_{t} \frac{C_{t+1}^{-\sigma}}{C_{t}^{-\sigma}} \frac{e_{t+1}}{e_{t}^{2}} \pi_{H, t+1}^{* \epsilon} K_{H, t+1}^{*}+\lambda_{22, t-1} \theta \frac{C_{t}^{-\sigma}}{C_{t-1}^{-\sigma}} \frac{1}{e_{t-1}} \pi_{H, t}^{* \epsilon} K_{H, t}^{*} \\
+\lambda_{29, t} \beta \theta \mathbb{E}_{t} \frac{C_{t+1}^{*-\sigma}}{C_{t}^{*-\sigma}} \frac{1}{e_{t+1}} \pi_{F, t+1}^{* \epsilon-1} F_{F, t+1}^{*}-\lambda_{29, t-1} \theta \frac{C_{t}^{*-\sigma}}{C_{t-1}^{*-\sigma}} \frac{e_{t-1}}{e_{t}^{2}} \pi_{F, t}^{* \epsilon-1} F_{F, t}^{*} \\
+\lambda_{30, t} \beta \theta \mathbb{E}_{t} \frac{C_{t+1}^{*-\sigma}}{C_{t}^{*-\sigma}} \frac{1}{e_{t+1}} \pi_{F, t+1}^{* \epsilon} K_{F, t+1}^{*}-\lambda_{30, t-1} \theta \frac{C_{t}^{*-\sigma}}{C_{t-1}^{*-\sigma}} \frac{e_{t-1}}{e_{t}^{2}} \pi_{F, t}^{* \epsilon} K_{F, t}^{*} \\
+\lambda_{32, t} \beta \theta E_{t} \frac{C_{t+1}^{*-\sigma}}{C_{t}^{*-\sigma}} \frac{1}{e_{t+1}} \pi_{F, t+1}^{\epsilon-1} F_{F, t+1}-\lambda_{32, t-1} \theta \frac{C_{t}^{*-\sigma}}{C_{t-1}^{*-\sigma}} \frac{e_{t-1}}{e_{t}^{2}} \pi_{F, t}^{\epsilon-1} F_{F, t} \\
+\lambda_{33, t} \beta \theta \mathbb{E}_{t} \frac{C_{t+1}^{*-\sigma}}{C_{t}^{*-\sigma}} \frac{1}{e_{t+1}} \pi_{F, t+1}^{\epsilon} K_{F, t+1}-\lambda_{33, t-1} \theta \frac{C_{t}^{*-\sigma}}{C_{t-1}^{*-\sigma}} \frac{e_{t-1}}{e_{t}^{2}} \pi_{F, t}^{\epsilon} K_{F, t}
\end{array}
$$

- $M C_{t}$ :

$$
-\lambda_{12, t}+\lambda_{19, t} \frac{C_{H, t}}{e_{t}}+\lambda_{22, t} \frac{C_{H, t}^{*}}{e_{t}}=0
$$

- $M C_{t}^{*}$ :

$$
-\lambda_{23, t}+\lambda_{30, t} e_{t} C_{F, t}^{*}+\lambda_{33, t} e_{t} C_{F, t}=0
$$

- $Y_{t}$ :

$$
\lambda_{14, t}=0
$$

- $Y_{t}^{*}$ :

$$
\lambda_{25, t}=0
$$


- $\Delta_{H, t}$ :

$$
\lambda_{13, t} C_{H, t}-\lambda_{15, t}+\lambda_{15, t+1} \beta \theta \mathbb{E}_{t}\left(\pi_{H, t+1}\right)^{\epsilon}=0
$$

- $\Delta_{H, t}^{*}$ :

$$
\lambda_{13, t} C_{H, t}^{*}-\lambda_{16, t}+\lambda_{16, t+1} \beta \theta \mathbb{E}_{t}\left(\pi_{H, t+1}^{*}\right)^{\epsilon}=0
$$

- $\Delta_{F, t}$ :

$$
\lambda_{24, t} C_{F, t}-\lambda_{26, t}+\lambda_{26, t+1} \beta \theta \mathbb{E}_{t}\left(\pi_{F, t+1}\right)^{\epsilon}=0
$$

- $\Delta_{F, t}^{*}$ :

$$
\lambda_{24, t} C_{F, t}^{*}-\lambda_{27, t}+\lambda_{27, t+1} \beta \theta \mathbb{E}_{t}\left(\pi_{F, t+1}^{*}\right)^{\epsilon}=0
$$

- $F_{H, t}$ :

$$
\lambda_{17, t}\left[\frac{1-\theta\left(\frac{1}{\pi_{H, t}}\right)^{1-\epsilon}}{1-\theta}\right]^{\frac{1}{1-\epsilon}}-\lambda_{18, t}+\lambda_{18, t-1} \theta \frac{C_{t}^{-\sigma}}{C_{t-1}^{-\sigma}} \frac{e_{t}}{e_{t-1}} \pi_{H, t}^{\epsilon-1}=0
$$

- $K_{H, t}$ :

$$
-\lambda_{17, t}-\lambda_{19, t}+\lambda_{19, t-1} \theta \frac{C_{t}^{-\sigma}}{C_{t-1}^{-\sigma}} \frac{e_{t}}{e_{t-1}} \pi_{H, t}^{\epsilon}=0
$$

- $F_{H, t}^{*}$ :

$$
\lambda_{20, t}\left[\frac{1-\theta\left(\frac{1}{\pi_{H, t}^{*}}\right)^{1-\epsilon}}{1-\theta}\right]^{\frac{1}{1-\epsilon}}-\lambda_{21, t}+\lambda_{21, t-1} \theta \frac{C_{t}^{-\sigma}}{C_{t-1}^{-\sigma}} \frac{e_{t}}{e_{t-1}} \pi_{H, t}^{* \epsilon-1}=0
$$

- $K_{H, t}^{*}$ :

$$
-\lambda_{20, t}-\lambda_{22, t}+\lambda_{22, t-1} \theta \frac{C_{t}^{-\sigma}}{C_{t-1}^{-\sigma}} \frac{e_{t}}{e_{t-1}} \pi_{H, t}^{* \epsilon}=0
$$


- $F_{F, t}$ :

$$
\lambda_{31, t}\left[\frac{1-\theta\left(\frac{1}{\pi_{F, t}}\right)^{1-\epsilon}}{1-\theta}\right]^{\frac{1}{1-\epsilon}}-\lambda_{32, t}+\lambda_{32, t-1} \theta \frac{C_{t}^{*-\sigma}}{C_{t-1}^{*-\sigma}} \frac{e_{t-1}}{e_{t}} \pi_{F, t}^{\epsilon-1}=0
$$

- $K_{F, t}$ :

$$
-\lambda_{31, t}-\lambda_{33, t}+\lambda_{33, t-1} \theta \frac{C_{t}^{*-\sigma}}{C_{t-1}^{*-\sigma}} \frac{e_{t-1}}{e_{t}} \pi_{F, t}^{\epsilon}=0
$$

- $F_{F, t}^{*}$ :

$$
\lambda_{28, t}\left[\frac{1-\theta\left(\frac{1}{\pi_{F, t}^{*}}\right)^{1-\epsilon}}{1-\theta}\right]^{\frac{1}{1-\epsilon}}-\lambda_{29, t}+\lambda_{29, t-1} \theta \frac{C_{t}^{*-\sigma}}{C_{t-1}^{*-\sigma}} \frac{e_{t-1}}{e_{t}} \pi_{F, t}^{* \epsilon-1}=0
$$

- $K_{F, t}^{*}$ :

$$
-\lambda_{28, t}-\lambda_{30, t}+\lambda_{30, t-1} \theta \frac{C_{t}^{*-\sigma}}{C_{t-1}^{*-\sigma}} \frac{e_{t-1}}{e_{t}} \pi_{F, t}^{* \epsilon}=0
$$

The cooperative Ramsey problem thus consists of the above 76 equations for 76 unknowns.

The deterministic steady state is derived in two steps: First, steady-state values of the 39 endogenous variables are derived in Appendix A.2. Given these steady-state endogenous variables, the above optimality conditions (dropping time subscripts) can solve for the steady-state values of the 37 Lagrange multipliers.

\section{B.2 Noncooperation}

The home policy maker maximizes

$$
W_{H, t_{0}}=\mathbb{E}_{t_{0}} \sum_{t=t_{0}}^{\infty} \beta^{t-t_{0}}\left(\frac{C_{t}^{1-\sigma}-1}{1-\sigma}-\chi \frac{h_{t}^{1+\omega}}{1+\omega}\right)
$$

with respect to 38 endogenous variables $\left\{i_{t}, i_{t}^{*}, C_{t}, C_{t}^{*}, C_{H, t}, C_{F, t}, C_{H, t}^{*}, C_{F, t}^{*}, h_{t}, h_{t}^{*}\right.$, $\pi_{t}, \pi_{t}^{*}, \pi_{H, t}, \pi_{H, t}^{*}, \pi_{F, t}, p_{H, t}, p_{F, t}, p_{H, t}^{*} p_{F, t}^{*}, w_{t}, w_{t}^{*}, e_{t}, M C_{t}, M C_{t}^{*}, Y_{t}, Y_{t}^{*}, \Delta_{H, t}, \Delta_{H, t}^{*}$ $\left.\Delta_{F, t}, \Delta_{F, t}^{*}, K_{H, t}, F_{H, t}, K_{H, t}^{*}, F_{H, t}^{*}, K_{F, t}, F_{F, t}, K_{F, t}^{*}, F_{F, t}^{*}\right\}$, taking as given $\left\{\pi_{F, t}^{*}\right\}$ for all $t \geq t_{0}$, subject to 37 structural constraints equations (6.2) (6.38) associated with Lagrangian multipliers $\lambda_{1, t} \sim \lambda_{37, t}$ in sequence. 
The 38 first-order conditions are as follows:

- $i_{t}$ : equation (6.39)

- $i_{t}^{*}$ : equation (6.40)

- $C_{t}$ : equation (6.41)

- $C_{t}^{*}$ :

$$
\begin{array}{r}
\lambda_{6, t}(-\sigma) C_{t}^{*-\sigma-1} w_{t}^{*}+\lambda_{8, t}\left(1-\frac{v}{2}\right) p_{H, t}^{*-1}+\lambda_{9, t} \frac{v}{2} p_{F, t}^{*-1}-\lambda_{11, t}(-\sigma) C_{t}^{*-\sigma-1} \\
+\lambda_{29, t} \beta \theta \sigma \mathbb{E}_{t} \frac{C_{t+1}^{*-\sigma} e_{t}}{C_{t}^{*-\sigma+1} e_{t+1}}\left(\pi_{F, t+1}^{*}\right)^{\epsilon-1} F_{F, t+1}^{*}-\lambda_{29, t-1} \theta \sigma \frac{C_{t}^{*-\sigma-1}}{C_{t-1}^{*-\sigma}} \frac{e_{t-1}}{e_{t}}\left(\pi_{F, t}^{*}\right)^{\epsilon-1} F_{F, t}^{*} \\
+\lambda_{30, t} \beta \theta \sigma \mathbb{E}_{t} \frac{C_{t+1}^{*-\sigma} e_{t}}{C_{t}^{*-\sigma+1} e_{t+1}}\left(\pi_{F, t+1}^{*}\right)^{\epsilon} K_{F, t+1}^{*}-\lambda_{30, t-1} \theta \sigma \frac{C_{t}^{*-\sigma-1}}{C_{t-1}^{*-\sigma}} \frac{e_{t-1}}{e_{t}}\left(\pi_{F, t}^{*}\right)^{\epsilon} K_{F, t}^{*} \\
+\lambda_{32, t} \beta \theta \sigma \mathbb{E}_{t} \frac{C_{t+1}^{*-\sigma} e_{t}}{C_{t}^{*-\sigma+1} e_{t+1}}\left(\pi_{F, t+1}\right)^{\epsilon-1} F_{F, t+1}-\lambda_{32, t-1} \theta \sigma \frac{C_{t}^{*-\sigma-1}}{C_{t-1}^{*-\sigma}} \frac{e_{t-1}}{e_{t}}\left(\pi_{F, t}\right)^{\epsilon-1} F_{F, t} \\
+\lambda_{33, t} \beta \theta \sigma \mathbb{E}_{t} \frac{C_{t+1}^{*-\sigma} e_{t}}{C_{t}^{*-\sigma+1} e_{t+1}}\left(\pi_{F, t+1}\right)^{\epsilon} K_{F, t+1}-\lambda_{33, t-1} \theta \sigma \frac{C_{t}^{*-\sigma-1}}{C_{t-1}^{*-\sigma}} \frac{e_{t-1}}{e_{t}}\left(\pi_{F, t}\right)^{\epsilon} K_{F, t} \\
=0
\end{array}
$$

- $C_{H, t}$ : equation (6.43)

- $C_{F, t}$ : equation (6.45)

- $C_{H, t}^{*}$ : equation (6.44)

- $C_{F, t}^{*}$ : equation (6.46)

- $h_{t}$ : equation (6.47)

- $h_{t}^{*}$ :

$$
-\lambda_{6, t} \omega \chi h_{t}^{* \omega-1}-\lambda_{24, t} \exp \left(z_{t}^{*}\right)+\lambda_{25, t} \exp \left(z_{t}^{*}\right)=0
$$

- $\pi_{t}$ : equation (6.49)

- $\pi_{t}^{*}$ : equation (6.50)

- $\pi_{H, t}$ : equation (6.51)

- $\pi_{H, t}^{*}:$ equation $(6.52)$

- $\pi_{F, t}$ : equation (6.53) 
- $p_{H, t}$ : equation (6.55)

- $p_{H, t}^{*}$ : equation (6.56)

- $p_{F, t}$ : equation (6.57)

- $p_{F, t}^{*}:$ equation (6.58)

- $w_{t}$ : equation (6.59)

- $w_{t}^{*}$ : equation (6.60)

- $e_{t}$ : equation (6.61)

- $M C_{t}$ : equation (6.62)

- $M C_{t}^{*}$ : equation (6.63)

- $Y_{t}$ : equation (6.64)

- $Y_{t}^{*}$ : equation (6.65)

- $\Delta_{H, t}$ : equation (6.66)

- $\Delta_{H, t}^{*}$ : equation (6.67)

- $\Delta_{F, t}$ : equation (6.68)

- $\Delta_{F, t}^{*}$ : equation (6.69)

- $F_{H, t}$ : equation (6.70)

- $K_{H, t}$ : equation (6.71)

- $F_{H, t}^{*}$ : equation (6.72)

- $K_{H, t}^{*}$ : equation (6.73)

- $F_{F, t}$ : equation (6.74)

- $K_{F, t}$ equation (6.75)

- $F_{F, t}^{*}:$ equation (6.76)

- $K_{F, t}^{*}$ : equation (6.77).

The foreign policy maker maximizes

$$
W_{F, t_{0}}=\mathbb{E}_{t_{0}} \sum_{t=t_{0}}^{\infty} \beta^{t-t_{0}}\left(\frac{C_{t}^{* 1-\sigma}-1}{1-\sigma}-\chi \frac{h_{t}^{* 1+\omega}}{1+\omega}\right)
$$


with respect to 38 endogenous variables $\left\{i_{t}, i_{t}^{*}, C_{t}, C_{t}^{*}, C_{H, t}, C_{F, t}, C_{H, t}^{*}, C_{F, t}^{*}, h_{t}, h_{t}^{*}, \pi_{t}\right.$, $\pi_{t}^{*}, \pi_{H, t}^{*}, \pi_{F, t}, \pi_{F, t}^{*}, p_{H, t}, p_{F, t}, p_{H, t}^{*} p_{F, t}^{*}, w_{t}, w_{t}^{*}, e_{t}, M C_{t}, M C_{t}^{*}, Y_{t}, Y_{t}^{*}, \Delta_{H, t}, \Delta_{H, t}^{*}, \Delta_{F, t}$, $\left.\Delta_{F, t}^{*}, K_{H, t}, F_{H, t}, K_{H, t}^{*}, F_{H, t}^{*}, K_{F, t}, F_{F, t}, K_{F, t}^{*}, F_{F, t}^{*}\right\}$, taking as given $\left\{\pi_{H, t}\right\}$ for all $t \geq t_{0}$, subject to 37 structural constraint equations (6.2) (6.38) associated with Lagrangian multipliers $\lambda_{1, t}^{*} \sim \lambda_{37, t}^{*}$ in sequence.

Note that we use lambda with asterisk as Lagrangian multipliers for the foreign maximization problem. While most of the first-order conditions in this optimization problem are the same with those in the cooperative optimization above, and we indeed make references to them to save space, one needs to keep in mind that all $\lambda_{i, t}$ in the following first-order conditions should be replaced to $\lambda_{i, t}^{*}$ for $i=\{1, \ldots 37\}$.

The 38 first-order conditions are

- $i_{t}$ : equation (6.39)

- $i_{t}^{*}$ : equation (6.40)

- $C_{t}$ :

$$
\begin{array}{r}
\lambda_{1, t}^{*}(-\sigma) C_{t}^{-\sigma-1} w_{t}+\lambda_{3, t}^{*} \frac{v}{2} p_{H, t}^{-1}+\lambda_{4, t}^{*}\left(1-\frac{v}{2}\right) p_{F, t}^{-1}+\lambda_{11, t}^{*}(-\sigma) C_{t}^{-\sigma-1} e_{t} \\
+\lambda_{18, t}^{*} \beta \theta \sigma \mathbb{E}_{t} \frac{C_{t+1}^{-\sigma}}{C_{t}^{-\sigma+1}} \frac{e_{t+1}}{e_{t}} \pi_{H, t+1}^{\epsilon-1} F_{H, t+1}+\lambda_{18, t-1}^{*} \theta(-\sigma) \frac{C_{t}^{-\sigma-1}}{C_{t-1}^{-\sigma}} \frac{e_{t}}{e_{t-1}} \pi_{H, t}^{\epsilon-1} F_{H, t} \\
+\lambda_{19, t}^{*} \beta \theta \sigma \mathbb{E}_{t} \frac{C_{t+1}^{-\sigma}}{C_{t}^{-\sigma+1}} \frac{e_{t+1}}{e_{t}} \pi_{H, t+1}^{\epsilon} K_{H, t+1}+\lambda_{19, t-1}^{*} \theta(-\sigma) \frac{C_{t}^{-\sigma-1}}{C_{t-1}^{-\sigma}} \frac{e_{t}}{e_{t-1}} \pi_{H, t}^{\epsilon} K_{H, t} \\
+\lambda_{21, t}^{*} \beta \theta \sigma \mathbb{E}_{t} \frac{C_{t+1}^{-\sigma}}{C_{t}^{-\sigma+1}} \frac{e_{t+1}}{e_{t}} \pi_{H, t+1}^{* \epsilon-1} F_{H, t+1}^{*}+\lambda_{21, t-1}^{*} \theta(-\sigma) \frac{C_{t}^{-\sigma-1}}{C_{t-1}^{-\sigma}} \frac{e_{t}}{e_{t-1}} \pi_{H, t}^{* \epsilon-1} F_{H, t}^{*} \\
+\lambda_{22, t}^{*} \beta \theta \sigma \mathbb{E}_{t} \frac{C_{t+1}^{-\sigma}}{C_{t}^{-\sigma+1}} \frac{e_{t+1}}{e_{t}} \pi_{H, t+1}^{* \epsilon} K_{H, t+1}^{*}+\lambda_{22, t-1}^{*} \theta(-\sigma) \frac{C_{t}^{-\sigma-1}}{C_{t-1}^{-\sigma}} \frac{e_{t}}{e_{t-1}} \pi_{H, t}^{* \epsilon} K_{H, t}^{*}
\end{array}
$$

- $C_{t}^{*}$ : equation (6.42)

- $C_{H, t}$ : equation (6.43)

- $C_{F, t}$ : equation (6.45)

- $C_{H, t}^{*}$ : equation (6.44)

- $C_{F, t}^{*}$ : equation (6.46)

- $h_{t}$ :

$$
-\lambda_{1, t}^{*} \omega \chi h_{t}^{\omega-1}-\lambda_{13, t}^{*} \exp \left(z_{t}\right)+\lambda_{14, t}^{*} \exp \left(z_{t}\right)=0
$$


- $h_{t}^{*}$ : equation (6.48)

- $\pi_{t}$ : equation (6.49)

- $\pi_{t}^{*}$ : equation (6.50)

- $\pi_{H, t}^{*}$ : equation (6.52)

- $\pi_{F, t}$ : equation (6.53)

- $\pi_{F, t}^{*}$ : equation (6.54)

- $p_{H, t}$ : equation (6.55)

- $p_{H, t}^{*}$ : equation (6.56)

- $p_{F, t}:$ equation (6.57)

- $p_{F, t}^{*}$ : equation (6.58)

- $w_{t}$ : equation (6.59)

- $w_{t}^{*}$ : equation (6.60)

- $e_{t}$ : equation (6.61)

- $M C_{t}$ : equation (6.62)

- $M C_{t}^{*}$ : equation (6.63)

- $Y_{t}$ : equation (6.64)

- $Y_{t}^{*}$ : equation (6.65)

- $\Delta_{H, t}:$ equation (6.66)

- $\Delta_{H, t}^{*}$ : equation (6.67)

- $\Delta_{F, t}$ : equation (6.68)

- $\Delta_{F, t}^{*}$ : equation (6.69)

- $F_{H, t}$ : equation (6.70)

- $K_{H, t}$ : equation (6.71)

- $F_{H, t}^{*}$ : equation (6.72)

- $K_{H, t}^{*}:$ equation (6.73)

- $F_{F, t}:$ equation (6.74) 
- $K_{F, t}$ : equation (6.75)

- $F_{F, t}^{*}$ : equation $(6.76)$

- $K_{F, t}^{*}$ : equation $(6.77)$

The noncooperative Ramsey problem thus consists of 113 equations for 113 unknowns.

The deterministic steady state is derived in two steps: First, steady-state values of the 39 endogenous variables are derived in Appendix A.2. Given these values, the above optimality conditions (dropping time subscripts) can solve for the steady-state values of 74 Lagrange multipliers.

We note that thanks to the efficient subsidy, the steady-state values of endogenous variables are always given by Appendix A.2 regardless of strategic games, which allows for meaningful welfare comparison. 


\section{Appendix C. Second-order Approximation}

Section (C.1) to (C.4) show how to substitute linear terms $\hat{c}_{t}-\hat{h}_{t}$ and $\hat{c}_{t}^{*}-\hat{h}_{t}^{*}$ with second-order terms by using the second-order approximation to some of the structural equations. Specifically, C.1 shows the second-order approximation to the price dispersion terms which comes in useful later. C. 2 shows the second-order approximation to the price setting conditions to obtain AS equations. C.3 shows the second-order approximation to the resource constraints. C.4 solves for the linear terms using results obtained in C.1-3.

Section C.5 presents the general form and simplified form of the quadratic loss functions for noncooperative policy makers under LCP, making use of the results in C.4.

\section{C.1}

Price dispersion terms are shown in equations (ix)-(x) and (xxvii)-(xxviii) in the text.

Take a second-order approximation to equation (ix) around its deterministic steady state $\Delta_{H}=1$ and we have

$$
\hat{\Delta}_{H, t}=\frac{\theta \epsilon}{2(1-\theta)} \pi_{H, t}^{2}+\theta \hat{\Delta}_{H, t-1}
$$

Taking a summation on both sides from initial time $t_{0}$ to infinity gives

$$
\mathbb{E}_{t_{0}} \sum_{t=t_{0}}^{\infty} \beta^{t-t_{0}} \hat{\Delta}_{H, t}=\mathbb{E}_{t_{0}} \sum_{t=t_{0}}^{\infty} \beta^{t-t_{0}} \frac{\theta \epsilon}{2(1-\theta)} \pi_{H, t}^{2}+\theta \hat{\Delta}_{H, t_{0}-1}+\theta \beta \mathbb{E}_{t_{0}} \sum_{t=t_{0}}^{\infty} \beta^{t-t_{0}} \hat{\Delta}_{H, t},
$$

that is

$$
\mathbb{E}_{t_{0}} \sum_{t=t_{0}}^{\infty} \beta^{t-t_{0}} \hat{\Delta}_{H, t}=\mathbb{E}_{t_{0}} \sum_{t=t_{0}}^{\infty} \beta^{t-t_{0}} \frac{\epsilon \theta}{2(1-\beta \theta)(1-\theta)} \pi_{H, t}^{2},
$$

where $\hat{\Delta}_{H, t_{0}-1}=0$.

Analogously, equations (x), (xxvii) and (xxviii) are approximated to be

$$
\begin{aligned}
\mathbb{E}_{t_{0}} \sum_{t=t_{0}}^{\infty} \beta^{t-t_{0}} \hat{\Delta}_{H, t}^{*} & =\mathbb{E}_{t_{0}} \sum_{t=t_{0}}^{\infty} \beta^{t-t_{0}} \frac{\epsilon \theta}{2(1-\beta \theta)(1-\theta)} \pi_{H, t}^{* 2} \\
\mathbb{E}_{t_{0}} \sum_{t=t_{0}}^{\infty} \beta^{t-t_{0}} \hat{\Delta}_{F, t} & =\mathbb{E}_{t_{0}} \sum_{t=t_{0}}^{\infty} \beta^{t-t_{0}} \frac{\epsilon \theta}{2(1-\beta \theta)(1-\theta)} \pi_{F, t}^{2} \\
\mathbb{E}_{t_{0}} \sum_{t=t_{0}}^{\infty} \beta^{t-t_{0}} \hat{\Delta}_{F, t}^{*} & =\mathbb{E}_{t_{0}} \sum_{t=t_{0}}^{\infty} \beta^{t-t_{0}} \frac{\epsilon \theta}{2(1-\beta \theta)(1-\theta)} \pi_{F, t}^{* 2} .
\end{aligned}
$$




\section{C.2}

We consider home firms' optimal pricing conditions first. Consider an arbitrary period of time in the infinite time horizon, $t$, where $t \geq t_{0}$, as shown in equations (xi)(xvi) in the text, the optimality conditions with LCP can be written as

$$
\begin{aligned}
& \frac{\tilde{P}_{H, t}}{P_{H, t}}=\frac{K_{H, t}}{F_{H, t}} \\
& \frac{\tilde{P}_{H, t}}{P_{H, t}}=\left[\frac{1-\theta\left(\frac{P_{H, t-1}}{P_{H, t}}\right)^{1-\epsilon}}{1-\theta}\right]^{\frac{1}{1-\epsilon}}
\end{aligned}
$$

where

$$
\begin{aligned}
K_{H, t} & \equiv \mathbb{E}_{t} \sum_{T=t}^{\infty}(\beta \theta)^{T-t} C_{T}^{-\sigma} C_{H, T} M C_{T}\left(\frac{P_{H, t}}{P_{H, T}}\right)^{-\epsilon} \\
F_{H, t} & \equiv \mathbb{E}_{t} \sum_{T=t}^{\infty}(\beta \theta)^{T-t} C_{T}^{-\sigma} C_{H, T} p_{H, T}\left(\frac{P_{H, t}}{P_{H, T}}\right)^{1-\epsilon}
\end{aligned}
$$

for choosing $\tilde{P}_{H, t}$ for the domestic market, and

$$
\begin{aligned}
\frac{\tilde{P}_{H, t}^{*}}{P_{H, t}^{*}} & =\frac{K_{H, t}^{*}}{F_{H, t}^{*}} \\
\frac{\tilde{P}_{H, t}^{*}}{P_{H, t}^{*}} & =\left[\frac{1-\theta\left(\frac{P_{H, t-1}^{*}}{P_{H, t}^{*}}\right)^{1-\epsilon}}{1-\theta}\right]^{\frac{1}{1-\epsilon}}
\end{aligned}
$$

where

$$
\begin{aligned}
K_{H, t}^{*} & \equiv \mathbb{E}_{t} \sum_{T=t}^{\infty}(\beta \theta)^{T-t} C_{T}^{-\sigma} C_{H, T}^{*} M C_{T}\left(\frac{P_{H, t}^{*}}{P_{H, T}^{*}}\right)^{-\epsilon} \\
F_{H, t}^{*} & \equiv \mathbb{E}_{t} \sum_{T=t}^{\infty}(\beta \theta)^{T-t} C_{T}^{-\sigma} C_{H, T}^{*} e_{T} p_{H, T}^{*}\left(\frac{P_{H, t}^{*}}{P_{H, T}^{*}}\right)^{1-\epsilon} .
\end{aligned}
$$

for choosing $\tilde{P}_{H, t}^{*}$ for the export destination market. Note that we use a slightly different notation for summation as we are now considering the path from an arbitrary time $t$ onward.

Following Benigno and Woodford (2005) we take a second-order approximation to (6.86) and (6.87) and make use of the second-order approximation to equations (6.88) 
and (6.89). After a few messy steps we obtain the second-order home AS equation

$$
\begin{aligned}
& \mathbb{E}_{t_{0}} \sum_{t=t_{0}}^{\infty} \beta^{t-t_{0}}\left(\widehat{m c}_{t}-\hat{p}_{H, t}\right) \\
= & -\mathbb{E}_{t_{0}} \sum_{t=t_{0}}^{\infty} \beta^{t-t_{0}}\left[\frac{1}{2}\left(\widehat{m c}_{t}-\hat{p}_{H, t}\right)\left(2\left(-\sigma \hat{c}_{t}+\hat{c}_{H, t}\right)+\hat{p}_{H, t}+\widehat{m c}_{t}\right)+\frac{\epsilon}{2 \delta} \pi_{H, t}^{2}\right]+\text { t.i.p }
\end{aligned}
$$

where we have used equation (6.82), and the t.i.p term contains terms that are independent of policy and determined by parameters and predetermined initial conditions only:

$$
V_{H, t_{0}}=\pi_{H, t_{0}}-\frac{(1-2 \epsilon+\epsilon \theta)}{2(1-\theta)} \pi_{H, t_{0}}^{2}+\frac{(1-\beta \theta)}{2} \pi_{H, t_{0}} \bar{Z}_{H, t_{0}}
$$

where $\bar{Z}_{H, t_{0}}=\mathbb{E}_{t_{0}} \sum_{t=t_{0}}^{\infty}(\beta \theta)^{t-t_{0}}\left(2\left(-\sigma \hat{c}_{t}+\hat{c}_{H, t}\right)+\hat{p}_{H, t}+\widehat{m c}_{t}-\frac{\beta \theta(1-2 \epsilon)}{(1-\beta \theta)} \pi_{H, t+1}\right)$.

Similarly we approximate equations (6.90) and (6.91) along with (6.92) and (6.93) up to the second order and obtain

$$
\begin{aligned}
& \mathbb{E}_{t_{0}} \sum_{t=t_{0}}^{\infty} \beta^{t-t_{0}}\left(\widehat{m c}_{t}-\hat{p}_{H, t}^{*}-\hat{e}_{t}\right) \\
= & -\mathbb{E}_{t_{0}} \sum_{t=t_{0}}^{\infty} \beta^{t-t_{0}}\left[\frac{1}{2}\left(\widehat{m c}_{t}-\hat{p}_{H, t}^{*}-\hat{e}_{t}\right)\left(2\left(-\sigma \hat{c}_{t}+\hat{c}_{H, t}^{*}\right)+\hat{p}_{H, t}^{*}+\hat{e}_{t}+\widehat{m c}_{t}\right)+\frac{\epsilon}{2 \delta} \pi_{H, t}^{* 2}\right]+\text { t.i.p, }
\end{aligned}
$$

where we have used equation (6.83) and the t.i.p term contains

$$
V_{H, t_{0}}^{*}=\pi_{H, t_{0}}^{*}-\frac{(1-2 \epsilon+\epsilon \theta)}{2(1-\theta)} \pi_{H, t_{0}}^{* 2}+\frac{(1-\beta \theta)}{2} \pi_{H, t_{0}}^{*} \bar{Z}_{H, t_{0}}^{*}
$$

where $\bar{Z}_{H, t_{0}}^{*}=\mathbb{E}_{t_{0}} \sum_{t=t_{0}}^{\infty}(\beta \theta)^{t-t_{0}}\left(2\left(-\sigma \hat{c}_{t}+\hat{c}_{H, t}^{*}\right)+\widehat{m c}_{t}+\hat{p}_{H, t}^{*}+\hat{e}_{t}-\frac{\beta \theta(1-2 \epsilon)}{(1-\beta \theta)} \pi_{H, t+1}^{*}\right)$.

We then look at foreign firms' optimal pricing conditions. As shown in equations (xxix)-(xxxiv) in the text, the optimality conditions can be written as

$$
\begin{aligned}
\frac{\tilde{P}_{F, t}^{*}}{P_{F, t}^{*}} & =\frac{K_{F, t}^{*}}{F_{F, t}^{*}} \\
\frac{\tilde{P}_{F, t}^{*}}{P_{F, t}^{*}} & =\left[\frac{1-\theta\left(\frac{P_{F, t-1}^{*}}{P_{F, t}^{*}}\right)^{1-\epsilon}}{1-\theta}\right]^{\frac{1}{1-\epsilon}}
\end{aligned}
$$

where

$$
K_{F, t}^{*}=\mathbb{E}_{t} \sum_{T=t}^{\infty}(\beta \theta)^{T-t} C_{T}^{*-\sigma} C_{F, T}^{*} M C_{T}^{*}\left(\frac{P_{F, t}^{*}}{P_{F, T}^{*}}\right)^{-\epsilon}
$$




$$
F_{F, t}^{*}=\mathbb{E}_{t} \sum_{T=t}^{\infty}(\beta \theta)^{T-t} C_{T}^{*-\sigma} C_{F, T}^{*} p_{F, T}^{*}\left(\frac{P_{F, t}^{*}}{P_{F, T}^{*}}\right)^{1-\epsilon}
$$

for choosing $\tilde{P}_{F, t}^{*}$ for the domestic market and

$$
\begin{aligned}
& \frac{\tilde{P}_{F, t}}{P_{F, t}}=\frac{K_{F, t}}{F_{F, t}} \\
& \frac{\tilde{P}_{F, t}}{P_{F, t}}=\left[\frac{1-\theta\left(\frac{P_{F, t-1}}{P_{F, t}}\right)^{1-\epsilon}}{1-\theta}\right]^{\frac{1}{1-\epsilon}}
\end{aligned}
$$

where

$$
\begin{aligned}
& K_{F, t}=\mathbb{E}_{t} \sum_{T=t}^{\infty}(\beta \theta)^{T-t} C_{T}^{*-\sigma} C_{F, T} M C_{T}^{*}\left(\frac{P_{F, t}}{P_{F, T}}\right)^{-\epsilon} \\
& F_{F, t}=\mathbb{E}_{t} \sum_{T=t}^{\infty}(\beta \theta)^{T-t} C_{T}^{*-\sigma} C_{F, T} p_{F, T} e_{T}^{-1}\left(\frac{P_{F, t}}{P_{F, T}}\right)^{1-\epsilon}
\end{aligned}
$$

for choosing $\tilde{P}_{F, t}$ for the export destination market.

Repeat the exact same procedure as in approximating home firms' price setting equations and we obtain the two second-order foreign AS equations

$$
\begin{aligned}
& \mathbb{E}_{t_{0}} \sum_{t=t_{0}}^{\infty} \beta^{t-t_{0}}\left(\widehat{m c}_{t}^{*}-\hat{p}_{F, t}^{*}\right) \\
= & -\mathbb{E}_{t_{0}} \sum_{t=t_{0}}^{\infty} \beta^{t-t_{0}}\left[\frac{1}{2}\left(\widehat{m c}_{t}^{*}-\hat{p}_{F, t}^{*}\right)\left(2\left(-\sigma \hat{c}_{t}^{*}+\hat{c}_{F, t}^{*}\right)+\hat{p}_{F, t}^{*}+\widehat{m c}_{t}^{*}\right)+\frac{\epsilon}{2 \delta} \pi_{F, t}^{* 2}\right]+\text { t.i.p, }
\end{aligned}
$$

and

$$
\begin{aligned}
& \mathbb{E}_{t_{0}} \sum_{t=t_{0}}^{\infty} \beta^{t-t_{0}}\left(\widehat{m c}_{t}^{*}-\hat{p}_{F, t}+\hat{e}_{t}\right) \\
= & -\mathbb{E}_{t_{0}} \sum_{t=t_{0}}^{\infty} \beta^{t-t_{0}}\left[\frac{1}{2}\left(\widehat{m c}_{t}^{*}-\hat{p}_{F, t}+\hat{e}_{t}\right)\left(2\left(-\sigma \hat{c}_{t}^{*}+\hat{c}_{F, t}\right)+\hat{p}_{F, t}-\hat{e}_{t}+\widehat{m c}_{t}^{*}\right)+\frac{\epsilon}{2 \delta} \pi_{F, t}^{2}\right]+\text { t.i.p, }
\end{aligned}
$$

where we have used equations (6.85) and (6.84), and the first t.i.p contains

$$
V_{F, t_{0}}^{*}=\pi_{F, t_{0}}^{*}-\frac{(1-2 \epsilon+\epsilon \theta)}{2(1-\theta)} \pi_{F, t_{0}}^{* 2}+\frac{(1-\beta \theta)}{2} \pi_{F, t_{0}}^{*} \bar{Z}_{F, t_{0}^{\prime}}^{*}
$$


where $\bar{Z}_{F, t_{0}}^{*}=\mathbb{E}_{t_{0}} \sum_{t=t_{0}}^{\infty}(\beta \theta)^{t-t_{0}}\left(2\left(-\sigma \hat{c}_{t}^{*}+\hat{c}_{F, t}^{*}\right)+\hat{p}_{F, t}^{*}+\widehat{m c}_{t}^{*}-\frac{\beta \theta(1-2 \epsilon)}{(1-\beta \theta)} \pi_{F, t+1}^{*}\right)$, and the second t.i.p contains

$$
V_{F, t_{0}}=\pi_{F, t_{0}}-\frac{(1-2 \epsilon+\epsilon \theta)}{2(1-\theta)} \pi_{F, t_{0}}^{2}+\frac{(1-\beta \theta)}{2} \pi_{F, t_{0}} \bar{Z}_{F, t_{0}}
$$

where $\bar{Z}_{F, t_{0}}=\mathbb{E}_{t_{0}} \sum_{t=t_{0}}^{\infty}(\beta \theta)^{t-t_{0}}\left(2\left(-\sigma \hat{c}_{t}^{*}+\hat{c}_{F, t}\right)+\hat{p}_{F, t}-\hat{e}_{t}+\widehat{m c}_{t}^{*}-\frac{\beta \theta(1-2 \epsilon)}{(1-\beta \theta)} \pi_{F, t+1}\right)$.

Look at the four AS equations. The real marginal costs and aggregate consumption of each type of goods can be substituted out by using the exact and approximated log-linear forms of structural equations (ii)-(viii) and (xx)-(xxvi). ${ }^{26}$ They are now expressed as

$$
\begin{aligned}
\omega \hat{h}_{t}+\sigma \hat{c}_{t}-\hat{p}_{H, t}= & -\frac{1}{2}\left[(\omega+1)\left(\hat{y}_{t}-z_{t}\right)+\frac{2-v}{2}\left(\hat{p}_{H, t}^{*}+\frac{1}{\sigma} \hat{e}_{t}-\hat{p}_{H, t}\right)\right]^{2}(6.1 \\
& +\frac{1}{2}(1-\sigma)^{2} \hat{c}_{t}^{2}-\frac{\epsilon}{2 \delta} \pi_{H, t}^{2} \\
\omega \hat{h}_{t}+\sigma \hat{c}_{t}^{*}+\frac{v}{2-v} \hat{p}_{F, t}^{*}= & -\frac{1}{2}\left[(\omega+1)\left(\hat{y}_{t}-z_{t}\right)-\frac{v}{2}\left(\hat{p}_{H, t}^{*}+\frac{1}{\sigma} \hat{e}_{t}-\hat{p}_{H, t}\right)\right]^{2} \\
& +\frac{1}{2}(1-\sigma)^{2} \hat{c}_{t}^{* 2}-\frac{\epsilon}{2 \delta} \pi_{H, t}^{* 2} \\
\omega \hat{h}_{t}^{*}+\sigma \hat{c}_{t}^{*}-\hat{p}_{F, t}^{*}= & -\frac{1}{2}\left[(\omega+1)\left(\hat{y}_{t}^{*}-z_{t}^{*}\right)+\frac{2-v}{2}\left(\hat{p}_{F, t}-\frac{1}{\sigma} \hat{e}_{t}-\hat{p}_{F, t}^{*}\right)\right]^{2}(6.1 \\
& +\frac{1}{2}(1-\sigma)^{2} \hat{c}_{t}^{* 2}-\frac{\epsilon}{2 \delta} \pi_{F, t}^{* 2} \\
\omega \hat{h}_{t}^{*}+\sigma \hat{c}_{t}+\frac{v}{2-v} \hat{p}_{H, t}= & -\frac{1}{2}\left[(\omega+1)\left(\hat{y}_{t}^{*}-z_{t}^{*}\right)-\frac{v}{2}\left(\hat{p}_{F, t}-\frac{1}{\sigma} \hat{e}_{t}-\hat{p}_{F, t}^{*}\right)\right]^{2} \\
& +\frac{1}{2}(1-\sigma)^{2} \hat{c}_{t}^{2}-\frac{\epsilon}{2 \delta} \pi_{F, t}^{2}
\end{aligned}
$$

\section{C.3}

Now we approximate resource constraints, equations (vii) and (xxv), in the text.

Make use of equations (iii) and (xxi) to write equation (vii) as

$$
\exp \left(z_{t}\right) h_{t}=\frac{v}{2} p_{H, t}^{-1} C_{t} \Delta_{H, t}+\frac{2-v}{2} p_{H, t}^{*-1} C_{t}^{*} \Delta_{H, t}^{*}
$$

Take a second-order approximation around its deterministic steady state and we ob-

\footnotetext{
${ }^{26}$ Although one needs to be careful in the substitution: exact log-linear equations can be used to substitute both linear terms and squared terms while log-linearized equations can be used to substitute the squared terms only.
} 
tain

$$
\begin{aligned}
& z_{t}+\hat{h}_{t}-\frac{v}{2} \hat{c}_{t}-\frac{2-v}{2} \hat{c}_{t}^{*}+\frac{v}{2} \hat{p}_{H, t}+\frac{2-v}{2} \hat{p}_{H, t}^{*} \\
= & -\frac{1}{2}\left(\hat{h}_{t}+z_{t}\right)^{2}+\frac{v}{4}\left(\hat{p}_{H, t}-\hat{c}_{t}\right)^{2}+\frac{2-v}{4}\left(\hat{p}_{H, t}^{*}-\hat{c}_{t}^{*}\right)^{2} \\
& +\frac{v}{2} \hat{\Delta}_{H, t}+\frac{2-v}{2} \hat{\Delta}_{H, t}^{*} .
\end{aligned}
$$

Note that up to the first order, the above equation is approximated to

$$
z_{t}+\hat{h}_{t}=\frac{v}{2} \hat{c}_{t}-\frac{v}{2} \hat{p}_{H, t}+\frac{2-v}{2} \hat{c}_{t}^{*}-\frac{2-v}{2} \hat{p}_{H, t}^{*}
$$

which is sufficient to substitute $\left(\hat{h}_{t}+z_{t}\right)^{2}$. As Benigno and Woodford (2005) argue, linear technology terms are independent of policy when as part of quadratic policy objective, so we can drop out $z_{t}$. Then we make use of exact log-linear relations of price index (xxiii), risk sharing condition (xxxvii) and quadratic price dispersion equations (6.82)-(6.83) and obtain

$$
\begin{aligned}
& \mathbb{E}_{t_{0}} \sum_{t=t_{0}}^{\infty} \beta^{t-t_{0}}\left[\left(\hat{h}_{t}-\hat{c}_{t}\right)+\frac{2-v}{2}\left(\hat{c}_{t}-\hat{c}_{t}^{*}\right)+\frac{v}{2}\left(\hat{p}_{H, t}-\hat{p}_{F, t}^{*}\right)\right] \\
= & \mathbb{E}_{t_{0}} \sum_{t=t_{0}}^{\infty} \beta^{t-t_{0}}\left[\frac{v(2-v)}{8}\left(\hat{p}_{H, t}^{*}+\frac{1}{\sigma} \hat{e}_{t}-\hat{p}_{H, t}\right)^{2}+\frac{v}{2} \frac{\epsilon \theta}{2(1-\beta \theta)(1-\theta)} \pi_{H, t}^{2}+\frac{2-v}{2} \frac{\epsilon \theta}{2(1-\beta \theta)(1-\theta)} \pi_{H, t}^{* 2}\right] .
\end{aligned}
$$

Similarly foreign resource constraint, equation (xxv) is approximated as

$$
\begin{aligned}
& \mathbb{E}_{t_{0}} \sum_{t=t_{0}}^{\infty} \beta^{t-t_{0}}\left[\left(\hat{h}_{t}^{*}-\hat{c}_{t}^{*}\right)-\frac{2-v}{2}\left(\hat{c}_{t}-\hat{c}_{t}^{*}\right)-\frac{v}{2}\left(\hat{p}_{H, t}-\hat{p}_{F, t}^{*}\right)\right] \\
= & \mathbb{E}_{t_{0}} \sum_{t=t_{0}}^{\infty} \beta^{t-t_{0}}\left[\frac{v(2-v)}{8}\left(\hat{p}_{F, t}-\frac{1}{\sigma} \hat{e}_{t}-\hat{p}_{F, t}^{*}\right)^{2}+\frac{v}{2} \frac{\epsilon \theta}{2(1-\beta \theta)(1-\theta)} \pi_{F, t}^{* 2}+\frac{2-v}{2} \frac{\epsilon \theta}{2(1-\beta \theta)(1-\theta)} \pi_{F, t}^{2}\right] .
\end{aligned}
$$

\section{4}

Given the results in C.1-3, we now have enough second-order equations to find pure quadratic expressions for the linear terms $\hat{c}_{t}-\hat{h}_{t}$ and $\hat{c}_{t}^{*}-\hat{h}_{t}^{*}$. Note that the linear terms of interest appear explicitly in resource constraints (6.114) and (6.115) only. So our indirect goal is to find the appropriate linear combination for $\hat{c}_{t}-\hat{c}_{t}^{*}$ and $\hat{p}_{H, t}-\hat{p}_{F, t}^{*}$ first.

Write equations (6.110)-(6.113) (6.114)-(6.115) as a group and denote the (pure quadratic) expressions on the RHS of each of the equations as $f_{1}, f_{2}, f_{3}, f_{4}, f_{5}$ and 
$f_{6}$ :

$$
\begin{aligned}
\omega \hat{h}_{t}+\sigma \hat{c}_{t}-\hat{p}_{H, t} & =f_{1} \\
\omega \hat{h}_{t}+\sigma \hat{c}_{t}^{*}+\frac{v}{2-v} \hat{p}_{F, t}^{*} & =f_{2} \\
\omega \hat{h}_{t}^{*}+\sigma \hat{c}_{t}^{*}-\hat{p}_{F, t}^{*} & =f_{3} \\
\omega \hat{h}_{t}^{*}+\sigma \hat{c}_{t}+\frac{v}{2-v} \hat{p}_{H, t} & =f_{4} \\
\left(\hat{h}_{t}-\hat{c}_{t}\right)+\frac{2-v}{2}\left(\hat{c}_{t}-\hat{c}_{t}^{*}\right)+\frac{v}{2}\left(\hat{p}_{H, t}-\hat{p}_{F, t}^{*}\right) & =f_{5} \\
\left(\hat{h}_{t}^{*}-\hat{c}_{t}^{*}\right)-\frac{2-v}{2}\left(\hat{c}_{t}-\hat{c}_{t}^{*}\right)-\frac{v}{2}\left(\hat{p}_{H, t}-\hat{p}_{F, t}^{*}\right) & =f_{6}
\end{aligned}
$$

After a few steps of algebra we obtain

$$
\begin{aligned}
\hat{p}_{H, t}-\hat{p}_{F, t}^{*}= & -\frac{2-v}{2}\left(\frac{\sigma+\omega(1-v)}{\gamma}\right)\left(f_{1}-f_{3}\right) \\
& -\frac{2-v}{2}\left(\frac{\sigma-\omega(1-v)}{\gamma}\right)\left(f_{2}-f_{4}\right) \\
& +\frac{\sigma \omega(2-v)}{\gamma}\left(f_{5}-f_{6}\right) \\
\hat{c}_{t}-\hat{c}_{t}^{*}= & \frac{v}{2}\left(\frac{1+\omega(2-v)}{\gamma}\right)\left(f_{1}-f_{3}\right) \\
& -\frac{2-v}{2}\left(\frac{1+v \omega}{\gamma}\right)\left(f_{2}-f_{4}\right) \\
+ & \frac{\omega(1-v)}{\gamma}\left(f_{5}-f_{6}\right)
\end{aligned}
$$

where $\gamma=\sigma v \omega(2-v)+\sigma+\omega(1-v)^{2}$. Substitute the two expressions in equations (6.114) and (6.115) and we finally obtain

$$
\begin{aligned}
\hat{c}_{t}-\hat{h}_{t}= & -\frac{v 2}{2} \frac{2-v}{2}\left(\frac{\sigma-1-\omega}{\gamma}\right)\left(f_{1}-f_{3}\right) \\
& -\frac{v}{2} \frac{2-v}{2}\left(\frac{\sigma-1+\omega+\frac{2}{v}}{\gamma}\right)\left(f_{2}-f_{4}\right) \\
& -\frac{1}{2}\left(1+\frac{\sigma-\omega(1-v)}{\gamma}\right) f_{5} \\
& -\frac{1}{2}\left(1-\frac{\sigma-\omega(1-v)}{\gamma}\right) f_{6}
\end{aligned}
$$


and

$$
\begin{aligned}
\hat{c}_{t}^{*}-\hat{h}_{t}^{*}= & \frac{v}{2} \frac{2-v}{2}\left(\frac{\sigma-1-\omega}{\gamma}\right)\left(f_{1}-f_{3}\right) \\
& +\frac{v}{2} \frac{2-v}{2}\left(\frac{\sigma-1+\omega+\frac{2}{v}}{\gamma}\right)\left(f_{2}-f_{4}\right) \\
& -\frac{1}{2}\left(1-\frac{\sigma-\omega(1-v)}{\gamma}\right) f_{5} \\
& -\frac{1}{2}\left(1+\frac{\sigma-\omega(1-v)}{\gamma}\right) f_{6} .
\end{aligned}
$$

Plug in the denoted expressions of $f_{1}$ to $f_{6}$ and we obtain

$$
\begin{aligned}
-\left(\hat{c}_{t}-\hat{h}_{t}\right)= & +\frac{v(2-v)}{16}\left(1+\frac{\sigma-\omega(1-v)}{\gamma}\right)\left(\hat{p}_{H, t}^{*}+\frac{1}{\sigma} \hat{e}_{t}-\hat{p}_{H, t}\right)^{2} \\
& +\frac{v(2-v)}{16}\left(1-\frac{\sigma-\omega(1-v)}{\gamma}\right)\left(\hat{p}_{F, t}-\frac{1}{\sigma} \hat{e}_{t}-\hat{p}_{F, t}^{*}\right)^{2} \\
& +\frac{\epsilon}{4 \delta}\left[\frac{v}{2}\left(1+\frac{\alpha}{\gamma}\right) \pi_{H, t}^{2}+\frac{2-v}{2}\left(1+\frac{\alpha}{\gamma}\right) \pi_{F, t}^{2}\right] \\
& +\frac{\epsilon}{4 \delta}\left[\frac{v}{2}\left(1-\frac{\alpha}{\gamma}\right) \pi_{F, t}^{* 2}+\frac{2-v}{2}\left(1-\frac{\alpha}{\gamma}\right) \pi_{H, t}^{* 2}\right] \\
& -\frac{(\sigma-1)^{2}}{2}\left(\frac{2-v}{2}\right)\left(\frac{\omega v+1}{\gamma}\right)\left(\hat{c}_{t}\right)^{2} \\
& +\frac{(\sigma-1)^{2}}{2}\left(\frac{2-v}{2}\right)\left(\frac{\omega v+1}{\gamma}\right)\left(\hat{c}_{t}^{*}\right)^{2} \\
& +\frac{v(2-v)}{8}\left(\frac{-\sigma+1+\omega}{\gamma}\right)\left[(\omega+1)\left(\hat{y}_{t}-z_{t}\right)+\frac{2-v}{2}\left(\hat{p}_{H, t}^{*}+\frac{1}{\sigma} \hat{e}_{t}-\hat{p}_{H, t}\right)\right]^{2} \\
& +\frac{v(2-v)}{8}\left(\frac{\sigma-1+\omega+\frac{2}{v}}{\gamma}\right)\left[(\omega+1)\left(\hat{y}_{t}^{*}-z_{t}^{*}\right)-\frac{v}{2}\left(\hat{p}_{F, t}-\frac{1}{\sigma} \hat{e}_{t}-\hat{p}_{F, t}^{*}\right)\right]^{2} \\
& -\frac{v(2-v)}{8}\left(\frac{-\sigma+1+\omega}{\gamma}\right)\left[(\omega+1)\left(\hat{y}_{t}^{*}-z_{t}^{*}\right)+\frac{2-v}{2}\left(\hat{p}_{F, t}-\frac{1}{\sigma} \hat{e}_{t}-\hat{p}_{F, t}^{*}\right)\right]^{2} \\
& -\frac{v(2-v)}{8}\left(\frac{\sigma-1+\omega+\frac{2}{v}}{\gamma}\right)\left[(\omega+1)\left(\hat{y}_{t}-z_{t}\right)-\frac{v}{2}\left(\hat{p}_{H, t}^{*}+\frac{1}{\sigma} \hat{e}_{t}-\hat{p}_{H, t}\right)\right]^{2} .
\end{aligned}
$$


and

$$
\begin{aligned}
-\left(\hat{c}_{t}^{*}-\hat{h}_{t}^{*}\right)= & +\frac{v(2-v)}{16}\left(1-\frac{\sigma-\omega(1-v)}{\gamma}\right)\left(\hat{p}_{H, t}^{*}+\frac{1}{\sigma} \hat{e}_{t}-\hat{p}_{H, t}\right)^{2} \\
& +\frac{v(2-v)}{16}\left(1+\frac{\sigma-\omega(1-v)}{\gamma}\right)\left(\hat{p}_{F, t}-\frac{1}{\sigma} \hat{e}_{t}-\hat{p}_{F, t}^{*}\right)^{2} \\
& +\frac{\epsilon}{4 \delta}\left[\frac{v}{2}\left(1-\frac{\alpha}{\gamma}\right) \pi_{H, t}^{2}+\frac{2-v}{2}\left(1-\frac{\alpha}{\gamma}\right) \pi_{F, t}^{2}\right] \\
& +\frac{\epsilon}{4 \delta}\left[\frac{v}{2}\left(1+\frac{\alpha}{\gamma}\right) \pi_{F, t}^{* 2}+\frac{2-v}{2}\left(1+\frac{\alpha}{\gamma}\right) \pi_{H, t}^{* 2}\right] \\
& -\frac{(\sigma-1)^{2}}{2}\left(\frac{2-v}{2}\right)\left(\frac{\omega v+1}{\gamma}\right)\left(\hat{c}_{t}^{*}\right)^{2} \\
& +\frac{(\sigma-1)^{2}}{2}\left(\frac{2-v}{2}\right)\left(\frac{\omega v+1}{\gamma}\right)\left(\hat{c}_{t}\right)^{2} \\
& -\frac{v(2-v)}{8}\left(\frac{-\sigma+1+\omega}{\gamma}\right)\left[(\omega+1)\left(\hat{y}_{t}-z_{t}\right)+\frac{2-v}{2}\left(\hat{p}_{H, t}^{*}+\frac{1}{\sigma} \hat{e}_{t}-\hat{p}_{H, t}\right)\right]^{2} \\
& -\frac{v(2-v)}{8}\left(\frac{\sigma-1+\omega+\frac{2}{v}}{\gamma}\right)\left[(\omega+1)\left(\hat{y}_{t}^{*}-z_{t}^{*}\right)-\frac{v}{2}\left(\hat{p}_{F, t}-\frac{1}{\sigma} \hat{e}_{t}-\hat{p}_{F, t}^{*}\right)\right]^{2} \\
& +\frac{v(2-v)}{8}\left(\frac{-\sigma+1+\omega}{\gamma}\right)\left[(\omega+1)\left(\hat{y}_{t}^{*}-z_{t}^{*}\right)+\frac{2-v}{2}\left(\hat{p}_{F, t}-\frac{1}{\sigma} \hat{e}_{t}-\hat{p}_{F, t}^{*}\right)\right]^{2} \\
& +\frac{v(2-v)}{8}\left(\frac{\sigma-1+\omega+\frac{2}{v}}{\gamma}\right)\left[(\omega+1)\left(\hat{y}_{t}-z_{t}\right)-\frac{v}{2}\left(\hat{p}_{H, t}^{*}+\frac{1}{\sigma} \hat{e}_{t}-\hat{p}_{H, t}\right)\right]^{2},
\end{aligned}
$$

where we denote

$$
\begin{aligned}
& \alpha=\omega+1+(1-\sigma)(1-v) \\
& \gamma=\sigma \nu \omega(2-v)+\sigma+\omega(1-v)^{2} \\
& \delta=\frac{(1-\theta)(1-\beta \theta)}{\theta} .
\end{aligned}
$$


In the special case imposing $\sigma=1$, the above expressions reduce to

$$
\begin{aligned}
-\left(\hat{c}_{t}-\hat{h}_{t}\right)= & \frac{\epsilon v}{4 \delta}\left(\pi_{H, t}\right)^{2}+\frac{\epsilon(2-v)}{4 \delta}\left(\pi_{F, t}\right)^{2} \\
& +\frac{v(2-v) \Omega}{8}\left(\hat{d}_{t}\right)^{2}+\frac{v(2-v)(1-\Omega)}{8}\left(\hat{d}_{t}^{*}\right)^{2} \\
& +\frac{v(1-\Omega)}{4}\left((\omega+1)\left(\hat{y}_{t}-z_{t}\right)+\frac{2-v}{2} \hat{d}_{t}\right)^{2} \\
& +\frac{(2-v) \Omega}{4}\left((\omega+1)\left(\hat{y}_{t}^{*}-z_{t}^{*}\right)-\frac{v}{2} \hat{d}_{t}^{*}\right)^{2} \\
& -\frac{v(1-\Omega)}{4}\left((\omega+1)\left(\hat{y}_{t}^{*}-z_{t}^{*}\right)+\frac{2-v}{2} \hat{d}_{t}^{*}\right)^{2} \\
& -\frac{(2-v) \Omega}{4}\left((\omega+1)\left(\hat{y}_{t}-z_{t}\right)-\frac{v}{2} \hat{d}_{t}\right)^{2}
\end{aligned}
$$

and

$$
\begin{aligned}
-\left(\hat{c}_{t}^{*}-\hat{h}_{t}^{*}\right)= & \frac{\epsilon v}{4 \delta}\left(\pi_{F, t}^{*}\right)^{2}+\frac{\epsilon(2-v)}{4 \delta}\left(\pi_{H, t}^{*}\right)^{2} \\
& +\frac{v(2-v) \Omega}{8}\left(\hat{d}_{t}^{*}\right)^{2}+\frac{v(2-v)(1-\Omega)}{8}\left(\hat{d}_{t}\right)^{2} \\
& -\frac{v(1-\Omega)}{4}\left((\omega+1)\left(\hat{y}_{t}-z_{t}\right)+\frac{2-v}{2} \hat{d}_{t}\right)^{2} \\
& -\frac{(2-v) \Omega}{4}\left((\omega+1)\left(\hat{y}_{t}^{*}-z_{t}^{*}\right)-\frac{v}{2} \hat{d}_{t}^{*}\right)^{2} \\
& +\frac{v(1-\Omega)}{4}\left((\omega+1)\left(\hat{y}_{t}^{*}-z_{t}^{*}\right)+\frac{2-v}{2} \hat{d}_{t}^{*}\right)^{2} \\
& +\frac{(2-v) \Omega}{4}\left((\omega+1)\left(\hat{y}_{t}-z_{t}\right)-\frac{v}{2} \hat{d}_{t}\right)^{2} .
\end{aligned}
$$

where we denote $\Omega=\frac{1+\omega \frac{v}{2}}{1+\omega}, 0<\Omega \leqslant 1, \hat{d}_{t}=\hat{p}_{H, t}^{*}+\hat{e}_{t}-\hat{p}_{H, t}$ and $\hat{d}_{t}^{*}=\hat{p}_{F, t}-\hat{e}_{t}-\hat{p}_{F, t}^{*}$.

\section{C.5}

Given the second-order expressions of the linear terms in the utility functions, equations (6.118) and (6.119), the quadratic loss function of the home noncooperative pol- 
icy maker under LCP is given by

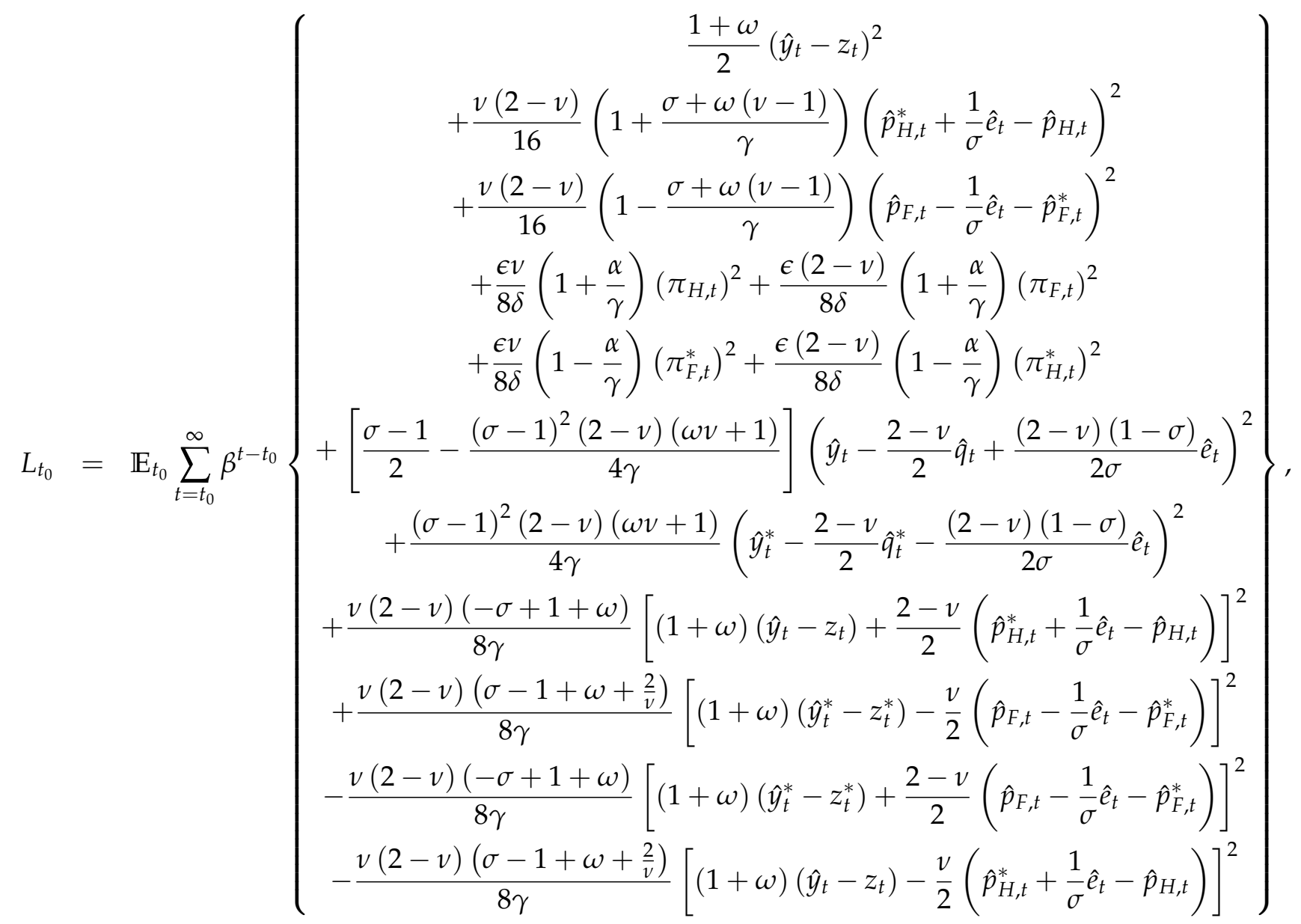


while the quadratic loss function of the foreign noncooperative policy maker under $\mathrm{LCP}$ is given by

$$
L_{t_{0}}^{*}=\mathbb{E}_{t_{0}} \sum_{t=t_{0}}^{\infty} \beta^{t-t_{0}}\left\{\begin{array}{c}
\frac{1+\omega}{2}\left(\hat{y}_{t}^{*}-z_{t}^{*}\right)^{2} \\
+\frac{v(2-v)}{16}\left(1-\frac{\sigma+\omega(v-1)}{\gamma}\right)\left(\hat{p}_{H, t}^{*}+\frac{1}{\sigma} \hat{e}_{t}-\hat{p}_{H, t}\right)^{2} \\
+\frac{v(2-v)}{16}\left(1+\frac{\sigma+\omega(v-1)}{\gamma}\right)\left(\hat{p}_{F, t}-\frac{1}{\sigma} \hat{e}_{t}-\hat{p}_{F, t}^{*}\right)^{2} \\
+\frac{\epsilon v}{8 \delta}\left(1-\frac{\alpha}{\gamma}\right)\left(\pi_{H, t}\right)^{2}+\frac{\epsilon(2-v)}{8 \delta}\left(1-\frac{\alpha}{\gamma}\right)\left(\pi_{F, t}\right)^{2} \\
+\frac{\epsilon v}{8 \delta}\left(1+\frac{\alpha}{\gamma}\right)\left(\pi_{F, t}^{*}\right)^{2}+\frac{\epsilon(2-v)}{8 \delta}\left(1+\frac{\alpha}{\gamma}\right)\left(\pi_{H, t}^{*}\right)^{2} \\
+\left(\frac{\sigma-1)^{2}(2-v)(\omega v+1)}{4 \gamma}\left(\hat{y}_{t}-\frac{2-v}{2} \hat{q}_{t}+\frac{(2-v)(1-\sigma)}{2 \sigma} \hat{e}_{t}\right)^{2}\right. \\
\left.-\frac{(\sigma-1)^{2}(2-v)(\omega v+1)}{4 \gamma}\right)\left(\hat{y}_{t}^{*}-\frac{2-v}{2} \hat{q}_{t}^{*}-\frac{(2-v)(1-\sigma)}{2 \sigma} \hat{e}_{t}\right)^{2} \\
-\frac{v(2-v)\left(\sigma-1+\omega+\frac{2}{v}\right)}{8 \gamma}\left[(1+\omega)\left(\hat{y}_{t}^{*}-z_{t}^{*}\right)-\frac{v}{2}\left(\hat{p}_{F, t}-\frac{1}{\sigma} \hat{e}_{t}-\hat{p}_{F, t}^{*}\right)\right]^{2} \\
+\frac{v(2-v)(-\sigma+1+\omega)}{8 \gamma}\left[(1+\omega)\left(\hat{y}_{t}^{*}-z_{t}^{*}\right)+\frac{2-v}{2}\left(\hat{p}_{F, t}-\frac{1}{\sigma} \hat{e}_{t}-\hat{p}_{F, t}^{*}\right)\right]^{2} \\
+\frac{v(2-v)\left(\sigma-1+\omega+\frac{2}{v}\right)}{8 \gamma}\left[(1+\omega)\left(\hat{y}_{t}-z_{t}\right)-\frac{v}{2}\left(\hat{p}_{H, t}^{*}+\frac{1}{\sigma} \hat{e}_{t}-\hat{p}_{H, t}\right)\right]^{2}
\end{array}\right\} .
$$

In the text, we obtain two simplified expressions of the loss functions by imposing $\sigma=1$. In this case, the second-order approximation of the welfare function will make use of equations (6.120) and (6.121) above. Specifically, the quadratic loss function of 
the home policy maker under LCP and noncooperation is given by

$$
L_{t_{0}}=\mathbb{E}_{t_{0}} \sum_{t=t_{0}}^{\infty} \beta^{t-t_{0}}\left\{\begin{array}{c}
\frac{1+\omega}{2}\left(\hat{y}_{t}-z_{t}\right)^{2} \\
+\frac{\epsilon v}{4 \delta}\left(\pi_{H, t}\right)^{2}+\frac{\epsilon(2-v)}{4 \delta}\left(\pi_{F, t}\right)^{2} \\
+\frac{v(2-v) \Omega}{8}\left(\hat{d}_{t}\right)^{2}+\frac{v(2-v)(1-\Omega)}{8}\left(\hat{d}_{t}^{*}\right)^{2} \\
+\frac{v(1-\Omega)}{4}\left((1+\omega)\left(\hat{y}_{t}-z_{t}\right)+\frac{2-v}{2} \hat{d}_{t}\right)^{2} \\
+\frac{(2-v) \Omega}{4}\left((1+\omega)\left(\hat{y}_{t}^{*}-z_{t}^{*}\right)-\frac{v}{2} \hat{d}_{t}^{*}\right)^{2} \\
-\frac{v(1-\Omega)}{4}\left((1+\omega)\left(\hat{y}_{t}^{*}-z_{t}^{*}\right)+\frac{2-v}{2} \hat{d}_{t}^{*}\right)^{2} \\
-\frac{(2-v) \Omega}{4}\left((1+\omega)\left(\hat{y}_{t}-z_{t}\right)-\frac{v}{2} \hat{d}_{t}\right)^{2}
\end{array}\right\},
$$

and the quadratic loss function of the foreign policy maker is given by

$$
L_{t_{0}}^{*}=\mathbb{E}_{t_{0}} \sum_{t=t_{0}}^{\infty} \beta^{t-t_{0}}\left\{\begin{array}{c}
\frac{1+\omega}{2}\left(\hat{y}_{t}^{*}-z_{t}^{*}\right)^{2} \\
+\frac{\epsilon v}{4 \delta}\left(\pi_{F, t}^{*}\right)^{2}+\frac{\epsilon(2-v)}{4 \delta}\left(\pi_{H, t}^{*}\right)^{2} \\
+\frac{v(2-v) \Omega}{8}\left(\hat{d}_{t}^{*}\right)^{2}+\frac{v(2-v)(1-\Omega)}{8}\left(\hat{d}_{t}\right)^{2} \\
+\frac{(2-v) \Omega}{4}\left((1+\omega)\left(\hat{y}_{t}^{*}-z_{t}^{*}\right)+\frac{2-v}{2} \hat{d}_{t}^{*}\right)^{2} \\
\left.\left.-\frac{v(1-\Omega)}{4}\left((1+\omega)\left(\hat{y}_{t}-z_{t}\right)-\frac{v}{2} \hat{d}_{t}\right)^{2}\right)+\frac{2-v}{2} \hat{d}_{t}\right)^{2} \\
-\frac{(2-v) \Omega}{4}\left((1+\omega)\left(\hat{y}_{t}^{*}-z_{t}^{*}\right)-\frac{v}{2} \hat{d}_{t}^{*}\right)^{2}
\end{array}\right\} .
$$

They are equations (3.2) and (3.3) in the text. 


\section{Appendix D. Log-linearization}

In this section, we show the complete set of exact or approximated log-linear form of the structural equations (as in Table 2 in the text).

Exact log-linear form of deviations from the law of one price:

$$
\begin{aligned}
& \hat{d}_{t}=\hat{p}_{H, t}^{*}+\hat{e}_{t}-\hat{p}_{H, t} \\
& \hat{d}_{t}^{*}=\hat{p}_{F, t}+\hat{e}_{t}-\hat{p}_{F, t}^{*} .
\end{aligned}
$$

Log deviations of the terms of trade from the steady state are

$$
\begin{aligned}
& \hat{q}_{t}=\hat{p}_{F, t}-\hat{e}_{t}-\hat{p}_{H, t}^{*}, \\
& \hat{q}_{t}^{*}=-\hat{q}_{t},
\end{aligned}
$$

and exact log-linear form of price indexes equations (v) and (xxiii):

$$
\begin{aligned}
& \frac{v}{2} \hat{p}_{H, t}+\frac{2-v}{2} \hat{p}_{F, t}=0, \\
& \frac{v}{2} \hat{p}_{F, t}^{*}+\frac{2-v}{2} \hat{p}_{H, t}^{*}=0 .
\end{aligned}
$$

Exact log-linear form of definitions of detrending, equations (xvii), (xviii), (xxxv) and (xxxvi):

$$
\begin{aligned}
\pi_{H, t} & =\pi_{t}+\hat{p}_{H, t}-\hat{p}_{H, t-1} \\
\pi_{F, t} & =\pi_{t}+\hat{p}_{F, t}-\hat{p}_{F, t-1} \\
\pi_{H, t}^{*} & =\pi_{t}^{*}+\hat{p}_{H, t}^{*}-\hat{p}_{H, t-1}^{*} \\
\pi_{F, t}^{*} & =\pi_{t}^{*}+\hat{p}_{F, t}^{*}-\hat{p}_{F, t-1}^{*} .
\end{aligned}
$$

Subtracting the first equation by the second and using (6.128) gives

$$
\hat{p}_{H, t}-\hat{p}_{H, t-1}=\frac{2-v}{2}\left(\pi_{H, t}-\pi_{F, t}\right) ;
$$

Subtracting the fourth equation by the third and using (6.129) gives

$$
\hat{p}_{F, t}^{*}-\hat{p}_{F, t-1}^{*}=\frac{2-v}{2}\left(\pi_{F, t}^{*}-\pi_{H, t}^{*}\right) .
$$

Exact log-linear form of equation (xxxvii):

$$
\hat{c}_{t}-\hat{c}_{t}^{*}=\frac{1}{\sigma} \hat{e}_{t}
$$


Exact log-linear form of equations (iii), (iv), (xxi) and (xxii):

$$
\begin{aligned}
\hat{c}_{H, t} & =-\hat{p}_{H, t}+\hat{c}_{t} \\
\hat{c}_{F, t} & =-\hat{p}_{F, t}+\hat{c}_{t} \\
\hat{c}_{H, t}^{*} & =-\hat{p}_{H, t}^{*}+\hat{c}_{t}^{*} \\
\hat{c}_{F, t}^{*} & =-\hat{p}_{F, t}^{*}+\hat{c}_{t}^{*}
\end{aligned}
$$

Exact log-linear form of equations (ii) and (xx):

$$
\begin{aligned}
\hat{w}_{t} & =\omega \hat{h}_{t}+\sigma \hat{c}_{t} \\
\hat{w}_{t}^{*} & =\omega \hat{h}_{t}^{*}+\sigma \hat{c}_{t}^{*}
\end{aligned}
$$

Exact log-linear form of equations (vi) and (xxiv):

$$
\begin{aligned}
& \widehat{m c}_{t}=\hat{w}_{t}-z_{t} \\
& \widehat{m c}_{t}^{*}=\hat{w}_{t}-z_{t}^{*}
\end{aligned}
$$

Exact log-linear form of equations (viii) and (xxvi):

$$
\begin{aligned}
& \hat{y}_{t}=z_{t}+\hat{h}_{t} \\
& \hat{y}_{t}^{*}=z_{t}^{*}+\hat{h}_{t}^{*}
\end{aligned}
$$

so from the above conditions (6.137)-(6.142) we obtain deviations from steady state of the real marginal costs: (equations (2.12)-(2.15) in the text.)

$$
\begin{aligned}
\widehat{m c}_{t}-\hat{p}_{H, t} & =(\sigma+\omega) \hat{y}_{t}-(1+\omega) z_{t}+\frac{2-v}{2}(1-\sigma)\left(\hat{q}_{t}+\hat{e}_{t}\right)+\frac{2-v}{2} \hat{d}_{t,} \\
\widehat{m c}_{t}^{*}-\hat{p}_{F, t}^{*} & =(\sigma+\omega) \hat{y}_{t}^{*}-(1+\omega) z_{t}^{*}+\frac{2-v}{2}(1-\sigma)\left(\hat{q}_{t}^{*}-\hat{e}_{t}\right)+\frac{2-v}{2} \hat{d}_{t}^{*}, \\
\widehat{m c}_{t}^{*}-\hat{p}_{F, t}+\hat{e}_{t} & =(\sigma+\omega) \hat{y}_{t}^{*}-(1+\omega) z_{t}^{*}+\frac{2-v}{2}(1-\sigma)\left(\hat{q}_{t}^{*}-\hat{e}_{t}\right)-\frac{v}{2} \hat{d}_{t}^{*}, \\
\widehat{m c}_{t}-\hat{p}_{H, t}^{*}-\hat{e}_{t} & =(\sigma+\omega) \hat{y}_{t}-(1+\omega) z_{t}+\frac{2-v}{2}(1-\sigma)\left(\hat{q}_{t}+\hat{e}_{t}\right)-\frac{v}{2} \hat{d}_{t} .
\end{aligned}
$$

Log-linearized resource constraints, equations (vii) and(xxv):

$$
\begin{aligned}
& \hat{y}_{t}=\hat{c}_{t}-\frac{v}{2} \hat{p}_{H, t}-\frac{2-v}{2} \hat{p}_{H, t}^{*}-\frac{2-v}{2} \frac{1}{\sigma} \hat{e}_{t}, \\
& \hat{y}_{t}^{*}=\hat{c}_{t}^{*}-\frac{v}{2} \hat{p}_{F, t}^{*}-\frac{2-v}{2} \hat{p}_{F, t}+\frac{2-v}{2} \frac{1}{\sigma} \hat{e}_{t},
\end{aligned}
$$

so subtracting equation (6.148) from (6.147) gives

$$
\hat{y}_{t}-\hat{y}_{t}^{*}=-\frac{v}{2} \hat{p}_{H, t}-\frac{2-v}{2} \hat{p}_{H, t}^{*}+\frac{(v-1)}{\sigma} \hat{e}_{t}+\frac{v}{2} \hat{p}_{F, t}^{*}+\frac{2-v}{2} \hat{p}_{F, t}
$$

where we have used equation (6.132). This is equation (2.20) in the text. 
New Keynesian Phillips curves are derived as follows. Write the second-order approximation of the AS equation (6.95) in Appendix $C$ in a recursive way:

$$
V_{H, t}=\delta \bar{z}_{H, t}+\frac{\delta}{2} \bar{z}_{H, t} \bar{x}_{H, t}+\frac{\epsilon}{2} \pi_{H, t}^{2}+\beta \mathbb{E}_{t}\left(V_{H, t+1}\right) .
$$

Up to the first order, it reduces to

$$
V_{H, t}=\delta \bar{z}_{H, t}+\beta \mathbb{E}_{t} \pi_{H, t+1} \text {. }
$$

where we have defined $\bar{z}_{H, t}=\widehat{m c}_{t}-\hat{p}_{H, t}$ and $\delta=\frac{(1-\beta \theta)(1-\theta)}{\theta}$. Up to the first order, equation (6.95) itself reduces to

$$
V_{H, t}=\pi_{H, t}
$$

so combining the above two equations, we obtain the corresponding log-linear NKPC

$$
\pi_{H, t}=\beta \mathbb{E}_{t} \pi_{H, t+1}+\frac{(1-\beta \theta)(1-\theta)}{\theta}\left(\widehat{m c}_{t}-\hat{p}_{H, t}\right) .
$$

Similarly, we can obtain the other three New Keynesian Phillips curves as follows:

$$
\begin{aligned}
\pi_{F, t}^{*} & =\beta \mathbb{E}_{t} \pi_{F, t+1}^{*}+\frac{(1-\beta \theta)(1-\theta)}{\theta}\left(\widehat{m c}_{t}^{*}-\hat{p}_{F, t}^{*}\right), \\
\pi_{F, t} & =\beta \mathbb{E}_{t} \pi_{F, t+1}+\frac{(1-\beta \theta)(1-\theta)}{\theta}\left(\widehat{m c}_{t}^{*}-\hat{p}_{F, t}+\hat{e}_{t}\right), \\
\pi_{H, t}^{*} & =\beta \mathbb{E}_{t} \pi_{H, t+1}^{*}+\frac{(1-\beta \theta)(1-\theta)}{\theta}\left(\widehat{m c}_{t}-\hat{p}_{H, t}^{*}-\hat{e}_{t}\right) .
\end{aligned}
$$

These are equations (2.8)-(2.11) in the text. 